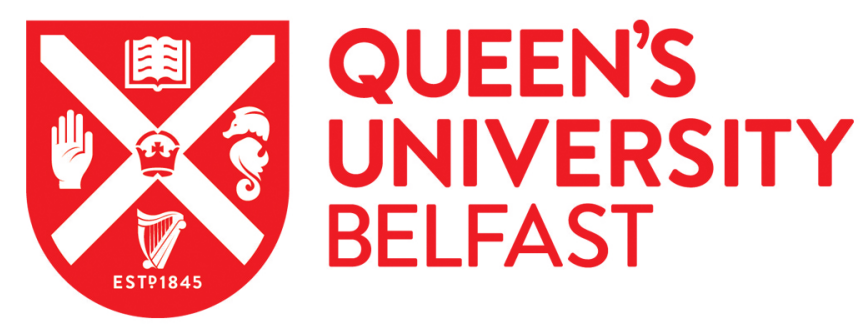

\title{
Photocatalytic oxidation of pollutants in gas-phase via Ag3PO4-based semiconductor photocatalysts: Recent progress, new trends, and
} future perspectives

Naciri, Y., Hsini, A., Bouziani, A., Djellabi, R., Ajmal, Z., Laabd, M., Navio, J. A., Mills, A., Bianchi, C. L., Li, H., Bakiz, B., \& Albourine, A. (2022). Photocatalytic oxidation of pollutants in gas-phase via Ag3PO4-based semiconductor photocatalysts: Recent progress, new trends, and future perspectives. Critical Reviews in Environmental Science and Technology, 52(13), 2339-2382. https://doi.org/10.1080/10643389.2021.1877977

Published in:

Critical Reviews in Environmental Science and Technology

Document Version:

Peer reviewed version

Queen's University Belfast - Research Portal:

Link to publication record in Queen's University Belfast Research Portal

Publisher rights

Copyright 2021 Taylor \& Francis Group

This work is made available online in accordance with the publisher's policies. Please refer to any applicable terms of use of the publisher.

\section{General rights}

Copyright for the publications made accessible via the Queen's University Belfast Research Portal is retained by the author(s) and / or other copyright owners and it is a condition of accessing these publications that users recognise and abide by the legal requirements associated with these rights.

Take down policy

The Research Portal is Queen's institutional repository that provides access to Queen's research output. Every effort has been made to ensure that content in the Research Portal does not infringe any person's rights, or applicable UK laws. If you discover content in the

Research Portal that you believe breaches copyright or violates any law, please contact openaccess@qub.ac.uk. 
1 Photocatalytic oxidation of pollutants in gas-phase via $\mathrm{Ag}_{3} \mathrm{PO}_{4}$-based semiconductor photocatalysts:

2 Recent Progress, New Trends, and Future Perspectives

3 Y. Naciri ${ }^{1,2, \dagger, *}$, A. Hsini ${ }^{1, \dagger}$, A. Bouziani $^{3}$, R. Djellabi ${ }^{4,5}$, Z. Ajmal ${ }^{6}$, M. Laabd ${ }^{1}$, J. A.

$5{ }^{1}$ Laboratoire Matériaux et Environnement LME, Faculté des Sciences, Université Ibn Zohr, BP 8106, Cité

6 Dakhla, Agadir, Morocco.

72 Institute for Energy Research, School of Chemistry and Chemical Engineering, Jiangsu University,

8 Zhenjiang, 212013 P. R. China.

$9 \quad{ }^{3}$ Chemical Engineering Department, Middle East Technical University, Ankara, Turkey

${ }^{4}$ Department of Chemistry, Università degli Studi di Milano, Via Golgi 19, Milano, Italy.

$11{ }^{5}$ Research Center for Eco-Environmental Sciences, Chinese Academy of Sciences, Beijing, 100085,

12 People's Republic of China Beijing, 100085, China

$13{ }^{6}$ College of Engineering, China Agricultural University, 100083, Beijing, PR China.

$14{ }^{7}$ Instituto de Ciencia de Materiales de Sevilla, Centro Mixto Universidad de Sevilla-CSIC, Américo

15 Vespucio 49, 41092 Sevilla, Spain.

$16{ }^{8}$ School of Chemistry and Chemical Engineering, Queens University Belfast, David Keir Building,

17 Stranmillis Road, Belfast, BT9 5AG, UK.

† These authors contributed equally to this work.

* Corresponding authors:

20 (Y. Naciri) E-mail address: yassine.naciri@edu.uiz.ac.ma

21 (J.A.Navio). E-mail address: navio@us.es

\section{Abstract}

As a solemn dilemma, due to numerous fatal diseases such as cancer, respiratory, heart

27 attack, and brain stroke, air pollution has become a significant challenge for both 
29 air pollution issues. The heterogeneous photocatalysis technique has emerged as an

30 effective air remediation strategy due to its field-scale application via free-solar light and

31 photoactive catalysts. The photocatalytic efficacy is utterly associated with the optical and

32 physical characteristics of the photocatalyst. Unlike conditional photocatalysts (e.g., $\mathrm{TiO}_{2}$,

$33 \mathrm{ZnO}$ ), recent studies showed that $\mathrm{Ag}_{3} \mathrm{PO}_{4}$ semiconductors with a $2.43 \mathrm{eV}$ bandgap exhibit

34 an excellent photocatalytic efficiency for the removal of many types of pollutants in the 35 gas phase.

36 Nevertheless, there are certain limitations with $\mathrm{Ag}_{3} \mathrm{PO}_{4}$ (i.e., photo-corrosion and the

37 inability to produce $\cdot \mathrm{O}_{2}^{-}$), which restricts its application. These limitations are critically 38 evaluated and outlined thoroughly in this review. Recent studies on the modification of $39 \mathrm{Ag}_{3} \mathrm{PO}_{4}$ via combination with the conventional heterojunctions or Z-scheme junctions, as 40 well as the photocatalytic mechanistic pathways for enhanced gas-pollutants removal, 41 were summarized and discussed. Finally, an outlook on future development is proposed 42 to overcome challenges and stimulate further research into this promising field.

43 Keywords: $\mathrm{Ag}_{3} \mathrm{PO}_{4}$; photocatalytic oxidation process; Z-scheme junctions; conventional 44 heterojunctions; gaseous pollutants.

\section{Introduction}

Currently, soil, aquatic, and air environment are severely affected by rapid population 
annually entering into the natural environment (Aarab et al., 2020a, 2020b; Abdellaoui et al., 2021; Ajmal et al., 2018; Ba Mohammed et al., 2020; Essekri et al., 2020; Hsini et al., 2020a, 2020b; Qadeer et al., 2020, 2019). The typical indoor air pollutants are generally volatile organic compounds (VOCs), particulate matter (PM), and inorganic oxides $\left(\mathrm{CO}_{2}\right.$,

$\mathrm{NO}_{x}$, and $\mathrm{SO}_{\mathrm{x}}$ ). Moreover, according to the world health organization survey, air pollution results in the death of about 7 million people around the globe. Among them, 4.3 million people were severely affected by indoor air pollution. That is one in eight total global deaths, which indicates that air pollution is now the world's most considerable single environmental health risk (da Costa Filho and Vilar, 2019; Hyuntae Cho, 2017).

To curb the pollution, most standard air purifying systems use air filters to remove particulate matter. Others use adsorbents (e.g., magnetite, almond shell derived biomass, granular activated carbon) for gaseous adsorption over their surface sites. However, these technologies cannot remove pollutants altogether but only transfer them from one phase to another (Ajmal et al., 2020b, 2020a; Benafqir et al., 2019; Hsini et al., 2020c; Sansotera et al., 2019; Zhao and Yang, 2003). Hence, it has become an urgent hot topic for policymakers and scientists to explore and introduce new cost-effective treatment strategies to overcome the existing air pollution problem.

Heterogeneous photocatalytic degradation due to numerous facets over conventional treatment strategies is regarded as an effective alternative remediation technology (S. (Ahsaine et al., 2018; Barebita et al., 2020; Bouziani et al., 2020; Erdogan et al., 2019; Naciri et al., 2020b; S. Ferraa et al., 2020; Shaim et al., 2019). Generally, it could be classified into two categories according to environmental implications. (Fig.1) (i) Aqueous phase organic pollutants degradation (Deng et al., 2020; Fiorenza et al., 2020; Naciri et 


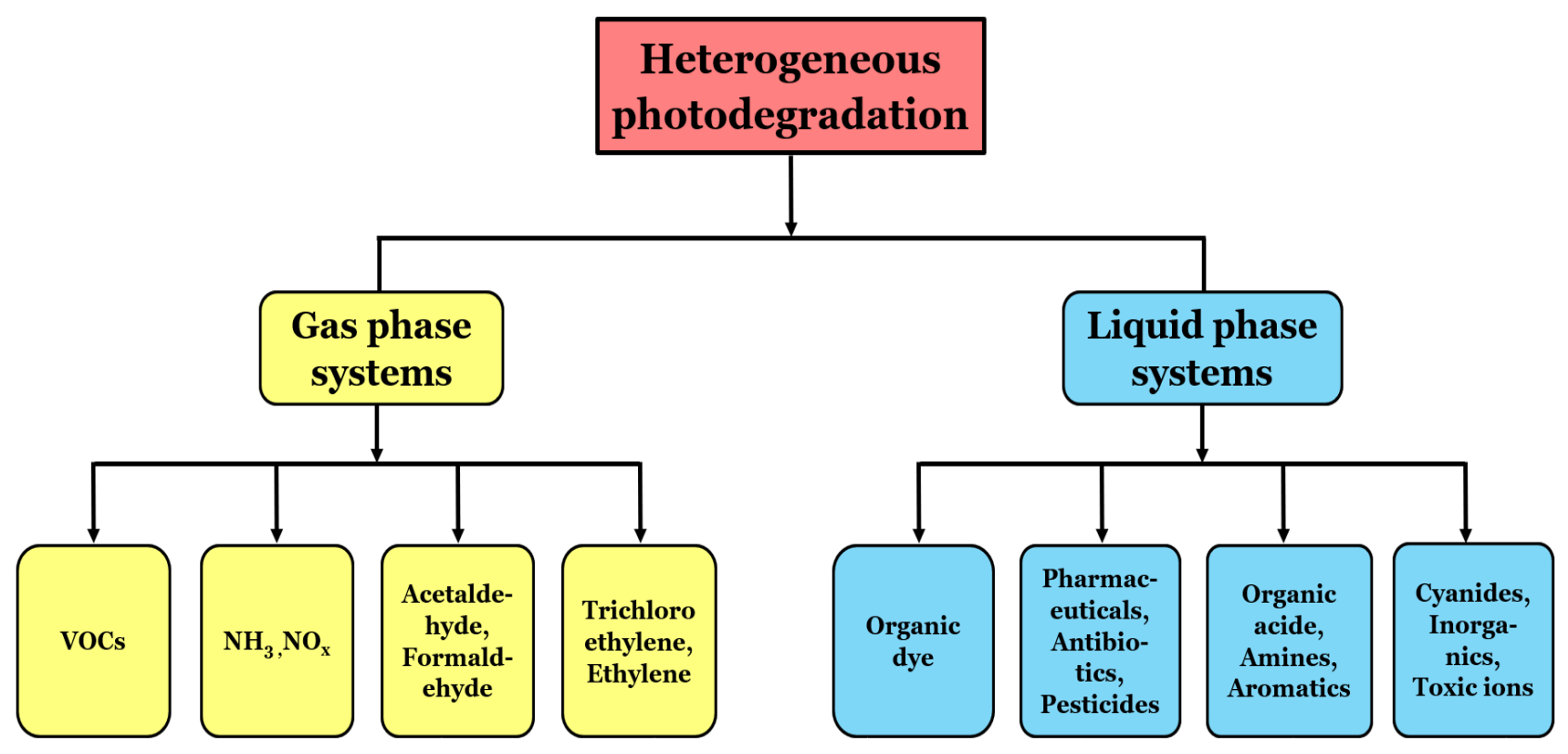

Fig.1. Heterogeneous photocatalytic remediation systems for various pollutants.

This technology is considered the newest generation of air cleaning technology. It has attracted considerable research interest over the last few decades owing to their great potential to eliminate continuously gaseous pollutants even at low concentrations and operating at low or room temperature (Aramendía et al., 2007; Araña et al., 2009, 2004; Murcia et al., 2012). Interestingly, it has been noted that this technique is proved to be most efficient for various gaseous pollutants (i.e., volatile organic compound, simple and chlorinated hydrocarbon) (Aramendía et al., 2007; Araña et al., 2009, 2004; Murcia et al., 2012; Zhou et al., 2019), as well as different carbon, hydrogen, and sulfur-based oxidesdioxides (Kato et al., 2005; Liao et al., 2017; Reyna-Cavazos et al., 2020). Since the first report on gas-solid heterogeneous photocatalytic oxidation conducted in the 1970s with the work of Djeghri's and Bickley's group (Bickley et al., 1973; Djeghri, N., Formenti, M., 
89 Juillet, F., Teichner, 1974), the photocatalytic oxidation of gaseous contaminants has been extensively studied, to confirm the validity and attractiveness of that remediation strategy for degrading a myriad of gaseous pollutants.

Among various semiconductors, the use of $\mathrm{TiO}_{2}$ is considered as one of the most renowned photocatalysts due to its low cost, higher chemical stability, and good surface structure characteristics. However, its application is restricted due to numerous facets,

i.e., wide bandgap (approximately $3.2 \mathrm{eV}$ ). As well- know, the UV light occupies just around $5 \%$ of the solar light, while the visible light occupies $43 \%$. Therefore, the development of visible-light-driven photocatalysts has become a subject of prime importance in the field of photocatalytic pollutants degradation (Chenchana et al., 2019; Likodimos, 2018; Mazierski et al., 2018; Puga et al., 2020).

100 Up to date, several Ag-based photocatalysts, including $\mathrm{AgX}(\mathrm{X}=\mathrm{Cl}, \mathrm{Br}, \mathrm{I})$ (Wang et al., 101 2019; Wen et al., 2020; Xin et al., 2019), $\mathrm{Ag}_{2} \mathrm{O}$ (Liang et al., 2019), $\mathrm{Ag}_{2} \mathrm{CO}_{3}$ (Y. Liu et al., 2018), and $\mathrm{Ag}_{3} \mathrm{PO}_{4}$ (Martín-Gómez et al., 2020), have demonstrated an outstanding 103 photocatalytic performance under natural sunlight or the visible light. Among them, 104 $\mathrm{Ag}_{3} \mathrm{PO}_{4}$ is extremely attractive since it could attain $90 \%$ efficiency over the $400-800 \mathrm{~nm}$ 105 wavelength (Chen et al., 2015, 2013). However, further reports on the origin of $\mathrm{Ag}_{3} \mathrm{PO}_{4}$ 106 photocatalytic activity indicated that both the inductive effect of $\mathrm{PO}_{4}^{3-}$ and the large 107 dispersion of the conduction band are considered the major contributor to the separation 108 of the electron-hole pairs for $\mathrm{Ag}_{3} \mathrm{PO}_{4}$ (Chen et al., 2013). Unfortunately, there are still 109 some inherent shortcomings in the photoactivity of $\mathrm{A}_{3} \mathrm{PO}_{4}$ for photodecomposition 110 gaseous organic contaminates. One reason is that the $\mathrm{Ag}_{3} \mathrm{PO}_{4}$ could not produce ${ }^{-\mathrm{O}_{2}}{ }^{-}$

111 radicals, just because of the existence of its conduction band at $+0.45 \mathrm{Vvs}$. NHE (pH 0$)$ 
112 is lower than the reduction potential of $\mathrm{O}_{2}\left(\mathrm{O}_{2}+\mathrm{e}^{-} \rightarrow \cdot \mathrm{O}_{2}^{-},-0.33 \mathrm{~V}\right.$ vs. NHE) (Wood, 1988).

113 As a result, the generated electrons cannot be consumed by $\mathrm{O}_{2}$, which is very important

114 for the photo-oxidation of various gaseous organic pollutants. Moreover, Ag particle by-

115 product formation in the absence of electron acceptor during $\mathrm{Ag}_{3} \mathrm{PO}_{4}$ photodecomposition

116 is considered a significant factor affecting its photocatalytic activity and stability and

117 ultimately restricts its potential practical application (Chai et al., 2015; Li et al., 2014, 118 2015). Therefore, it is crucial to introduce efficient approaches for improving $\mathrm{Ag}_{3} \mathrm{PO}_{4}$

119 photocatalytic activity without any reagents (Chai et al., 2015; Li et al., 2014, 2015). Thus,

120 numerous strategies have been applied to enhance the stability of $\mathrm{Ag}_{3} \mathrm{PO}_{4}$ under visible

121 light irradiation. Providentially, numerous studies verified that the formation of hybrid or

122 heterojunction between $\mathrm{Ag}_{3} \mathrm{PO}_{4}$ and semiconductor having proper band structure is a 123 promising strategy for enhancing the stability of $\mathrm{Ag}_{3} \mathrm{PO}_{4}$ for the reduction/removal of 124 inorganic gas pollutants (Chen et al., 2015; Guo et al., 2013; Huang et al., 2019; Jia et 125 al., 2019; Rao et al., 2020; Rawal et al., 2012).

126 To the best of our knowledge, this is the first review addressing the reported research 127 progress on the photocatalytic remediation of air using $\mathrm{Ag}_{3} \mathrm{PO}_{4}$-based semiconductor 128 photocatalytic systems. Thus, this review article focuses on investigating the recent 129 strategies for the photocatalytic oxidation of pollutants in gas-phase in the presence of $130 \mathrm{Ag}_{3} \mathrm{PO}_{4}$-based conventional and Z-scheme heterojunctions. Moreover, we introduce a 131 general overview of the current control techniques for gas-phase pollutants removal and 132 their limitations. Then, the photocatalytic properties of $\mathrm{Ag}_{3} \mathrm{PO}_{4}$ and its limitations as a 133 photocatalyst are discussed in detail. The improving photocatalytic activities of $\mathrm{Ag}_{3} \mathrm{PO}_{4}$ 134 photocatalyst towards gaseous-phase pollutants by constructing conventional 
135 heterojunctions or Z-scheme junction photocatalytic systems are then addressed as the main part of this review. Finally, numerous ways are presently proposed for future

137 research to overcome the existing challenges and design the most promising 138 heterojunctions based photocatalyst for air pollution reduction strategy.

\section{General overview of the current control techniques for the romal of} pollutants in gas-phase

141 The stability of gas pollutants and their severe toxic effects on human beings and the

142 ecological system are of prime importance. Many physicochemical abatement methods

143 such as adsorption (Li et al., 2020), absorption (Rodriguez Castillo et al., 2019),

144 condensation (Belaissaoui et al., 2016), botanical purification (Pettit et al., 2019, 2018),

145 catalytic combustion (Fino et al., 2016), photocatalytic oxidation (Kamal et al., 2016), bio-

146 filtration (Malakar et al., 2017), plasma oxidation (Malakar et al., 2017), biodegradation

147 (Malakar et al., 2017), and membrane separation (Malakar et al., 2017) have been used

148 extensively for the effective removal of gaseous pollutants. Based on the removal 149 mechanism, we can further classify these abatement techniques into two categories: 150 recovery techniques (adsorption, absorption, filtration, and condensation) and destructive 151 techniques (catalytic combustion, plasma oxidation, biodegradation, and botanical 152 purification). The destructive gas cleaning techniques are mainly based on the conversion 153 of gas-phase organic contaminants into water vapor, carbon dioxide, and other smaller 154 molecules by-products (Ehn et al., 2014), which consume a large amount of energy to 155 generate high temperature for the reaction, and they inevitably produce some toxic 156 byproducts such as $\mathrm{NOx}, \mathrm{O}_{3}, \mathrm{HO}$ - radicals, secondary organic aerosols, etc. (Ehn et al., 
157 2014; Li et al., 2020). In contrast, recovery technologies have often been reported as more efficient and economical gas cleaning strategies (Zhang et al., 2017). Among them, adsorption is recognized as one of the most promising strategies to abate the gas-phase 160 pollutants, which do not produce the secondary by-products (Li et al., 2020). In the 161 adsorption process, the storage of gaseous pollutants on the surface of adsorbent 162 material is commonly carried out via a pore-filling mechanism combined with the eventual 163 formation of physical and/or chemical gas-adsorbent bindings (Zhu et al., 2020). Thus, 164 the effectiveness and real applicability of adsorption techniques for gas pollutants 165 abatement are ultimately associated with adsorbent surface proprieties include functional groups and porous texture (Li et al., 2020). In this regard, a large variety of adsorbents, 167 including carbon-based materials (Azzouz et al., 2018; Zhang et al., 2017), organic 168 polymers (Azzouz et al., 2018; Zhu et al., 2020), aluminosilicates (Swetha et al., 2017; 169 Zhang et al., 2018), resins (Qiu et al., 2018), silica gels (Amonette and Matyáš, 2017; Sui 170 et al., 2017) and metal-organic frameworks (Barea et al., 2014; Xian et al., 2015) have 171 been recently developed to sequestrate gas-phase contaminants. The activated carbon 172 is a popular filter material with excellent gas sequestration ability because of its high 173 surface area, microporous structure, surface chemistry, etc. (Shammay et al., 2016; 174 Suresh and Bandosz, 2018). Nevertheless, the adsorption is a transfer process of 175 pollutants from the gas phase to the solid phase, which requires a post-treatment to 176 mineralize the adsorbed pollutants (Jo and Yang, 2009; Thevenet et al., 2014). Besides, 177 the contaminant load variations and regeneration costs, also the high humidity, restrict 178 the effectiveness of the adsorption process (Jo and Yang, 2009). Overall, the 179 conventional gaseous contaminants abatement techniques present the main limitations 
180 of the generation of secondary waste and high operation costs (Krishnamurthy et al., 181 2019; Luengas et al., 2015). The merits and demerits of some aforementioned 182 conventional processes for gaseous pollutants removal (see Supplementary Table. S1). 183 Therefore, it is urgent to explore and introduce alternative, cost-effective and 184 environmental strategies for gas-phase pollutants removal.

People spend almost $80 \%$ of their life in indoor places such as residential units, offices, 189 workshops, etc. Therefore, indoor air quality (IAQ) is vital for human health. On top of that, the outdoor air quality (OAQ) resulted from natural sources and mostly industrial 191 pollution/human activities can cause several environmental, medium-term, and long-term 192 health problems such as respiratory diseases (e.g., emphysema), heart damage, lung 193 cancer, sudden death and cognitive alterations (Olmo et al., 2011). As already reported 194 in section 2, we see that the conventional gaseous contaminants abatement techniques 195 encompass a wide range of limitations. Thus, they are considered to be uneconomical, 196 less effective as they further produce secondary toxic by-products. In order to address 197 these issues, it is an urgent need to explore the most advanced removal of gaseous 198 pollutants removal rather than conventional methods. The photocatalytic oxidation of 199 gaseous pollutants, including volatile organic compounds (VOCs) (Ardizzone et al., 2008; 200 Ganesh et al., 2011; Lopes et al., 2012; Monteiro et al., 2015) or inorganic gaseous (e.g., 201 NOx (Ballari et al., 2010; Zouzelka and Rathousky, 2017), SOx (Li et al., 2016) and H2S 
202 (Navakoteswara Rao et al., 2019) on the surface of a photocatalyst under light into less-

203 toxic and odorless compounds is a fascinating technology. The photocatalytic oxidation

204 reaction is focused on the production of reactive oxygen species (ROSs) having high

205 oxidizing potentials such as $\mathrm{HO}, \mathrm{O}_{2}{ }^{-}, \mathrm{HO}_{2}{ }^{-}$, and $\mathrm{H}_{2} \mathrm{O}_{2}{ }^{-}$, which can oxidize pollutants

206 being adsorbed on the photocatalyst in water or air phases; also, direct oxidation of

207 pollutants via positive holes $\left(\mathrm{h}^{+}\right)$on the surface of the photo-excited photocatalyst can

208 take place as well (Djellabi et al., 2020). As showed in Fig.2A, unlike the extensive use

209 of photocatalysis for water treatment, less attention has been given to the application of

210 heterogeneous photocatalysis for air purification over the last two decades. Fig.2B shows

211 the mechanistic pathways of organic pollutants photocatalytic oxidation over

212 photocatalyst surface sites.
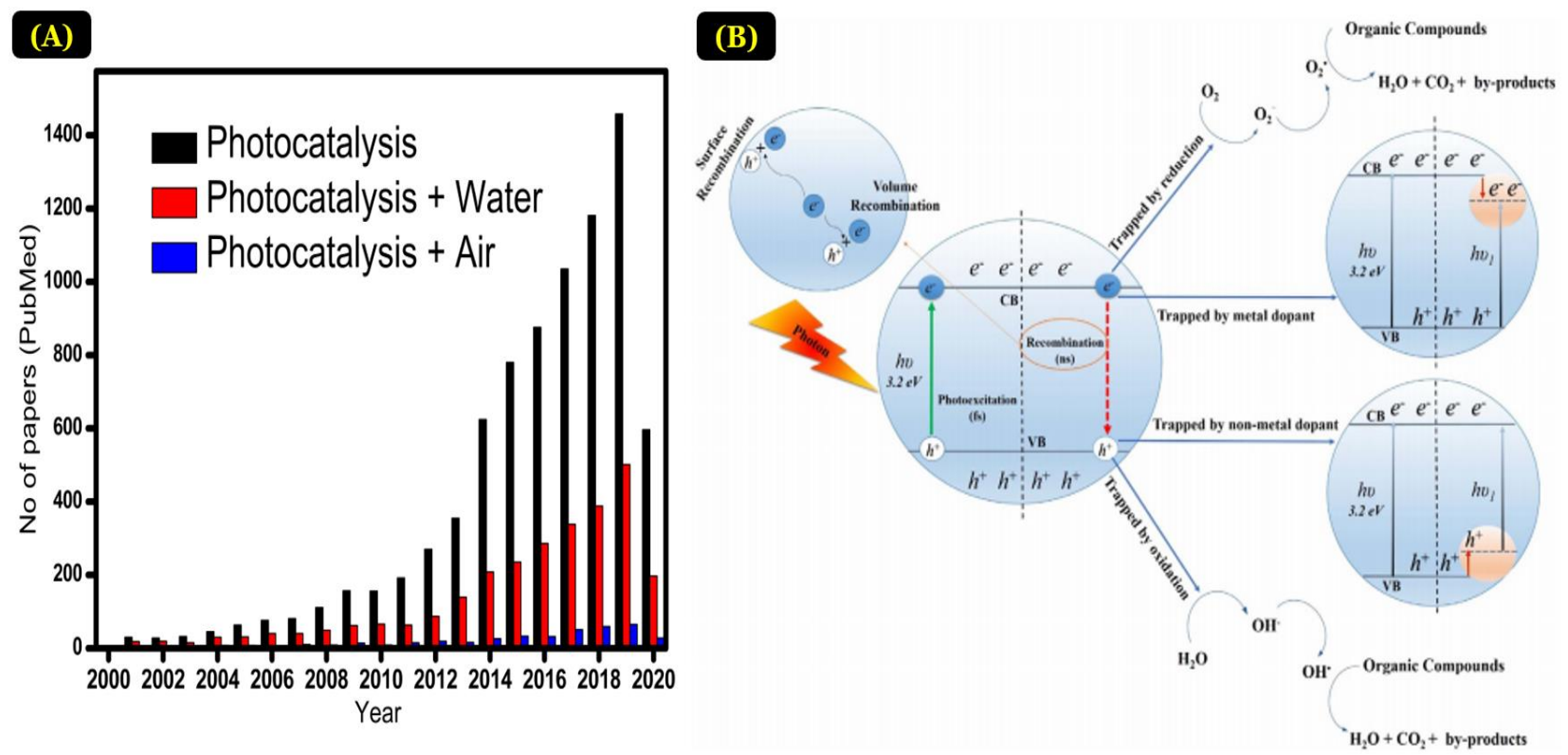

Fig. 2. (A) Publications trends in photocatalysis, photocatalysis for water and air treatment over the last two decades, obtained from PubMed (up to Apr. 2020) (B). Photocatalytic oxidation of 
organic pollutants, including gas substances, by heterogenous photocatalysis process (Adapted with permission from ref (Shayegan et al., 2018), copyright 2017 Elsevier).

\subsection{Parameters affected the photocatalytic efficiency}

The efficiency of photocatalytic degradation of gas pollutants highly depends upon many factors. Since the production of $\mathrm{HO} \cdot$ is carried out via the reaction of water molecules or $\mathrm{HO}^{-}$species with positive holes, in air medium, relative humidity $(\mathrm{RH})$ is a very beneficial resource for the generation of $\mathrm{HO}$ - radicals for the oxidation of gas pollutants ( Amaterz et al., 2020; Amaterz et al., 2020; Guo et al., 2008; Mamaghani et al., 2017). It is essential to point out that water vapor concentration over the photocatalyst surface is a very influencing parameter for the photocatalytic performance (Aghighi and Haghighat, 2015). A high quantity of water adsorbed on the surface can prevent/inhibit the adsorption of gas compounds, reducing their chance of being oxidized. C.A. Korologos et al. reported that the presence of water enhances the oxidation of benzene and toluene effectively (Korologos et al., 2011). It was reported that gaseous phase pollutants (to $\mathrm{CO}_{2}$ ) mineralization without humidity is impossible. Airflow is another important factor that showed a dual antagonistic effect on gas contaminants' photocatalytic oxidation (Shayegan et al., 2018). In low airflow rates, the higher residence time of pollutants gives the pollutant species in the gas phase the opportunity to be adsorbed on the photocatalyst and further oxidized by photo produced ROSs and $\mathrm{h}^{+}$. However, at higher airflow rates, the residence time and mass transfer decrease on the photocatalyst's surface, resulting in lower oxidation/mineralization efficiency. Therefore, in the photocatalytic reactor, the airflow should be optimized to obtain an enhanced photocatalytic efficiency depending on the reactor and the operating conditions such as the gas contaminant concentration. In 
242 addition, the airflow rate may also affect the formation of the by-product during photo243 oxidation of contaminants and the total mineralization to $\mathrm{CO}_{2}$ (Farhanian et al., 2013;

244 Sleiman et al., 2009; Yang et al., 2015). The type of photocatalyst is also an important 245 key for the photocatalytic oxidation in water or air phases. Therefore, over more than 246 three decades, most scientific research has been carried out to develop photoactive 247 materials and nanomaterials for environmental remediation and energy production, 248 especially to enhance the adsorption capacity, improve the visible light response, and 249 reduce the recombination of electron/hole charges. Several strategies have been 250 employed, such as the modification of photocatalysts (e.g., $\mathrm{TiO}_{2}$ ) by metal (Karafas et al., 251 2019; Nie et al., 2019) and non-metal doping (Jo and Kim, 2009; Patil et al., 2019), the 252 combination of semiconductors with high adsorbing materials (Shayegan et al., 2020), 253 photosensitizing (Park et al., 2013; Xiao et al., 2008) and coupling of semiconductors 254 (Djellabi et al., 2019b, 2019a). So far, a wide variety of titania and non-titania-based 255 photocatalysts have been employed for air purification (Boyjoo et al., 2017). Many 256 physicochemical factors must be taken into consideration for developing a photocatalyst 257 for air treatment, such as the enlargement of visible light response, enhancing the 258 selectivity towards some pollutants (i.e., NOx), and also to enhance the gaseous phase 259 pollutants mineralization into preferred products $\left(\mathrm{CO}_{2}, \mathrm{H}_{2} \mathrm{O}\right.$, and inorganic species) and 260 to avoid the formation of unwanted coke on the surface of the photocatalyst, resulting in 261 its deactivation. The type and the concentration of the gas pollutant significantly affect the 262 photocatalytic oxidation efficiency. Indeed, the photooxidation efficiency depends on the 263 photocatalyst's affinity towards the type of pollutant, wherein species showing good 264 adsorption on the photocatalyst have more possibility to be oxidized. Furthermore, the 
265 concentration of gas species on the photocatalyst's surface plays an essential factor 266 (Jafarikojour et al., 2015; Mamaghani et al., 2017; Zhong et al., 2013). More by-products

267 are likely to be adsorbed on the photocatalyst at higher gas species concentration, 268 impeding gas species' oxidation progress. Therefore, photocatalysis for air purification is 269 more effective in lower concentrations of contaminants depending on the photocatalyst's 270 surface chemistry and porosity.

271 One of the successful applications of photocatalysis for air treatment was the 272 development of self-cleaning photo-materials. These smart materials have been applied 273 for different purposes, such as house furniture and glasses, roofs, solar panel cleaning, 274 cement, and self-cleaning building (Banerjee et al., 2015; Ganesh et al., 2011). Under 275 solar light, self-cleaning materials can remove adsorbed gas contaminants/or bacteria via 276 photocatalytic action, and then by the action of rain, clean themselves. Claudia Bianchi's 277 group has developed many self-cleaning materials to remove several types of 278 contaminants in the gas phase (Ardizzone et al., 2008, 2007; Bianchi et al., 2020, 2016, 279 2014; Cappelletti et al., 2009).

280 Many semiconductor composite photocatalysts with different geometrical configurations 281 and compositions have been extensively synthesized and applied to the oxidation of 282 various gaseous phase pollutants. Table. S2 (see Supplementary) summarizes the 283 recent studies of representative composite semiconductor photocatalysts for removing 284 many types of pollutants in the gas phase.

$285 \quad$ 3.3. Photocatalytic reactors for air treatment 
286 The photocatalytic reactor type and its geometry are also significant factors for air 287 purification since they can directly influence the contact of contaminantes and the 288 immobilized photocatalyst (Boyjoo et al., 2017). For this purpose, many photo-reactor 289 configurations have been designed for contaminants oxidation in the gas phase, such as 290 packed bed (Lopes et al., 2012), annular reactor (Monteiro et al., 2015), flat plate reactor 291 (Passalía et al., 2017), honeycomb monolith (Taranto et al., 2009), and multi-

292 plate/annular (Zazueta et al., 2013). In order to improve the surface of coated 293 photocatalyst per volume of the reactor, which in turn enhances the uniform irradiated 294 photocatalyst surface and the mass transfer, da Costa Filhoa's group (da Costa Filho et 295 al., 2019a, 2019b, 2017) have developed a new microreactor based on NET mix 296 technology (see Supplementary Fig. S1) for the oxidation of VOCs in the gas phase.

\section{General overview of $\mathrm{Ag}_{3} \mathrm{PO}_{4}$ photocatalyst}

\subsection{Crystal structure of $\mathrm{Ag}_{3} \mathrm{PO}_{4}$ photocatalyst}

$301 \mathrm{Ag}_{3} \mathrm{PO}_{4}$ is a cubic crystal structure with a space group (P4-3n) and parameter lattice

$302 \approx 6.004 \AA$. Isolated, regular $\mathrm{PO}_{4}$ tetrahedral creates a body-centered cubic lattice, with a $303 \mathrm{P}$-O distance is $\approx 1.539 \AA$. The $\mathrm{Ag}^{+}$ions are dispersed between twelve sites with double 304 symmetry ( $\mathrm{Ng}$ et al., 1978). Every $\mathrm{Ag}$ atom on the 2-fold axis mainly uses one of the two 305 sites at $(x, 0,0.50)$ and $(0.5-x, 0,0.50)$. The $A g$ atom has 4 -fold coordination by four $\mathrm{O}$ 306 atoms (Ma et al., 2011). The P atoms experience 4-fold coordination encircled by four 
307 atoms of $\mathrm{O}$, while $\mathrm{O}$ atoms experience 4-fold coordination encircled by three atoms of $\mathrm{Ag}$ 308 and one atom of $\mathrm{P}$ (Kahk et al., 2014) (see Supplementary Fig. S2).

309 Kahk et al. (Kahk et al., 2014) reported that the lattice parameter of $\mathrm{Ag}_{3} \mathrm{PO}_{4}$ acquired 310 theoretically from DFT calculations is $6.072 \AA$. In addition, Ma et al. (Ma et al., 2011) 311 concluded that $\mathrm{Ag}_{3} \mathrm{PO}_{4}$ with polyhedron configuration mainly contains tetrahedral $\mathrm{AgO}_{4}$ 312 and $\mathrm{PO}_{4}$. They stated that three $\mathrm{AgO}_{4}$ and one $\mathrm{PO}_{4}$ are joint over the corner oxygen. They 313 explained that $\mathrm{Ag}_{3} \mathrm{PO}_{4}$ photocatalytic activity is due to $\mathrm{PO}_{4}^{3-}$ ions owing to its higher 314 negative charge, thus maintaining a large dipole in the $\mathrm{Ag}_{3} \mathrm{PO}_{4}$, resulting in the distortion 315 of $\mathrm{AgO}_{4}$ (Ma et al., 2011).

\subsection{Electronic structure of $\mathrm{Ag}_{3} \mathrm{PO}_{4}$ photocatalyst}

317 In order to have a better understanding of the source of the photocatalytic activity of $318 \mathrm{Ag}_{3} \mathrm{PO}_{4}$, a thoroughly electronic study is essential. Assumed from the ultraviolet-visible 319 diffuse reflectance spectrum, the indirect and direct transition bandgap energy of $\mathrm{Ag}_{3} \mathrm{PO}_{4}$ 320 is $2.36 \mathrm{eV}$ and $2.43 \mathrm{eV}$, respectively ( $\mathrm{Yi}$ et al., 2010). Therefore, $\mathrm{Ag}_{3} \mathrm{PO}_{4}$ can adsorb 321 illumination under visible light with an average wavelength $(<530 \mathrm{~nm})$. Using density 322 functional theory (DFT), several studies have been done to understand $\mathrm{Ag}_{3} \mathrm{PO}_{4}$ high 323 photocatalytic activity (see Supplementary Fig. S3.A).

$324 \mathrm{Ma}$ et al. (Ma et al., 2011) reported that $\mathrm{Ag}_{3} \mathrm{PO}_{4}$ has a conduction band with large 325 dispersion that enables the separation of charge carriers. Furthermore, the vacancies 326 present in $\mathrm{Ag}_{3} \mathrm{PO}_{4}$ could play a significant role in the separation of the electron-hole pairs.

327 Liu et al. (Liu et al., 2011) also reported that $\mathrm{Ag}_{3} \mathrm{PO}_{4}$ has a bandgap energy of $2.43 \mathrm{eV}$ 328 (see Supplementary Fig. S3.B). The conduction and valence bands are mainly 
329 consisting of $(\mathrm{Ag} 5 \mathrm{~s}, 5 \mathrm{p})$ and $(\mathrm{O} 2 \mathrm{p}, \mathrm{Ag} 4 \mathrm{~d})$ states, respectively. A VBM potential of 2.67

$330 \mathrm{eV}$ implies a sufficient driving force for the oxidation of water and pollutants' degradation.

$331 \mathrm{Xu}$ et al. (Xu et al., 2014) studied $\mathrm{Ag}_{3} \mathrm{PO}_{4}$ and graphene (GR) surface interaction and 332 established good stability and electron transfer mechanism along with the photocatalytic 333 activity. The strength of interfacial interaction is attributed to the geometry and separation 334 of $\mathrm{Ag}_{3} \mathrm{PO}_{4} / \mathrm{GR}$.

335 Kahk et al. (Kahk et al., 2014) studied the relation between the experiment and theoretical 336 results. They demonstrated that the prediction of the electronic, structural, and optical 337 characteristics of $\mathrm{Ag}_{3} \mathrm{PO}_{4}$ using DFT calculations was of excellent precision. The 338 molecular orbital $(\mathrm{MO})$ theory was used to propose an interpretation of the electronic 339 structure of $\mathrm{Ag}_{3} \mathrm{PO}_{4}$ (see Supplementary Fig. S3.C). Based on the MO theory, the 340 electronic structure of $\mathrm{Ag}_{3} \mathrm{PO}_{4}$ was simplified. The covalent interactions between silver 341 and oxygen are weaker than those between phosphorus and oxygen, commencing from 342 an isolated $\left(\mathrm{PO}_{4}\right)^{3-}$ unit, a molecular orbital diagram for $\mathrm{Ag}_{3} \mathrm{PO}_{4}$ was created.

343 Moreover, only sigma interactions between orbitals over $\mathrm{O}$ and $\mathrm{P}$ were considered for $344\left(\mathrm{PO}_{4}\right)^{-}$, two orbitals of sigma symmetry were provided by four oxygen atoms: $2 \mathrm{~s}$ and one 345 of the three $2 p$. The two triply degenerate ligand group orbital (LGO) is t2 symmetry, and 346 two LGO of a1 symmetry in a tetrahedral environment. These overlap with the P $3 s\left(a_{1}\right)$ 347 and P $3 p\left(t_{2}\right)$ orbitals and form twelve molecular orbitals, as demonstrated in (see 348 Supplementary Fig. S3.C).

\subsection{Photocatalytic properties of $\mathrm{Ag}_{3} \mathrm{PO}_{4}$ photocatalyst}


350 In general, there are some factors that can effectively evaluate the photocatalyst activity 351 during organic pollutants oxidation into water or gas phases such as: (i) the successful 352 photo-excitation and the formation of separated electron/hole pairs during visible or UV 353 light, wherein, a better visible light responsive photocatalyst was recommended; (ii) the 354 ability of photocatalyst conduction band to condense dissolved $\mathrm{O}_{2}$ to yield oxidizing ${ }^{\circ} \mathrm{O}_{2}{ }^{-}$ 355 species $\left(\mathrm{E}_{0}\left(\mathrm{O}_{2} / \mathrm{O}_{2}{ }^{--}=-0.33 \mathrm{~V}\right.\right.$ vs. the $\mathrm{NHE}$ at $\mathrm{pH}$ 7) (Wood, 1988); (iii) the valance band of 356 the photocatalyst is able to oxidize $\mathrm{H}_{2} \mathrm{O}$ or ${ }^{-} \mathrm{OH}$ into ${ }^{\circ} \mathrm{OH}$ hydroxyl radicals $\left(\mathrm{E}_{0}\left(\mathrm{H}_{2} \mathrm{O} / \mathrm{HO}^{*}\right)=\right.$ $3572.73 \vee$ vs the $\mathrm{NHE} ; \mathrm{E}_{0}\left(\mathrm{HO}^{-} / \mathrm{HO}^{*}\right)=1.9 \mathrm{~V}$ vs the $\mathrm{NHE}$ ) (Schneider et al., 2014); (iv) 358 photocatalyst surface area is a crucial parameters since the most photocatalytic action 359 takes place over photocatalyst surface sites, therefore, adsorbed pollutants have more 360 chance of being oxidized via ROSs (Djellabi et al., 2020); (v) the stability of the 361 photocatalyst is also considered as a critical key for practical application. Since 2010, $362 \mathrm{Ag}_{3} \mathrm{PO}_{4}$ has been identified as a photocatalyst for organic pollutant oxidation and water 363 splitting (Yi et al., 2010). Ming Ge et al. (Ge et al., 2012) reported that the scavenging of $364 \mathrm{HO}$ and ${ }^{\circ} \mathrm{O}_{2}{ }^{-}$species by isopropyl alcohol and benzoquinone, respectively, does not affect 365 visible-light-driven $\mathrm{RhB}$ photocatalytic degradation using $\mathrm{Ag}_{3} \mathrm{PO}_{4}$. It further points out that 366 these ROSs do not contribute much to the oxidation of RhB. In other words, the photo367 production of $\mathrm{HO}^{\cdot}$ and ${ }^{\circ} \mathrm{O}_{2}{ }^{-}$via the $\mathrm{Ag}_{3} \mathrm{PO}_{4} /$ visible light system is not very efficient. They 368 reported that the $\mathrm{CB}$ and $\mathrm{VB}$ are not thermodynamically able to convert $\mathrm{O}_{2}$ and $\mathrm{H}_{2} \mathrm{O}$ into $369 \mathrm{O}_{2}{ }^{--}$and $\mathrm{HO}^{*}$, respectively. However, the photocatalytic degradation of $\mathrm{RhB}$ was utterly 370 inhibited when EDTA was added to the reaction, which confirms that direct oxidation of

$371 \mathrm{RhB}$ by photoinduced $\mathrm{h}^{+}$on $\mathrm{Ag}_{3} \mathrm{PO}_{4}$ is the primary oxidation mechanism. Dong et al. 372 (Dong et al., 2016) also showed that the direct hole oxidation of $\mathrm{MB}$ by $\mathrm{Ag}_{3} \mathrm{PO}_{4}$ (oxidized 
373 at $200^{\circ} \mathrm{C}$ ) is the most crucial pathway, while there is also the participation of $\mathrm{HO} \cdot$ species.

374 As shown in Fig. 3A, $\mathrm{Ag}_{3} \mathrm{PO}_{4}$ is very effective for oxygen evolution via the conversion of $375 \mathrm{H}_{2} \mathrm{O}$ molecules into $\mathrm{O}_{2}$ by the VB (Bierman et al., 2008). The photo produced electrons 376 on the $\mathrm{CB}$ reduce $\mathrm{Ag}^{+}$to $\mathrm{Ag}$.

377 One of the main hindrances of $\mathrm{Ag}_{3} \mathrm{PO}_{4}$ for environmental remediation is the photo378 corrosion issue due to $\mathrm{Ag}^{+}$reduction into metallic $\mathrm{Ag}$ (Martin et al., 2015), thus leading to 379 the deactivation of the photocatalyst. On the other hand, due to the CB and VB potential 380 edges, the efficiency of $\mathrm{Ag}_{3} \mathrm{PO}_{4}$ photocatalyst for photo-producing ROSs is very low. Thus 381 only the pollutants that are adsorbed on the $\mathrm{Ag}_{3} \mathrm{PO}_{4}$ surface have more possibility of being 382 oxidized and mineralized directly by positive holes. It is essential to point out that the 383 surface area of $\mathrm{Ag}_{3} \mathrm{PO}_{4}$ is tiny as reported by some studies, e.g., 0:98 $\mathrm{m}^{2} / \mathrm{g}$ (Yi et al., 384 2010); 0.16-1.02 m²/g (Dong et al., 2016); $2 \mathrm{~m}^{2} / \mathrm{g}$ (Ge et al., 2012). 


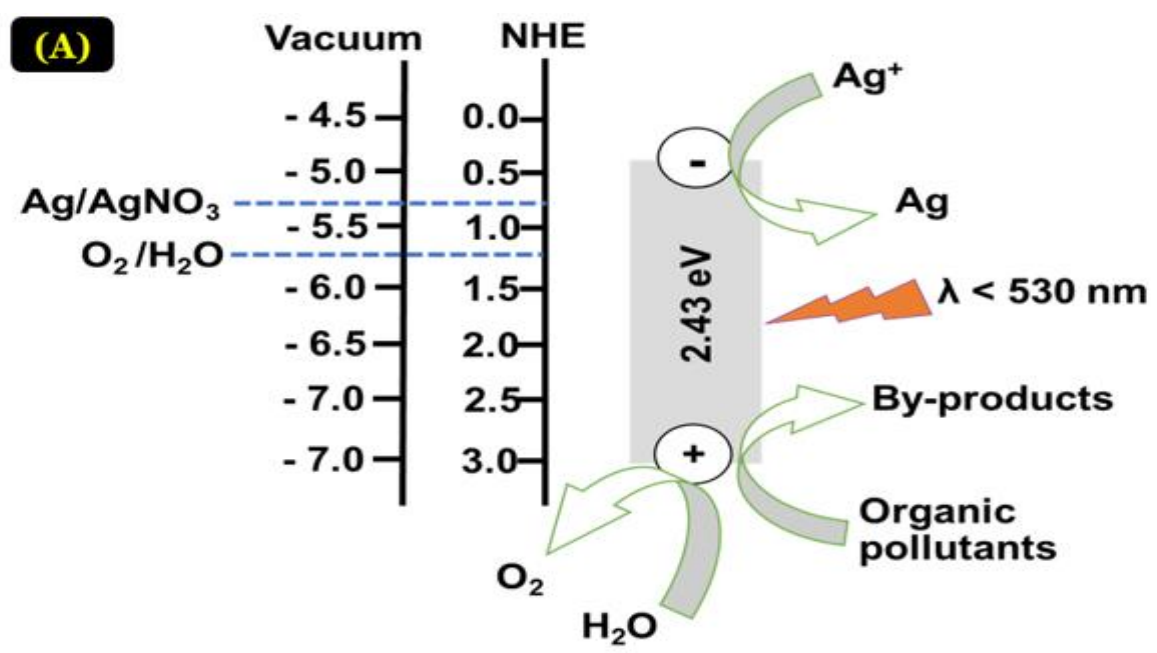

\section{(B)}

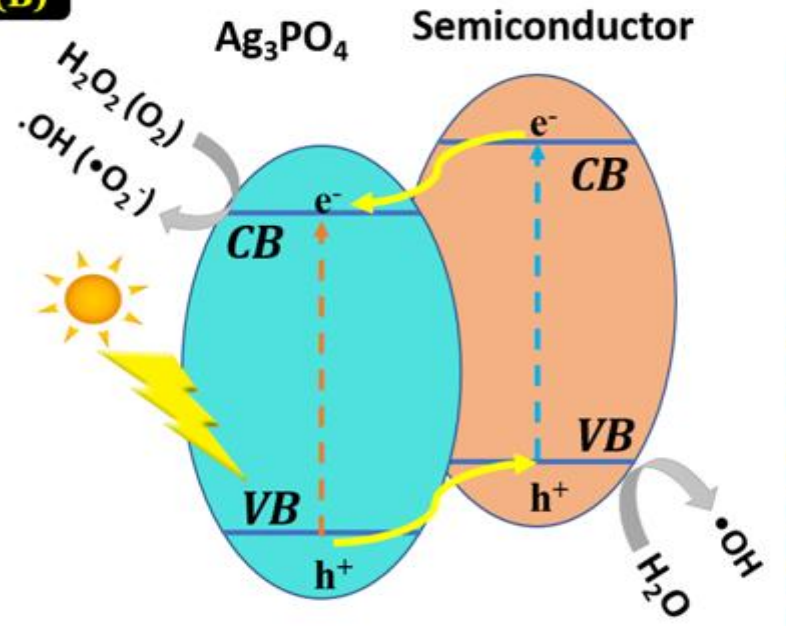

Conventional type-II heterojunction

(C) $\mathrm{Ag}_{3} \mathrm{PO}_{4} \quad$ Semiconductor

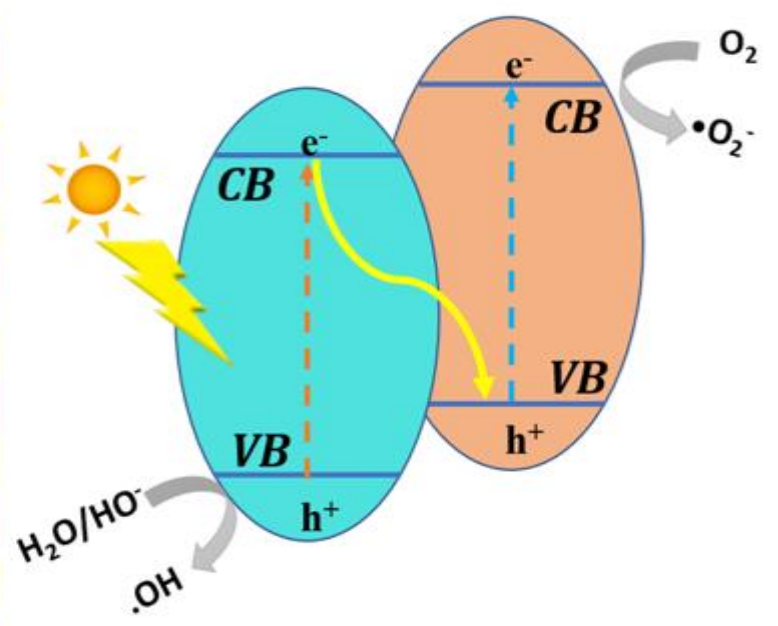

\section{Z-Scheme heterojunction}

Fig.3 (A). Mechanistic pathway of photocatalytic oxidation of organic pollutants in $\mathrm{Ag}_{3} \mathrm{PO}_{4} /$ visible light; (B) Schematic of the conventional type-II heterojunction; (C) Schematic of the $\mathrm{Ag}_{3} \mathrm{PO}_{4^{-}}$ Based Z-scheme heterojunction photocatalyst (inspired from (Xue et al., 2020; Yi et al., 2010)). the degradation of pollutants in gas-phase mediums is a serious issue that faces the application of photocatalysis systems in the 
394 real-world (Pichat, 2019). However, the photocatalytic system under sunlight can 395 continuously produce ROSs to mineralize such by-products further or decrease their 396 medium concentration. Mostly, photocatalysis cannot be used as a single treatment 397 process when it comes to the real application due to its shortcoming in terms of the 398 formation of by-products. Therefore, the combination of photocatalysis with other systems 399 is crucial to help the appropriate treatment of air.

400 The formation of heterojunctions between $\mathrm{Ag}_{3} \mathrm{PO}_{4}$ and other semiconductors is an 401 attractive option to vary interfacial interactions, further offers a series of novel 402 characteristics rather than that by single nanomaterial characteristics (Cai et al., 2020; 403 Tang et al., 2020). A prolonged carrier lifetime and an enhancing interfacial charge 404 transfer can be obtained from such heterostructures. However, it is also well understood 405 that this is not easy to get the desired properties of heterojunctions material with well406 matched valence and conduction band level in the two semiconductors (Lu et al., 2015; 407 Wang et al., 2015).

$408 \mathrm{Ag}_{3} \mathrm{PO}_{4}$-Based $\mathrm{Z}$-scheme and conventional heterojunctions have already been 409 extensively investigated to enhance photo-generated charges responsible for 410 photocatalysis reactions and ultimately inhibited its photo-corrosion (Chen et al., 2014;

411 Lu et al., 2015; Rao et al., 2020; Tang et al., 2020). The type II junction is the most 412 common in conventional heterojunctions (Fig. 3B). In contrast, the newly emerged direct 413 Z-scheme heterojunction (Fig. 3C) is regarded as the most efficient in Z-scheme systems 414 to explore photo-generated carriers (He et al., 2018). Both heterojunctions have different 415 charge carrier transport mechanisms, but the structure of both direct Z-scheme and type416 II heterojunctions is the same. 
417 The formation of conventional type-II heterojunction is mainly dependent on combining 418 the proper two different semiconductors (SC-I) and (SC-II) having proper CB and VB band 419 structure for proper electron-hole pairs transferring Fig. 3B. During light irradiation, the 420 produced electron and holes from SC-I and SC-II will move towards SC-II (CB) and SC-I 421 (VB), respectively. Thus, the photogenerated electron-hole pair recombination possibility 422 would be reduced, and oxidation and reduction reactions without interfering occur over 423 two semiconductors. (Huang et al., 2019; Lam et al., 2012; Pirhashemi et al., 2018). In 424 contrast, a completely different mechanism of charge carrier migration was observed for 425 direct Z-scheme heterojunctions. During light irradiation, the electron produced on 426 semiconductor II (SC-II) would automatically transfer towards the higher reduction 427 potential of semiconductor I (SC-I) (Fig. 3C), while the photogenerated holes remain on 428 semiconductor II (SC-II), resulting in the spatial separation of charge carriers. Therefore, 429 spatial separation of useful charge carrier in direct Z-scheme heterojunction will remove 430 useless charge carriers by optimizing SC-I and SC-II composition system redox ability. 431 Therefore, a direct Z-scheme heterojunction photocatalyst could enhance the 432 photocatalytic activity more specifically (He et al., 2018; Huang et al., 2019). Moreover, 433 the direct Z-scheme photocatalyst fabrication cost seems to be significantly reduced. 434 Substantially, the direct Z-scheme heterojunction prepared photocatalyst offers two 435 obvious merits, a highly efficient photocatalytic reduction (high redox ability) and a low436 cost fabrication (Huang et al., 2019; Low et al., 2017; Zhou et al., 2014).

437 The bottom of the $\mathrm{Ag}_{3} \mathrm{PO}_{4}$ conduction band (CB) energy level is more positive than the 438 reduction potential of $\mathrm{O}_{2}\left(\mathrm{O}_{2}+\mathrm{e}^{-} \rightarrow{ }^{-} \mathrm{O}_{2}^{-},-0.33 \mathrm{~V}\right.$ vs. NHE) (Wood, 1988). Therefore, 439 introducing another semiconductor to produce the Z-scheme system is beneficial for the 
440 degradation of gaseous pollutants and the extension of $\mathrm{Ag}_{3} \mathrm{PO}_{4}$ lifetime if the photo441 excited electrons in the $\mathrm{CB}$ of $\mathrm{Ag}_{3} \mathrm{PO}_{4}$ can be transferred to the newly introduced 442 semiconductor.

443 A wide range of $\mathrm{Ag}_{3} \mathrm{PO}_{4}$-based heterojunctions photocatalysts by exhibiting various 444 composition and structural characteristics have been proposed through various well445 established synthesis protocols for photocatalytic oxidation gas-phase pollutants. It is 446 systematically summarized in this section.

\subsection{Coupling $\mathrm{Ag}_{3} \mathrm{PO}_{4}$ with graphitic carbon nitride $\left(\mathrm{g}-\mathrm{C}_{3} \mathrm{~N}_{4}\right)$}

448 Graphitic carbon nitride $\left(\mathrm{g}-\mathrm{C}_{3} \mathrm{~N}_{4}\right)$ has gained considerable interest as a metal-free 449 polymer n-type semiconductor due to favorable characteristics such as its 2D structure, 450 tunable electric structure, and good chemical stability, It is a visible-light-driven 451 semiconductor with (2.7 eV bandgap), and the CB and VB energy position exist at -1.1 452 and $1.6 \mathrm{eV}$ vs. standard hydrogen electrode (NHE), respectively (Che et al., 2020; Dong 453 et al., 2014; He et al., 2020; Masih et al., 2017; Tian et al., 2017). These characteristics 454 make $\left(\mathrm{g}-\mathrm{C}_{3} \mathrm{~N}_{4}\right)$ the most attractive candidate for highly efficient photocatalysis of gas455 phase volatile pollutant degradation.

456 There are several reports regarding the degradation of gaseous pollutants. They include 457 volatile organic pollutants (toluene, Ethylene, isopropanol, formaldehyde) and nitrogen 458 oxide (NOx) by $\mathrm{Ag}_{3} \mathrm{PO}_{4} / \mathrm{g}-\mathrm{C}_{3} \mathrm{~N}_{4}$ composite photocatalyst (Chen et al., 2014; Rao et al., 459 2020; Shen et al., 2018; Zhao et al., 2017). For instance, Chen and his co-workers (Chen

460 et al., 2014) recently prepared a direct Z-scheme configuration-based novel g- $\mathrm{C}_{3} \mathrm{~N}_{4}$ $461 \mathrm{Ag}_{3} \mathrm{PO}_{4}$ composite for visible-light-driven (300 W Xe lamp) photocatalytic oxidation of 
462 ethylene $\left(\mathrm{C}_{2} \mathrm{H}_{4}\right)$. The results indicate that the introduction of $\mathrm{g}-\mathrm{C}_{3} \mathrm{~N}_{4}$ in $\mathrm{Ag}_{3} \mathrm{PO}_{4}$ resulted in 463 enhanced gas adsorption. Notably, by using (30:70\%) ratio of $\mathrm{Ag}_{3} \mathrm{PO}_{4}$ and $\mathrm{g}-\mathrm{C}_{3} \mathrm{~N}_{4}$ 464 composite, the complete decomposition of $\mathrm{C}_{2} \mathrm{H}_{4}(90 \mu \mathrm{L})$ was achieved after $3 \mathrm{~h}$ under 465 visible light, whereas bare $\mathrm{Ag}_{3} \mathrm{PO}_{4}$ needs $20 \mathrm{~h}$ for complete decomposition of $\mathrm{C}_{2} \mathrm{H}_{4}$ under 466 visible light irradiation (Fig. 4A). Moreover, it was noted that $\mathrm{g}-\mathrm{C}_{3} \mathrm{~N}_{4}-\mathrm{Ag}_{3} \mathrm{PO}_{4}$ composites 467 exhibited higher $k$ values $\left(1.0464 \mathrm{~h}^{-1}\right)$ than by pristine $\mathrm{g}-\mathrm{C}_{3} \mathrm{~N}_{4}\left(12.38\right.$ times) and $\mathrm{Ag}_{3} \mathrm{PO}_{4}$ 468 (3.7 times). Hence, it is confirmed that the synergetic $\mathrm{Ag}_{3} \mathrm{PO}_{4}$ and $\mathrm{g}-\mathrm{C}_{3} \mathrm{~N}_{4}$ effect eases 469 photogenerated charge carriers separation and their mobility thereby, resulting into 470 superior photocatalytic performance. Furthermore, It was observed that during the photo471 oxidation of $\mathrm{C}_{2} \mathrm{H}_{4}$, no other products except $\mathrm{CO}_{2}$ were detected (Fig. 4B). The fact that 472 the $\mathrm{CO}_{2}$ yields for all $\mathrm{g}-\mathrm{C}_{3} \mathrm{~N}_{4}$-containing samples were greater than that which can be 473 generated from $\mathrm{C}_{2} \mathrm{H}_{4}$ reveals an obvious adsorption effect of $\mathrm{g}-\mathrm{C}_{3} \mathrm{~N}_{4}$. Moreover, this 474 composite was stable for the photocatalytic oxidation of $\mathrm{C}_{2} \mathrm{H}_{4}$ and it can be recycled upto 4755 cycles without significant decrease in its activity.

476 According to their investigation, the reaction mechanism under sunlight illumination during 477 ethylene photocatalytic oxidation using $70 \%$ g- $\mathrm{C}_{3} \mathrm{~N}_{4}-30 \% \quad \mathrm{Ag}_{3} \mathrm{PO}_{4}$ catalysts may be 478 elucidated by the model presented in Fig. 4C.

479 During sunlight irradiation, a photo-excited electron of $\mathrm{Ag}_{3} \mathrm{PO}_{4}(\mathrm{CB})$ will transfer towards $480 \mathrm{~g}-\mathrm{C}_{3} \mathrm{~N}_{4}$ (VB) by recombining with holes or excited over $\mathrm{g}-\mathrm{C}_{3} \mathrm{~N}_{4} \mathrm{CB}$, thus resulting in 481 efficient charge separation of the photo-generated electron with no $\mathrm{Ag}_{3} \mathrm{PO}_{4}$ sacrificing. 482 Thus, the photo-excited electrons present over the $\mathrm{g}-\mathrm{C}_{3} \mathrm{~N}_{4}$ conduction band are 483 captivated by atmospheric $\mathrm{O}_{2}$ near the $\mathrm{g}-\mathrm{C}_{3} \mathrm{~N}_{4}$ surface site and generate more reactive 484 superoxide radical anions $\left(\mathrm{O}_{2}{ }^{-}\right)$. Conversely, the presence of holes over the $\mathrm{Ag}_{3} \mathrm{PO}_{4} \mathrm{VB}$ 
485 site automatically react with $\mathrm{Ag}_{3} \mathrm{PO}_{4}$ surface site adsorbed water molecules (or surface 486 hydroxyl groups) to produce hydroxyl radicals $(\cdot \mathrm{OH})$, thus resulting in the highly efficient 487 oxidation of $\mathrm{C}_{2} \mathrm{H}_{4}$ into water and carbon dioxide via reactive $\cdot \mathrm{OH}$ and $\mathrm{O}_{2}{ }^{-}$- radicals and 488 ultimately give higher stability of $\mathrm{Ag}_{3} \mathrm{PO}_{4}$ (Chen et al., 2014).

489 Similarly, the formation of $\mathrm{Ag}_{3} \mathrm{PO}_{4} / \mathrm{g}-\mathrm{C}_{3} \mathrm{~N}_{4}$ composite by adopting a simple in-situ 490 solvothermal process with different mass ratios $(1: 0,19: 1,9: 1,17: 3,4: 1,7: 3$, and 1:1) of $491 \mathrm{C}_{3} \mathrm{~N}_{4}$ have already been reported under different light wavelength for the decomposition 492 of NOx (Zhao et al., 2017). The result indicated no apparent NOx destruction was 493 observed at $510 \mathrm{~nm}$ wavelength using both $\mathrm{Ag}_{3} \mathrm{PO}_{4}$ or $\mathrm{g}-\mathrm{C}_{3} \mathrm{~N}_{4}$ (Fig. 4D). Although, the 494 photocatalytic activity of $\mathrm{Ag}_{3} \mathrm{PO}_{4} / 20 \% \mathrm{gC}_{3} \mathrm{~N}_{4}, \mathrm{Ag}_{3} \mathrm{PO}_{4} / 30 \% g-\mathrm{C}_{3} \mathrm{~N}_{4}$, and $\mathrm{Ag}_{3} \mathrm{PO} 4 / 50 \% \mathrm{~g}$ $495 \mathrm{C}_{3} \mathrm{~N}_{4}$ composites catalysts was observed to be preferable for NOx decomposition under 496 irradiation of $>400 \mathrm{~nm}$ with an average performance rate (15.52\%), (4.35\%), (10.64\%) 497 (Fig. 4D). Also, the fixing of irradiation wavelength at $290 \mathrm{~nm}$ leads to an incremental 498 increase of all $\mathrm{Ag}_{3} \mathrm{PO}_{4} / 20 \% g \mathrm{C}_{3} \mathrm{~N}_{4}, \quad \mathrm{Ag}_{3} \mathrm{PO}_{4} / 30 \% g-\mathrm{C}_{3} \mathrm{~N}_{4}$, and $\mathrm{Ag}_{3} \mathrm{PO}_{4} / 50 \% g-\mathrm{C}_{3} \mathrm{~N}_{4}$ 499 composites activity for photocatalytic decomposition of NOx and an average 500 decomposition rate $(41.76,51.09,47.87 \%)$, respectively was obtained (Fig. 4D). 501 However, these decomposition rates were comparatively higher than the pristine $g-\mathrm{C}_{3} \mathrm{~N}_{4}$, $502 \mathrm{Ag}_{3} \mathrm{PO}_{4}$, and $\mathrm{P} 25$, thus demonstrating the promising efficiency of $\mathrm{Ag}_{3} \mathrm{PO} / \mathrm{g}-\mathrm{C}_{3} \mathrm{~N}_{4}$ 503 composite under both ultraviolet and visible irradiation due to enhanced light absorption 504 after $\mathrm{Ag}_{3} \mathrm{PO}_{4}$ and $\mathrm{g}-\mathrm{C}_{3} \mathrm{~N}_{4}$ composite formation (Fig. 4E). Moreover, the authors stated that 505 composite materials with an average $\mathrm{g}-\mathrm{C}_{3} \mathrm{~N}_{4}$ content of $20 \%$ and $30 \%$ demonstrate the 506 best visible light and UV light-driven decomposition of NOx, respectively. Additionally, it 507 is also noted that under irradiation $>290 \mathrm{~nm}$, excellent stability, and the remarkable 
508 efficiency of the $\mathrm{Ag}_{3} \mathrm{PO}_{4} / 30 \% \mathrm{~g}-\mathrm{C}_{3} \mathrm{~N}_{4}$ catalyst even after four cycles. Simultaneously, the

509 NOx decomposition rate of $\mathrm{Ag}_{3} \mathrm{PO}_{4}$ somehow decreased (Fig. 4F). Hence, it is undeniable

510 that the $\mathrm{g}-\mathrm{C}_{3} \mathrm{~N}_{4}$ addition automatically improves $\mathrm{Ag}_{3} \mathrm{PO}_{4}$ stability and thus inhibiting its

511 photo-corrosion.

512 The photocatalytic mechanistic pathways on $\mathrm{Ag}_{3} \mathrm{PO}_{4} / \mathrm{g}^{-}-\mathrm{C}_{3} \mathrm{~N}_{4}$ photocatalysts under visible

513 light is illustrated in Fig. 4G. When $\mathrm{Ag}_{3} \mathrm{PO}_{4} / \mathrm{g}-\mathrm{C}_{3} \mathrm{~N}_{4}$ photocatalysts composite is irradiated

514 by visible light (Eq. 1), the transfer of photoexcited electron occurs from $\mathrm{g}-\mathrm{C}_{3} \mathrm{~N}_{4} \mathrm{CB}$ to $515 \mathrm{Ag}_{3} \mathrm{PO}_{4}$, inhibiting electron and holes recombination behavior. Thus, the hole present over

516 the $\mathrm{g}-\mathrm{C}_{3} \mathrm{~N}_{4}$ valence band (VB) is scavenged by water molecules to generate more free

517 hydroxyl radical $(\mathrm{OH} \bullet)($ Eq. 2). Conversely, the photogenerated and transfer electrons

518 over the $\mathrm{Ag}_{3} \mathrm{PO}_{4} \mathrm{CB}$ site automatically react with oxygen, thereby generating oxygen

519 radicals (Eq. 3) and resulting in the oxidation of nitrogen monoxide via oxygen, hydroxyl

520 radical, and water producing $\mathrm{NO}_{2}^{-}$or $\mathrm{NO}_{3}$. Moreover, it was noted that during light

521 irradiation, only $20 \%$ of $\mathrm{NO}$ was converted into $\mathrm{O}_{2}$ and $\mathrm{N}_{2}$, while the rest $80 \%$ was oxidized

522 to $\mathrm{NO}_{3}{ }^{-}$. The overall mechanism of photocatalytic $\mathrm{NOx}$ decomposition via $\mathrm{Ag}_{3} \mathrm{PO}_{4} / \mathrm{gC}_{3} \mathrm{~N}_{4}$

523 composite under visible light is presented below (Zhao et al., 2017):

$524 \quad \mathrm{Ag}_{3} \mathrm{PO}_{4} / \mathrm{gC}_{3} \mathrm{~N}_{4}+\mathrm{hv} \rightarrow \mathrm{h}^{+}+\mathrm{e}^{-}$

$525 \mathrm{H}_{2} \mathrm{O}+\mathrm{h}^{+} \rightarrow \cdot \mathrm{OH}+\mathrm{H}^{+}$

$526 \mathrm{O}_{2}+\mathrm{e}^{-} \rightarrow \cdot \mathrm{O}_{2}^{-}$

$527 \mathrm{NO}+2 \cdot \mathrm{OH} \rightarrow \mathrm{NO}_{2}+\mathrm{H}_{2} \mathrm{O}$

$528 \quad \mathrm{NO}_{2}+\cdot \mathrm{OH} \rightarrow \mathrm{NO}_{3}^{-}+\mathrm{H}^{+}$

$529 \mathrm{NOx}+\cdot \mathrm{O}_{2}^{-} \rightarrow \mathrm{NO}_{3}^{-}$ 
(A)
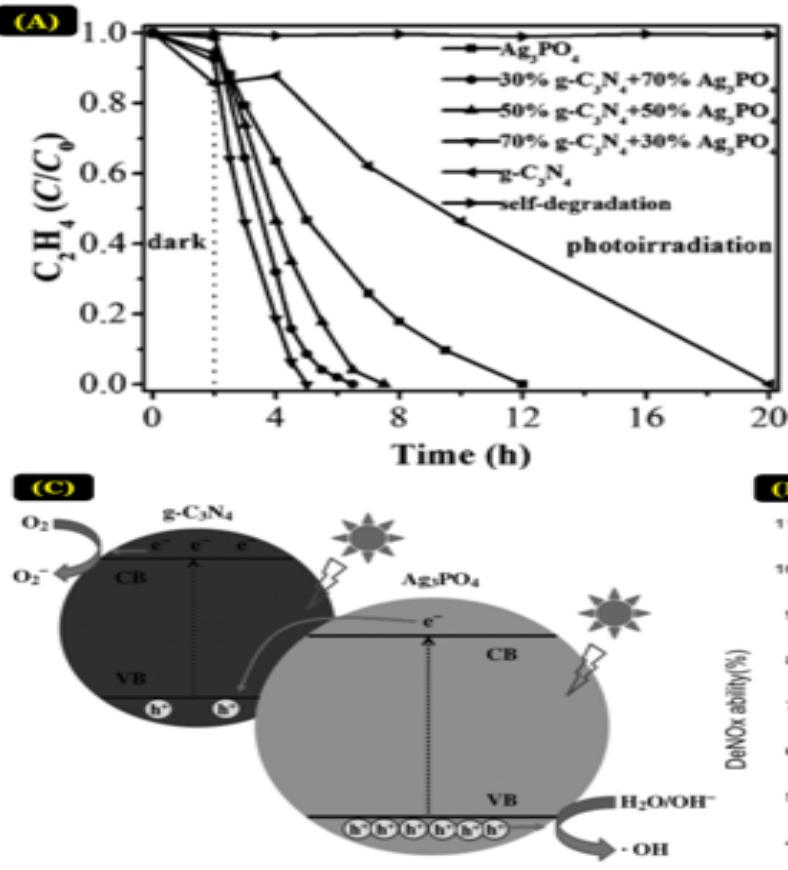

Z-Scheme

(E)

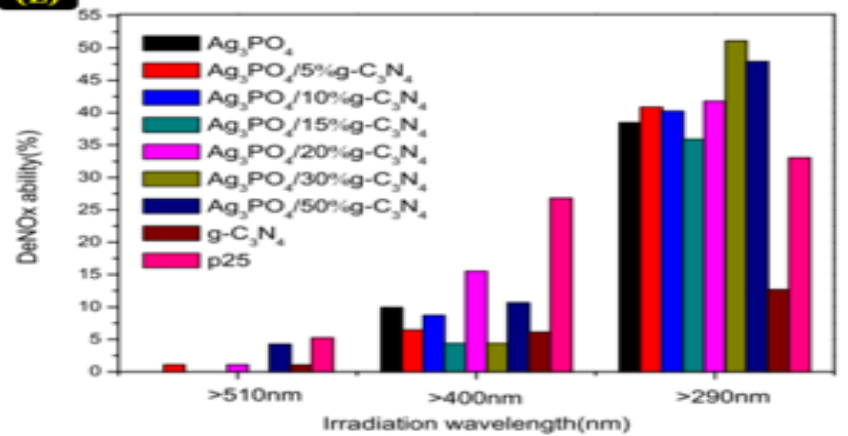

(B)
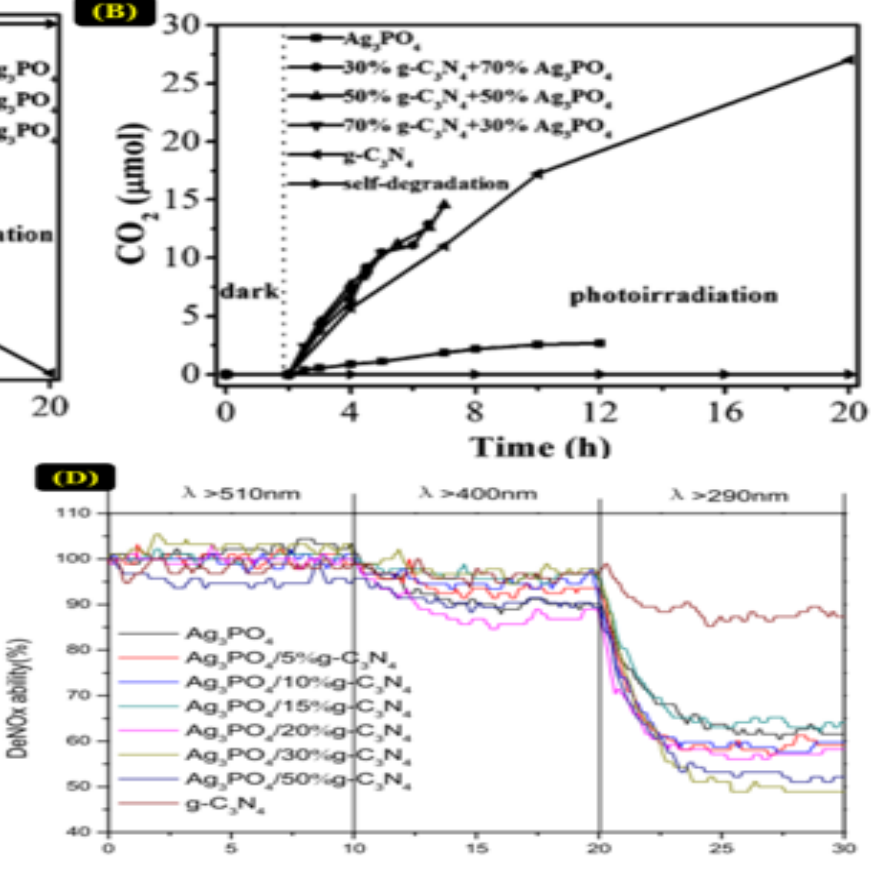

ime(min)

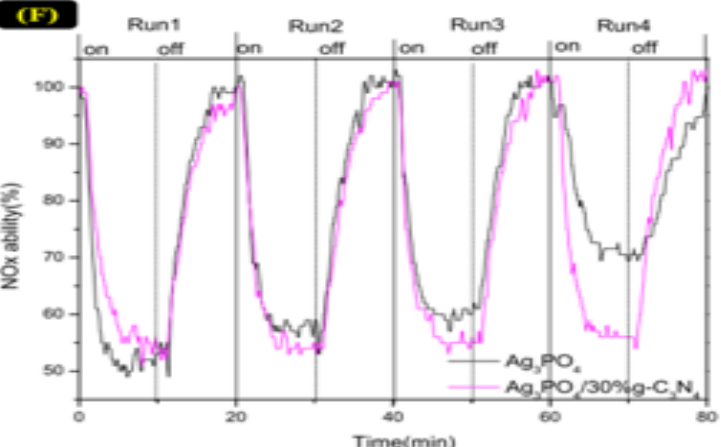

(G)

531

532

533

534

535

536

537

538
Fig.4. Time courses of (A) $\mathrm{C}_{2} \mathrm{H}_{4}$ degradation and (B) $\mathrm{CO}_{2}$ evolution on $\mathrm{g}-\mathrm{C}_{3} \mathrm{~N}_{4}-\mathrm{Ag}_{3} \mathrm{PO}_{4}$ composites, (C) Charge transfer in the $\mathrm{g}-\mathrm{C}_{3} \mathrm{~N}_{4}-\mathrm{Ag}_{3} \mathrm{PO}_{4}$ Z-Scheme mode under sunlight illumination (Figs 4A,4B and $4 \mathrm{C}$ are adapted with permission from ref (Chen et al., 2014), copyright 2014 Wiley Online Library). (D) and (E) NOx destruction activities of $\mathrm{Ag}_{3} \mathrm{PO}_{4} / \mathrm{g}_{-} \mathrm{C}_{3} \mathrm{~N}_{4}$ composites under the irradiation of different wavelengths of light, (F) Cycling photocatalytic degradation of NOx under $290 \mathrm{~nm}$ irradiation, (G) the possible mechanism of visible-light-induced photocatalysis of $\mathrm{Ag}_{3} \mathrm{PO}_{4} / \mathrm{gC}_{3} \mathrm{~N}_{4}$ composite (Figs $4 \mathrm{D}, 4 \mathrm{~F}, 4 \mathrm{E}$ and $4 \mathrm{G}$ are adapted with permission from ref (Zhao et al., 2017), copyright 2016 Elsevier). 
539 Similarly, Reo et al. (Rao et al., 2020) proposed a different mass ratio $(0.5,1.0,1.5$, to $5402.0 \mathrm{wt} \%$ ) to prepare $\mathrm{Ag}_{3} \mathrm{PO}_{4} / \mathrm{g}-\mathrm{C}_{3} \mathrm{~N}_{4}$ nanocomposites. In a continuous flow, at $420 \mathrm{~nm}$, 541 LED irradiation driven formaldehyde $(\mathrm{HCHO})\left(0.5 \mathrm{mg} / \mathrm{m}^{3}\right)$ photocatalytic decomposition 542 efficiency of $\mathrm{Ag}_{3} \mathrm{PO}_{4} / \mathrm{g}-\mathrm{C}_{3} \mathrm{~N}_{4}$ photocatalysts was tested. Their findings showed maximum 543 formaldehyde degradation rates $(8.51 \%, 10.60 \%, 22.4 \%, 10.60 \%$, and $6.38 \%)$, in the 544 order of $\mathrm{g}-\mathrm{C}_{3} \mathrm{~N}_{4}, 0.5 \mathrm{AP}-\mathrm{CN}, 1 \mathrm{AP}-\mathrm{CN}, 1.5 \mathrm{AP}-\mathrm{CN}$, and $2 \mathrm{AP}-\mathrm{CN}$, respectively Fig. 5A. The 545 optimum photoactivity of the $1 \mathrm{AP}-\mathrm{CN}$ heterojunction for $\mathrm{HCHO}$ degradation was about 546 (2.63) times fast than $\mathrm{g}-\mathrm{C}_{3} \mathrm{~N}_{4}$. After comprehensively evaluating the gas-phase 547 formaldehyde photocatalytic degradation in a continuous flowing mode of corresponding 548 composite photocatalysts, they found that when $\mathrm{Ag}_{3} \mathrm{PO}_{4}$ as an impurity semiconductor 549 was immersed into the $\mathrm{g}-\mathrm{C}_{3} \mathrm{~N}_{4}$ lattice, the formation of type II heterojunctions 550 semiconductor was observed (Fig. 5B), which can restrain photogenerated carriers 551 recombination thereby enhancing the overflow of the photogenerated electron over 552 photocatalyst surface to boost up the reaction. Therefore, under irradiation, the $\mathrm{Ag}_{3} \mathrm{PO}_{4} / \mathrm{g}$ $553 \mathrm{C}_{3} \mathrm{~N}_{4}$ nanocomposite photodegradation efficiency for formaldehyde increased. Moreover, 554 their results reveal that under visible light irradiation, the photogenerated electrons 555 trapped by $\mathrm{O}_{2}$ over conduction band CB produce more $\cdot \mathrm{O}_{2}{ }^{-}$radicals, and the presence of 556 holes over the valence band (VB) directly participate in the oxidation of water/- $\mathrm{OH}$ and/or 557 water by generating $\cdot \mathrm{OH}$ radicals and thereby resulting in further oxidation of $\mathrm{HCHO}$ into $558 \mathrm{H}_{2} \mathrm{O}$ and $\mathrm{CO}_{2}$ (Rao et al., 2020).

559 In another study, special attention towards the formation of Z-scheme g- $\mathrm{C}_{3} \mathrm{~N}_{4} / \mathrm{Ag} / \mathrm{Ag}_{3} \mathrm{PO}_{4}$ 560 composite was devoted to evaluate gaseous isopropanol photocatalytic oxidation (Shen 561 et al., 2018). The formation of $\mathrm{g}-\mathrm{C}_{3} \mathrm{~N}_{4} / \mathrm{Ag} / \mathrm{Ag}_{3} \mathrm{PO}_{4}$ composites at room temperature was 
562 carried via a simple in situ deposition method by coating regular rhombic dodecahedrons

$563 \mathrm{Ag}_{3} \mathrm{PO}_{4}$ particles over a $\mathrm{g}-\mathrm{C}_{3} \mathrm{~N}_{4}$ sheet. Later on different $\mathrm{Ag}_{3} \mathrm{PO}_{4}$ to $\mathrm{g}-\mathrm{C}_{3} \mathrm{~N}_{4}$ ratio were 564 denoted by $A C x$ and $x$ refer to various ratios $(x=0.3,0.5,0.7,0.9,1.0$ and 1.2). The 565 photocatalytic oxidation efficiency of $\mathrm{AC} 1.0(90 \mu \mathrm{L})$ is the highest among $\mathrm{Ag} / \mathrm{Ag}_{3} \mathrm{PO}_{4}$ and

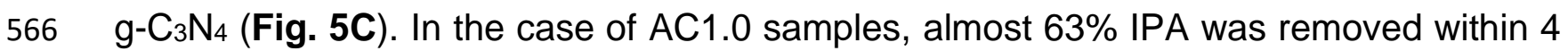
$567 \mathrm{~h}$, higher than that by $\mathrm{g}-\mathrm{C}_{3} \mathrm{~N}_{4}(14 \%)$ and $\mathrm{Ag} / \mathrm{Ag}_{3} \mathrm{PO}_{4}(40 \%)$. Their findings also showed 568 that acetone was the main outcome product during the photocatalytic oxidation of 569 isopropanol. The incremental increase in acetone concentration was attributed to 570 isopropanol's selective oxidation to acetone (Fig. 5D). As depicted in Fig. 5E, the use of $571 \mathrm{~g}-\mathrm{C}_{3} \mathrm{~N}_{4} / \mathrm{Ag} / \mathrm{Ag}_{3} \mathrm{PO}_{4}$ for isopropanol oxidation exhibited significant efficiency over five 572 consecutive cycles, thereby indicating higher stability of the studied photocatalyst. The 573 explanation of visible-light-driven photooxidation of gaseous isopropanol possible 574 mechanism over $\mathrm{g}-\mathrm{C}_{3} \mathrm{~N}_{4} / \mathrm{Ag} / \mathrm{Ag}_{3} \mathrm{PO}_{4}$ is shown in Fig. 5F. Moreover, the presence of 575 photogenerated electron and holes over $\mathrm{CB}$ of $\mathrm{g}_{-} \mathrm{C}_{3} \mathrm{~N}_{4}$ and $\mathrm{VB}$ of $\mathrm{Ag}_{3} \mathrm{PO}_{4}$ of $\mathrm{g}$ $576 \mathrm{C}_{3} \mathrm{~N}_{4} / \mathrm{Ag} / \mathrm{Ag}_{3} \mathrm{PO}_{4}$ exhibited efficient oxidation-reduction capability due to the transfer of 577 electrons from the $\mathrm{CB} \mathrm{Ag}_{3} \mathrm{PO}_{4}$ to $\mathrm{Ag}$ nanoparticles instead of remaining over $\mathrm{Ag}_{3} \mathrm{PO}_{4}$ 578 lattice and thereby resulting in the inhibition of $\mathrm{Ag}_{3} \mathrm{PO}_{4}$ self-reduction and enhancing $\mathrm{g}$ $579 \mathrm{C}_{3} \mathrm{~N}_{4} / \mathrm{Ag} / \mathrm{Ag}_{3} \mathrm{PO}_{4}$ composite stability (Shen et al., 2018). 

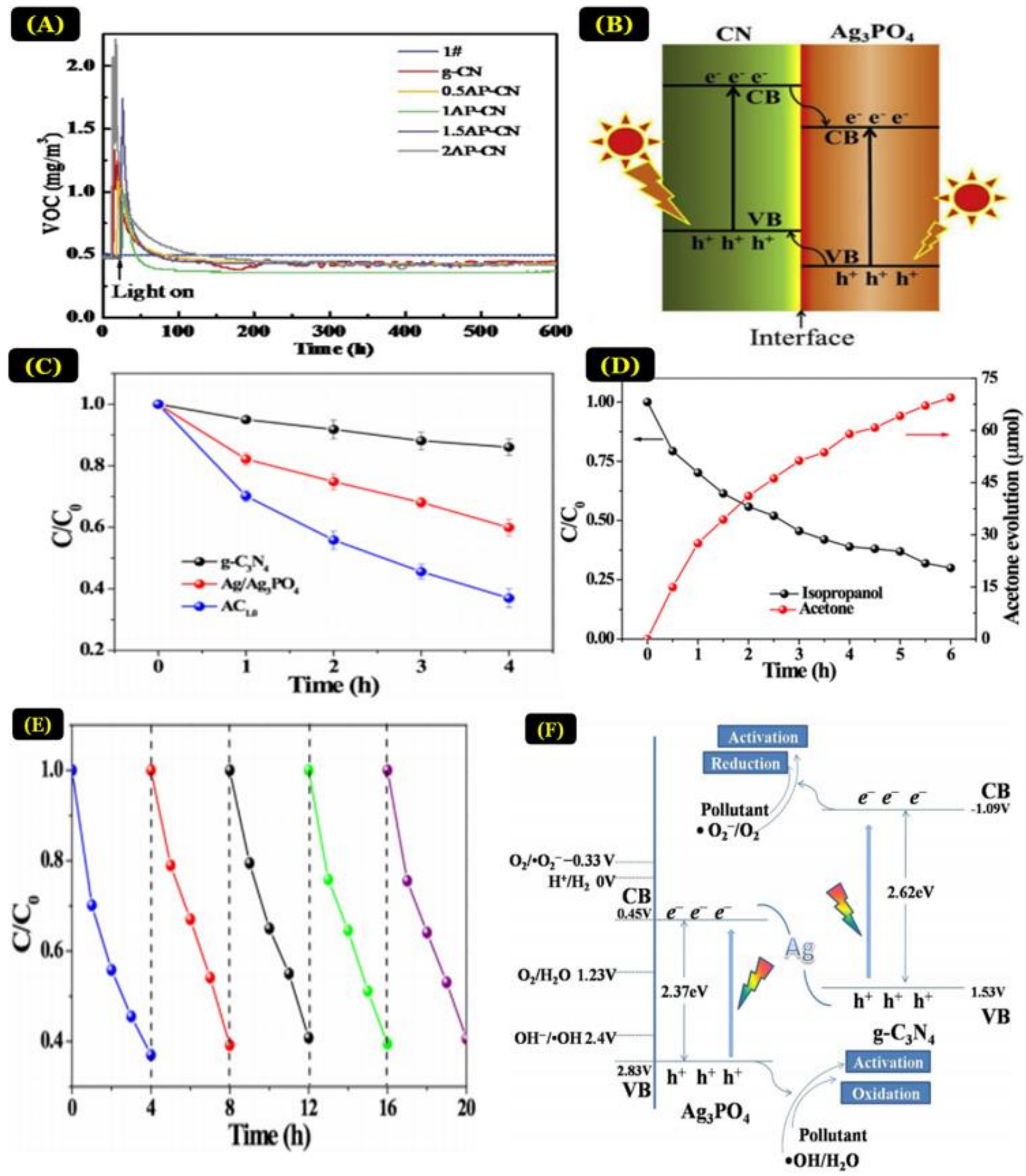

Fig. 5. (A) Degradation measurement of flowing gas-phase formaldehyde (B) Energy band schematic of $\mathrm{Ag}_{3} \mathrm{PO}_{4} / \mathrm{g}-\mathrm{C}_{3} \mathrm{~N}_{4}$ composites (Figs $5 \mathrm{~A}$ and $5 \mathrm{~B}$ are adapted with permission from ref (Rao et al., 2020), copyright 2019 Elsevier). (C) Photocatalytic degradation of gaseous isopropanol over $\mathrm{AC1}$.0, $\mathrm{Ag} / \mathrm{Ag}_{3} \mathrm{PO}_{4}$ and $\mathrm{g}-\mathrm{C}_{3} \mathrm{~N}_{4}$ samples, (D) Photocatalytic degradation of gaseous isopropanol and amounts of acetone evolution yield over AC1.0, (E) the cyclic stability tests of AC1.0, (F) Schematic illustration for the charge transfer and separation in Z-scheme g$\mathrm{C}_{3} \mathrm{~N}_{4} / \mathrm{Ag} / \mathrm{Ag}_{3} \mathrm{PO}_{4}$ photocatalytic composite under visible-light irradiation (Figs $5 \mathrm{C}, 5 \mathrm{D}, 5 \mathrm{E}$, and $5 \mathrm{~F}$ are adapted with permission from ref (Shen et al., 2018), copyright 2018 Elsevier). 


\subsection{Coupling $\mathrm{Ag}_{3} \mathrm{PO}_{4}$ with $\mathrm{TiO}_{2}$}

590 Nowadays, $\mathrm{TiO}_{2}$, as an efficient UV light-driven photocatalyst, is getting tremendous

591 attention due to its non-toxic nature and low cost. Many attempts have been made by 592 many researchers to construct a heterostructure with $\mathrm{Ag}_{3} \mathrm{PO}_{4}$, not for only enhancing $593 \mathrm{Ag}_{3} \mathrm{PO}_{4}$ stability but also its photocatalytic activity via decreasing its bandgap (Jia et al., 594 2019; Rawal et al., 2012; Xie et al., 2015; Zhao et al., 2014). For example, Rawal et al. 595 (Rawal et al. 2012) introduced a novel $\mathrm{Ag}_{3} \mathrm{PO}_{4} / \mathrm{TiO}_{2}$ heterojunction by coating $\mathrm{Ag}_{3} \mathrm{PO}_{4}$ 596 surface sites polycrystalline $\mathrm{TiO}_{2}$. The as-prepared heterojunctions formation pathway is 597 presented in Fig. 6A. Its photocatalytic performance under visible light irradiation $(\lambda \geq 420$ $598 \mathrm{~nm}$ ) was evaluated to remove gaseous 2-propanol (IP). Experimental reports implied that 599 several compositions of $\mathrm{Ag}_{3} \mathrm{PO}_{4} / \mathrm{TiO}_{2}$ composites photocatalytic activities were higher 600 than bare $\mathrm{Ag}_{3} \mathrm{PO}_{4}$ and $\mathrm{TiO}_{2}$, (Fig. 6B). Their findings implied that within 120 min of visible 601 light irradiation about $65 \%$ of 2-propanol was decomposed by the composites (3/97 $\left.602 \mathrm{Ag}_{3} \mathrm{PO}_{4} / \mathrm{TiO}_{2}\right)$ due to superior adsorption and higher photogenerated $\mathrm{e}^{-}$transfer over 603 interface between $\mathrm{TiO}_{2}$ and $\mathrm{Ag}_{3} \mathrm{PO}_{4}$ (Fig. 6B). Furthermore, under visible light the 604 evaluation of photocatalytic activity was investigated in term of $\mathrm{CO}_{2}$ evolution. From the 605 Fig. 6C, it can be seen that the higher $\mathrm{CO}_{2}$ evolving efficiency is about 11.4 ppmv was 606 achieved within 2 hour using 3/97 $\mathrm{Ag}_{3} \mathrm{PO}_{4} / \mathrm{TiO}_{2}$. The pristine $\mathrm{Ag}_{3} \mathrm{PO}_{4}$ and $\mathrm{TiO}_{2}$ 607 demonstrated an average $\mathrm{CO}_{2}$ evolution efficiency of about 0.9 and 2.9 ppmv, 608 respectively. Additionally, the $3 / 97 \mathrm{Ag}_{3} \mathrm{PO}_{4} / \mathrm{TiO}_{2}$ reusability potential was evaluated for 609 gaseous isopropanol decomposition and their result showed that the degradation of the $6103 / 97 \mathrm{Ag}_{3} \mathrm{PO}_{4} / \mathrm{TiO}_{2}$ composite after 5 and 10 times recycling did not showed considerable 611 alteration in $\mathrm{CO}_{2}$ evolution (Fig. 6D), thus indicating its high photocatalytic stability. 
(A)

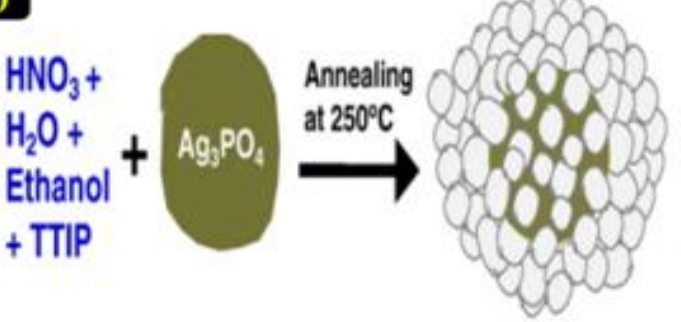

Ti-sol $\quad \mathrm{Ag}_{3} \mathrm{PO}_{4}$

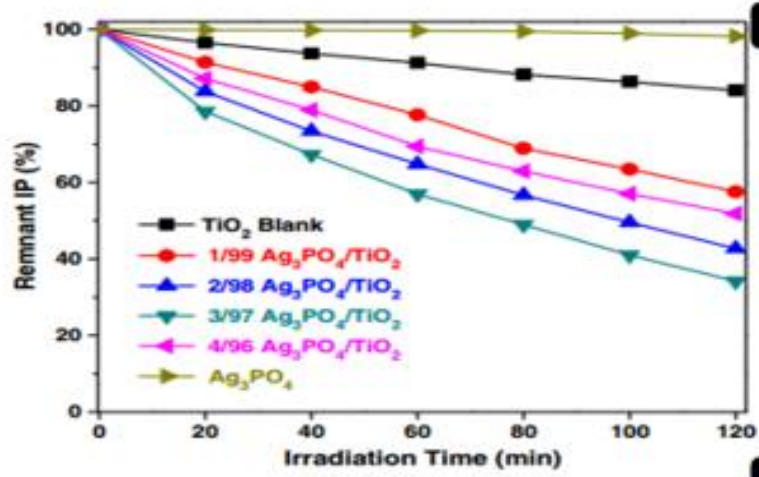

(B)

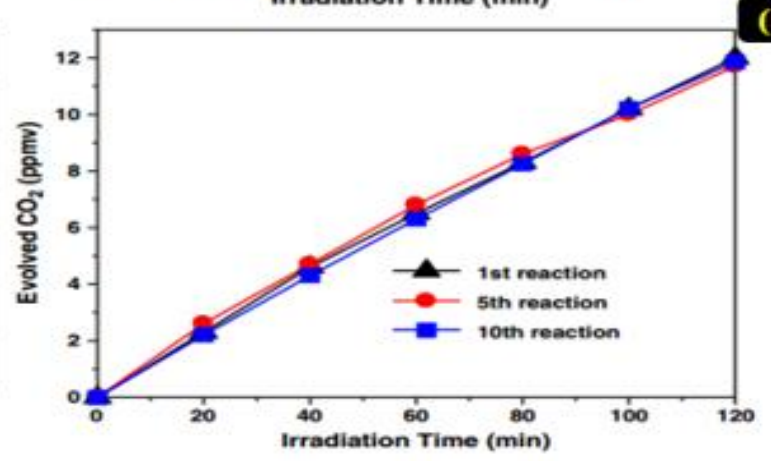

(D)
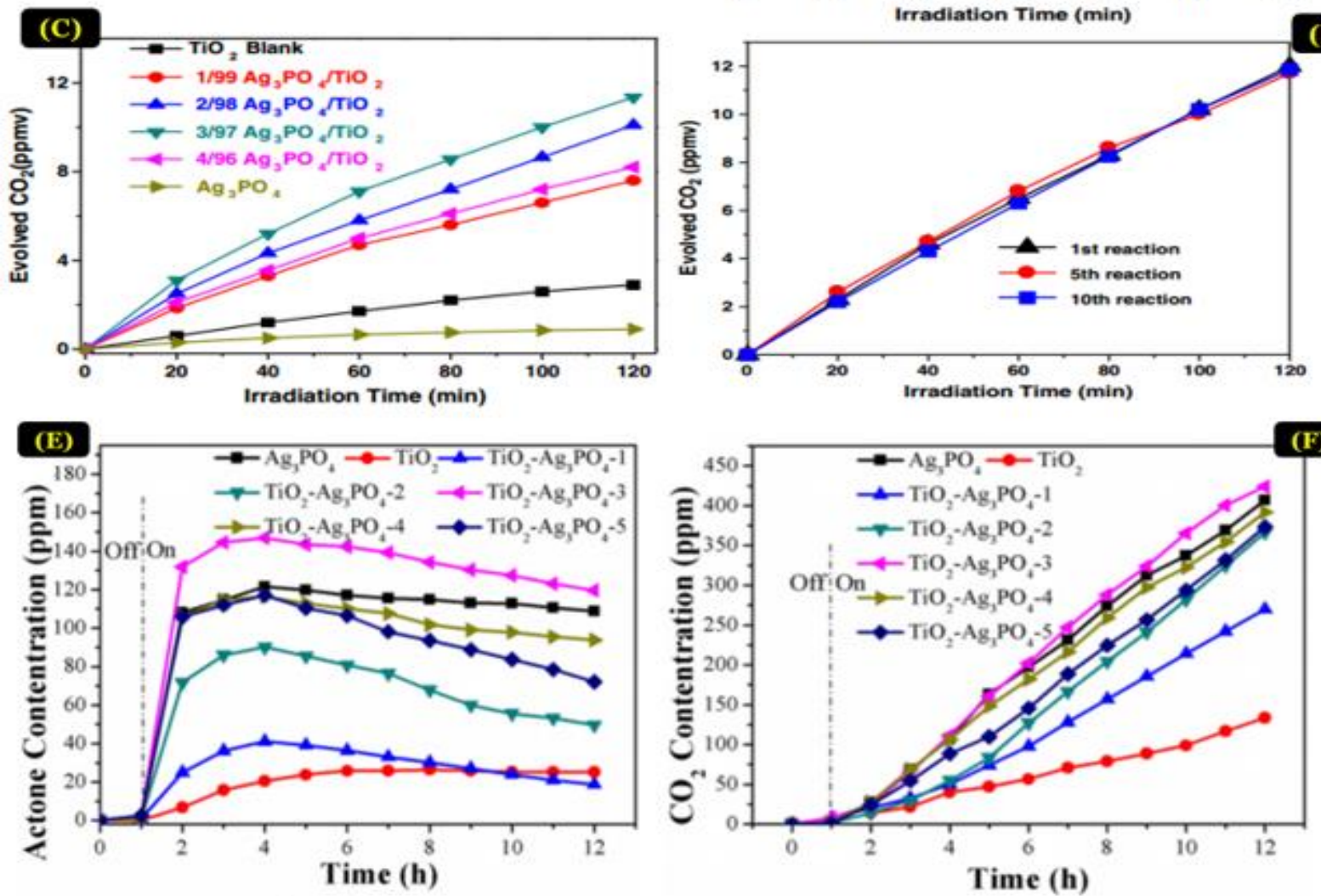

(G)

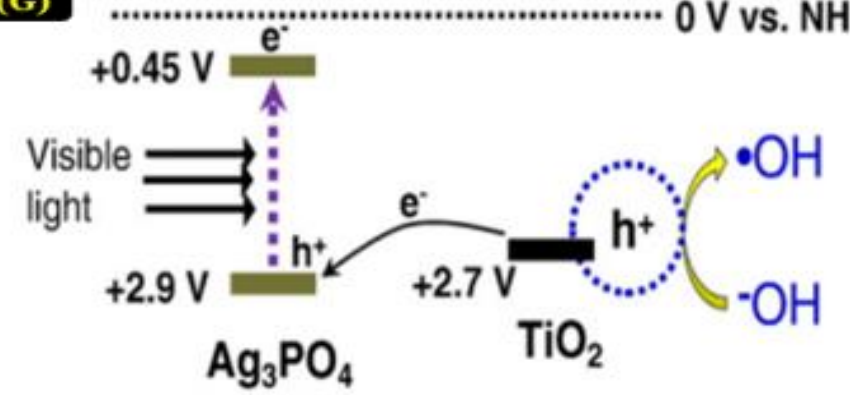

613 Fig. 6. (A) Preparation strategy for $\mathrm{Ag}_{3} \mathrm{PO}_{4} / \mathrm{TiO}_{2}$ composite; (B) Percentage of the remnant IP as a function of irradiation time in the presence of several $\mathrm{Ag}_{3} \mathrm{PO}_{4} / \mathrm{TiO}_{2}$ composites under visiblelight irradiation; (C) Amount of $\mathrm{CO}_{2}$ evolved (ppmv) in the presence of several $\mathrm{Ag}_{3} \mathrm{PO}_{4} / \mathrm{TiO}_{2}$ composites under visible-light irradiation, (D) Photocatalytic evolution of $\mathrm{CO}_{2}$ by the repeated use of $3 / 97 \mathrm{Ag}_{3} \mathrm{PO}_{4} / \mathrm{TiO}_{2}$. (Figs. $6 \mathrm{~A}, 6 \mathrm{~B}, 6 \mathrm{C}$, and $6 \mathrm{D}$ are adapted with permission from ref (Rawal et al., 
2012), copyright 2011 Elsevier). Acetone (E) and (F) $\mathrm{CO}_{2}$ evolution through degradation of 2propanol by $\mathrm{TiO}_{2}-\mathrm{Ag}_{3} \mathrm{PO}_{4}$ photocatalysts (Fig. 6E,6F are adapted with permission from ref (Jia et al., 2019), copyright 2019 Elsevier). (G) Diagram for the charge carrier transfer and formation of - $\mathrm{OH}$ radical in the $\mathrm{Ag}_{3} \mathrm{PO}_{4} / \mathrm{TiO}_{2}$ under visible light irradiation (Adapted with permission from ref (Rawal et al., 2012). copyright 2011 Elsevier).

Another study from Jia et al. (Jia et al., 2019) reported the preparation and utilization of $\left(\mathrm{Ag}_{3} \mathrm{PO}_{4} / \mathrm{TiO}_{2}\right)$ nanocomposites for gaseous 2-propanol decomposition. After using $\mathrm{Ag}_{3} \mathrm{PO}_{4} / \mathrm{TiO}_{2}$ as a photocatalyst under visible light, the high photocatalytic activity of $\mathrm{Ag}_{3} \mathrm{PO}_{4} / \mathrm{TiO}_{2}$ composites obtained was attributed to the superior surface area, which further enhances the visible light absorption capacity and thus increasing charge separation efficiency. Their results indicated a high photocatalytic performance of all hybrid $\mathrm{TiO}_{2}-\mathrm{Ag}_{3} \mathrm{PO}_{4}$ nanorods for 2-propanol degradation. Among them, $\mathrm{TiO}_{2}-\mathrm{Ag}_{3} \mathrm{PO}_{4}-3$ (13\% molar percentage of $\mathrm{Ag}_{3} \mathrm{PO}_{4}$ ) proved to be the best photocatalyst and produced about $147 \mathrm{ppm}$ and $424 \mathrm{ppm}$ of acetone and $\mathrm{CO}_{2}$ within the first $3 \mathrm{~h}$ (Fig. 6E) and $11 \mathrm{~h}$ (Fig. 6F), respectively.

Furthermore, to demonstrate the enhancement mechanism of photocatalytic degradation using $\mathrm{Ag}_{3} \mathrm{PO}_{4} / \mathrm{TiO}_{2}$ nanocomposites, a paradigm 2-propanol photocatalytic degradation was chosen (Rawal et al., 2012). However, it was observed that $\mathrm{Ag}_{3} \mathrm{PO}_{4} \mathrm{VB}$ electron excitement towards CB produced holes over its VB under visible light irradiation. The higher valence band position of $\mathrm{Ag}_{3} \mathrm{PO}_{4}(+2.9 \mathrm{eV}$ vs. $\mathrm{NHE})$ compared to $\mathrm{TiO}_{2}$ enables the holes transformation from $\mathrm{Ag}_{3} \mathrm{PO}_{4}$ to $\mathrm{TiO}_{2}(+2.7 \mathrm{eV}$ vs. $\mathrm{NHE})$ as shown in Fig. 6G. It indicates that the formation of holes over $\mathrm{TiO}_{2} \mathrm{VB}$ sites would be consumed through different oxidation reactions. During the inter-semiconductor hole-transfer mechanism, the photo-induced electron could be more stably separated, enabling the coupled system to effectively use the visible light for organic pollutant mineralization. On the other hand, 
644 considering $\mathrm{Ag}_{3} \mathrm{PO}_{4} \mathrm{CB}$ level $+0.45 \mathrm{~V}$ (vs. NHE), the direct electron transfers to oxygen 645 molecules $\left(-0.284 \mathrm{~V}\right.$ (vs. NHE) or formation of $\mathrm{HO}_{2} \bullet$ need about $-0.284 \mathrm{~V}$ (vs. $\mathrm{NHE}$ ) and $646-0.046 \mathrm{~V}$ (vs. NHE), respectively. would be difficult, as shown in Eqs. (7) and (8) 647 (Krungchanuchat et al., 2017), respectively. Thus, the electrons accumulated over CB of $648 \mathrm{Ag}_{3} \mathrm{PO}_{4}$ multi-electron processes would be transported to oxygen species described in 649 Eqs. (9) and (10) (Krungchanuchat et al., 2017). It is observed that the efficient photo650 induced charge separation may result in the enhancement of $\mathrm{Ag}_{3} \mathrm{PO}_{4} / \mathrm{TiO}_{2}$ composites' 651 photocatalytic activity.
$652 \mathrm{O}_{2}+\mathrm{e}^{-} \rightarrow \cdot \mathrm{O}_{2}^{-}$,
$\mathrm{E}_{0}=-0.284 \mathrm{~V}(\mathrm{vs} . \mathrm{NHE})$
$653 \mathrm{O}_{2}+\mathrm{H}^{+}+\mathrm{e}^{-} \rightarrow \mathrm{HO}_{2}$
$E_{0}=-0.046 \mathrm{~V}(\mathrm{vs} . \mathrm{NHE})$.
$654 \mathrm{O}_{2}+2 \mathrm{H}^{+}+2 \mathrm{e}^{-} \rightarrow \mathrm{H}_{2} \mathrm{O}_{2}$,
$\mathrm{E}_{0}=+0.682 \mathrm{~V}$ (vs. NHE).
$655 \mathrm{O}_{2}+4 \mathrm{H}^{+}+4 \mathrm{e}^{-} \rightarrow 2 \mathrm{H}_{2} \mathrm{O}$,
$\mathrm{E}_{0}=+1.23 \mathrm{~V}$ (vs. NHE)

\subsection{Coupling $\mathrm{Ag}_{3} \mathrm{PO}_{4}$ with $\mathrm{SrTiO}_{3}$}

$657 \mathrm{SrTiO}_{3}$ is one of the most commonly studied perovskite structures for photocatalytic 658 application (Ji et al., 2019; Kong et al., 2016; Yue et al., 2018); it exhibits high corrosion 659 resistance (Kong et al., 2016; Yue et al., 2018), chemical stability (Kong et al., 2016), low 660 cost (Kong et al., 2016), and non-toxicity (Kong et al., 2016; Zhang et al., 2010). It has 661 been verified as an efficient photocatalyst for improving $\mathrm{Ag}_{3} \mathrm{PO}_{4}$ photocatalytic activity 662 (Kong et al., 2016; Saadetnejad and Yıldırım, 2018; Yue et al., 2018).

663 In a study conducted by Guo et al. (Guo et al., 2013), a novel $\mathrm{Ag}_{3} \mathrm{PO}_{4} / \mathrm{Cr}-\mathrm{SrTiO}_{3}$ new 664 efficient heterojunction photocatalyst fabrication was performed by adopting a simple 665 sol-gel hydrothermal method. The photocatalytic activity of $\mathrm{Agg}_{3} \mathrm{PO}_{4} / \mathrm{Cr}-\mathrm{SrTiO}_{3}$ 
666 heterojunction under $300 \mathrm{~W}$ Xe-lamp as a source of solar light production (420 nm $<\lambda<$ $667800 \mathrm{~nm}$ ) was investigated for Isopropyl alcohol (IPA) (the initial concentration of IPA was 668 about 1250-1500 ppm) photocatalytic conversions into $\mathrm{CO}_{2}$. According to this study, the 669 prepared samples with varying ratios exhibited different efficiencies. In particular, $670 \mathrm{Ag}_{3} \mathrm{PO}_{4} / \mathrm{Cr}-\mathrm{SrTiO}_{3}$ heterojunction composite with (1:4) mass ratio exhibited the highest 671 photodegradation, about 97\% IPA within $3.8 \mathrm{~h}$ irradiation (Fig. 7A). In contrast, pure $\mathrm{Ag}_{3}$ $672 \mathrm{PO}_{4}$ and $\mathrm{Cr}-\mathrm{SrTiO}_{3}$ exhibited only $9 \%$ and $12 \%$ IPA decomposition within $8 \mathrm{~h}$ of irradiation, 673 respectively (Fig. 7A). Besides, the highest rate of $\mathrm{CO}_{2}$ evolution was found in the 674 presence of this heterojunction photocatalyst, and the amount of $\mathrm{CO}_{2}$ produced was 675291.2 ppm, which was 35 and 5 -fold higher than the bare $\mathrm{Ag}_{3} \mathrm{PO}_{4}$ and $\mathrm{Cr}-\mathrm{SrTiO}_{3}$, 676 respectively (Fig. 7B). Furthermore, the effect of calcination over photocatalytic 677 performance was also examined. Results indicated that higher photocatalytic activity was 678 observed for the samples calcined over $\left(500^{\circ} \mathrm{C}\right)$ than the ones calcined over $\left(300^{\circ} \mathrm{C}\right)$ and $679\left(700^{\circ} \mathrm{C}\right)(\mathrm{Fig} .7 \mathrm{C})$. As depicted from $\mathrm{Ag}_{3} \mathrm{PO}_{4} / \mathrm{Cr}-\mathrm{SrTiO}_{3}$ heterojunctions composites $\mathrm{XRD}$ 680 patterns in (Fig. 7D), calcined over different temperatures, the incremental increase 681 photocatalytic activity might be due to metallic silver particles presence over $\mathrm{Ag}_{3} \mathrm{PO}_{4}$, and 682 its behavior as photogenerated electrons trappers is more beneficial for electron 683 aggregation and transformation. The decrease in photocatalytic performance with an 684 increase in calcined temperature is might be due to the complete decomposition of $685 \mathrm{Ag}_{3} \mathrm{PO}_{4}$ at a higher temperature of $700^{\circ} \mathrm{C}$. 

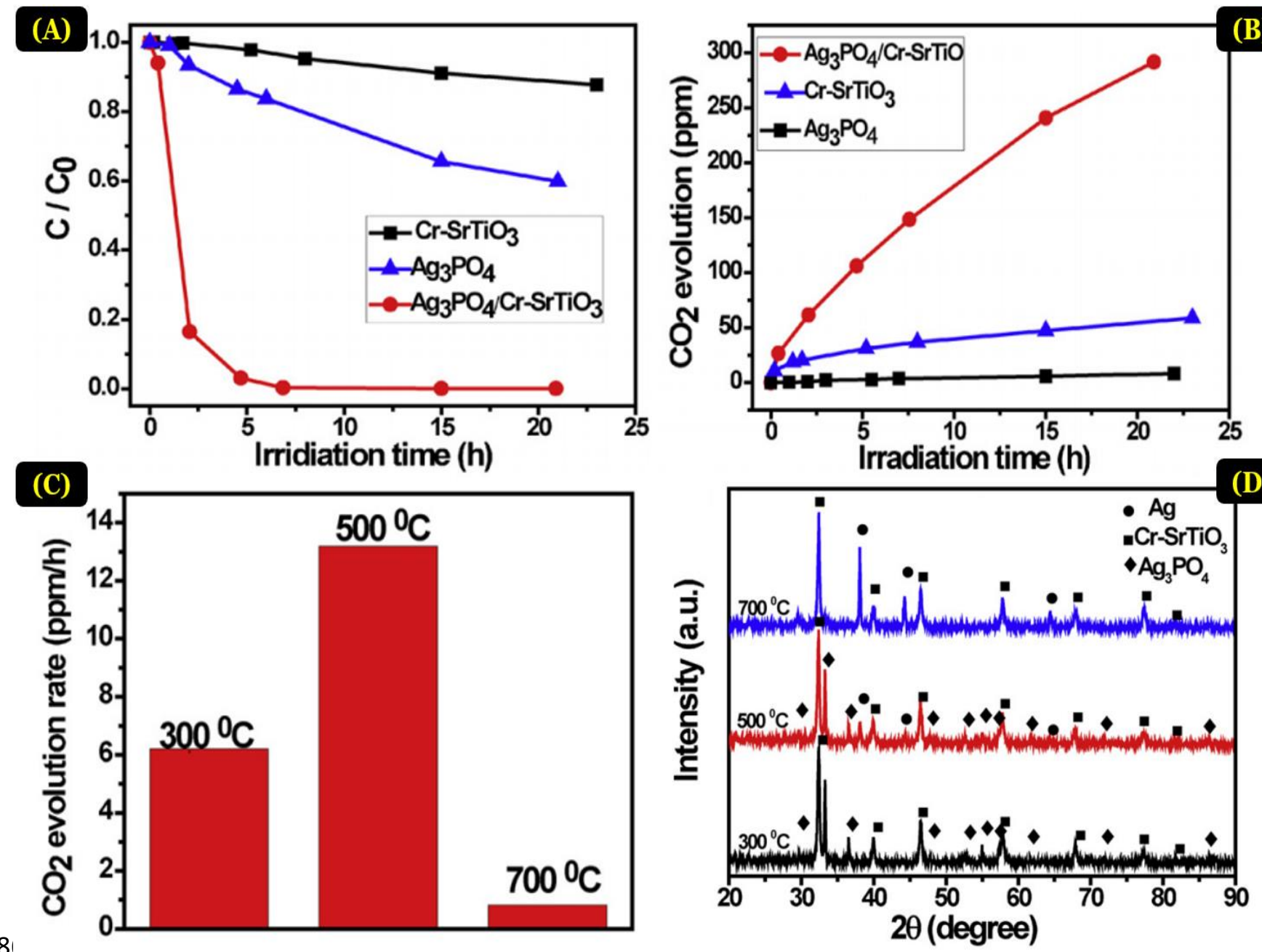

Fig.7. (A) The concentration change of IPA and (B) the evolution of $\mathrm{CO}_{2}$ over $\mathrm{Cr}-\mathrm{SrTiO}_{3}, \mathrm{Ag}_{3} \mathrm{PO}_{4}$ and $\mathrm{Ag}_{3} \mathrm{PO}_{4} / \mathrm{Cr}-\mathrm{SrTiO}_{3}(1: 4)$ composite powders under visible light irradiation; (C) the evolution rate of $\mathrm{CO}_{2}$ under visible light irradiation of the $\mathrm{Ag}_{3} \mathrm{PO}_{4} / \mathrm{Cr}-\mathrm{SrTiO}_{3}$ (1:4) composite powders calcined at different temperature over $(420 \mathrm{~nm}<\lambda<800 \mathrm{~nm}$ ); (D) The XRD patterns and. Adapted with permission from ref (Guo et al., 2013), copyright 2013 Elsevier).

Another report from Ji et al. (Ji et al., 2019) investigated the Z-scheme $\mathrm{Ag}_{3} \mathrm{PO}_{4} / \mathrm{Ag} / \mathrm{SrTiO}_{3}$ visible-light-driven $\left(\lambda \geq 420 \mathrm{~nm}, 150 \mathrm{~mW} / \mathrm{cm}^{2}\right)$ typical volatile organic compounds (xylene, toluene, and benzene) under mild heating (not higher than $90^{\circ} \mathrm{C}$ ). Their findings showed

697 that visible-light-driven $\mathrm{AgPO} / \mathrm{Ag} / \mathrm{STO}$ photocatalytic conversion (> 90\%) of toluene 698 (800ppm) was observed after $6 \mathrm{~h}$ reaction (Fig. 8A), which was better than (AgPO/STO, 
$\mathrm{Ag} / \mathrm{AgPO}$, and $\mathrm{Ag} / \mathrm{STO})$. The Ag NP bridge over AgPO/STO considerably enhances the photocatalytic performance. Furthermore, in their report, the effect of heat on photocatalytic behavior was also examined. As depicted in Fig. 8B, the toluene conversion during the photo-thermo-catalytic oxidation (PTO) process significantly increased from (65\% to $94 \%$ ) over $\mathrm{AgPO} / \mathrm{Ag} / \mathrm{STO}$ because of temperature increases (45 to $90^{\circ} \mathrm{C}$ ) for $3 \mathrm{~h}$. For the thermocatalytic oxidation (TCO) process, toluene conversion only increased from $3 \%$ to $14 \%$, and $59 \%$ toluene conversion via photocatalytic oxidation (PCO) was achieved at room temperature. Additionally, the photo-thermo-catalytic oxidation (PTO) process over AgPO/Ag/STO was tested for xylene and benzene degradation. Their results showed that after $4 \mathrm{~h}$ photo-thermo-catalytic oxidation (PTO) process at $90^{\circ} \mathrm{C}$, the conversion rates of xylene, toluene, and benzene were more than $85 \%$, thereby suggesting its potential practical application.

Furthermore, a clear description of the possible photocatalytic mechanism and the photothermo-catalytic oxidation of volatile organic compounds under visible-light irradiation over $\mathrm{Ag}_{3} \mathrm{PO}_{4} / \mathrm{Ag} / \mathrm{SrTiO}_{3}$ are exhibited in Fig. 8C.

As proposed in Fig. $\mathbf{8 C}$, the photogenerated electrons from the $\mathrm{Ag}_{3} \mathrm{PO}_{4}$ conduction band and the holes from the $\mathrm{SrTiO}_{3}$ valance band recombine via $\mathrm{Ag}$ nanoparticles using Z-scheme $\mathrm{Ag}_{3} \mathrm{PO}_{4} / \mathrm{Ag} / \mathrm{SrTiO}_{3}$ heterojunction structure as a photocatalyst. Such a distinctive Z-scheme charges transfer route could effectively restrain photogenerated charges recombination produced in $\mathrm{SrTiO}_{3}$ and $\mathrm{Ag}_{3} \mathrm{PO}_{4}$, thereby assuring a considerable generation of oxidative species $\left(\cdot \mathrm{OH}\right.$ and $\left.\cdot \mathrm{O}_{2}^{-}\right)$. Equally, photo-generated electrons from $\mathrm{SrTiO}_{3}$ reduction and the active $\cdot \mathrm{O}_{2}{ }^{-}$generation could also be enhanced. Moreover, in the surface of $\mathrm{Ag} \mathrm{NP}$, the photo-induced electron in $\mathrm{Ag}_{3} \mathrm{PO}_{4}$ and the holes in $\mathrm{SrTiO}_{3}$ 

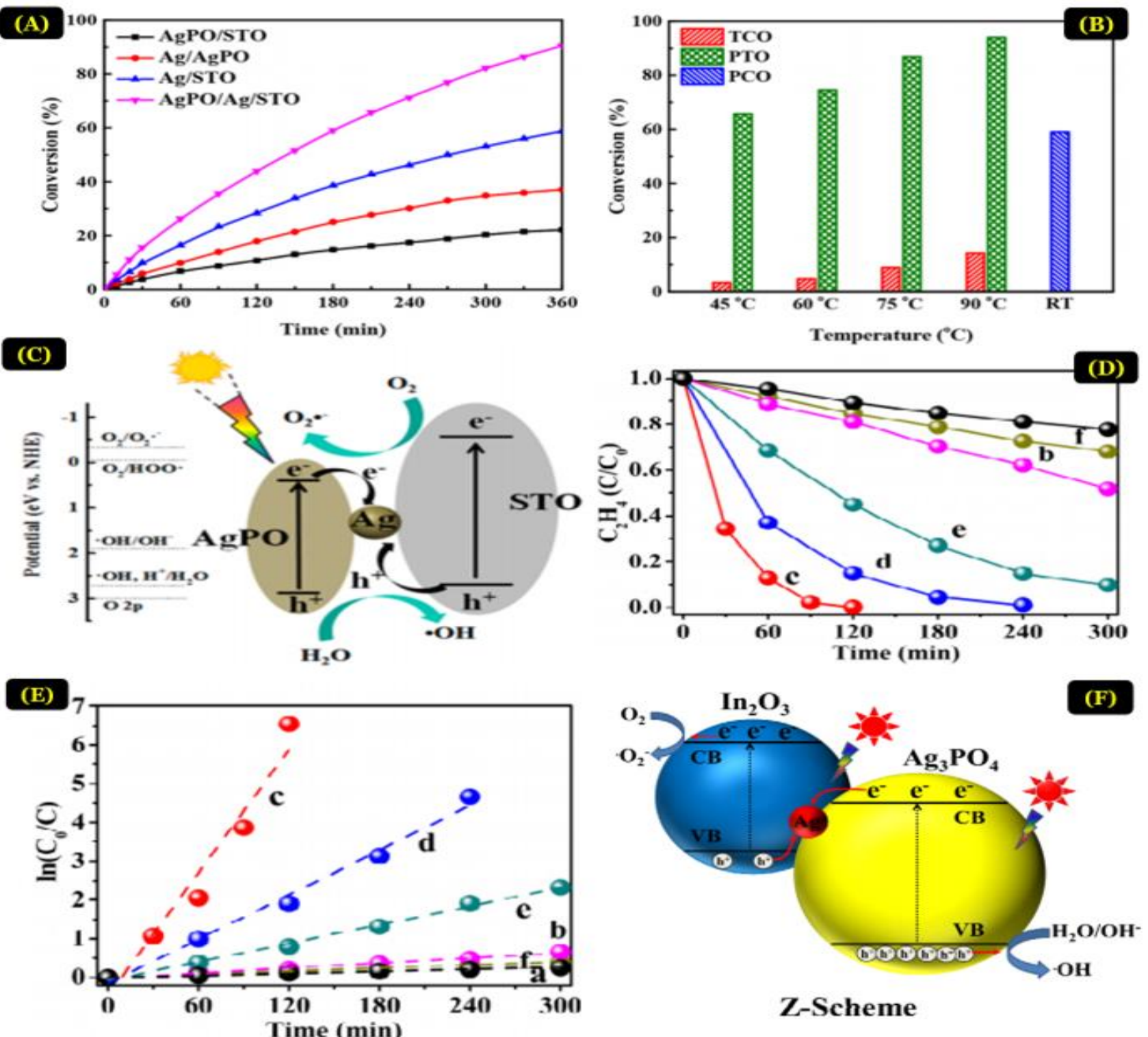

Fig. 8 (A) Photocatalytic oxidation (PCO) of toluene under visible light at room temperature for 6 h; (B) Thermocatalytic oxidation (TCO), Photocatalytic oxidation (PCO), and photothermocatalytic oxidation (PTO) of toluene over $\mathrm{Ag}_{3} \mathrm{PO}_{4} / \mathrm{Ag} / \mathrm{SrTiO}_{3}$ for $3 \mathrm{~h}$ (RT refers to room temperature);(C) Charge transfer process in the photocatalytic oxidation process over $\mathrm{Ag}_{3} \mathrm{PO}_{4} / \mathrm{Ag} / \mathrm{SrTiO}_{3}$. (Figs. 8A, 8B, and 8C are adapted with permission from ref (Ji et al., 2019), copyright 2019 American Chemical Society); (D) Time courses of $\mathrm{C}_{2} \mathrm{H}_{4}$ photodegradation and (E) pseudo-first-order kinetics plots: a. $\operatorname{In}_{2} \mathrm{O}_{3}$, 95-IO-Ag-5-AP, c. 90-IO-Ag-10-AP, d. 70-IO-Ag-30-AP, e. 50-IO-Ag-50-AP, f. $\mathrm{Ag}_{3} \mathrm{PO}_{4}$; (F) Charge transfer in the $\mathrm{In}_{2} \mathrm{O}_{3}-\mathrm{Ag}-\mathrm{Ag}_{3} \mathrm{PO}_{4} \mathrm{Z}$-scheme mode under sunlight illumination (Figs. 8D, 8E, and 8F are adapted with permission from ref (Chen et al., 2017), copyright 2017 Elsevier). 


\subsection{Coupling $\mathrm{Ag}_{3} \mathrm{PO}_{4}$ with $\mathrm{In}_{2} \mathrm{O}_{3}$}

$736 \mathrm{In}_{2} \mathrm{O}_{3}$ is an indirect band semiconductor with a direct bandgap of $3.6 \mathrm{eV}$ and an indirect

737 bandgap of $2.8 \mathrm{eV}$. The $\ln _{2} \mathrm{O}_{3}$ is regarded as an efficient photocatalyst, as it increases

738 the semiconductor absorption spectra from the UV region into the visible region (W. T.

739 Liu et al., 2018; Mu et al., 2012; Yang et al., 2017). In light of the Chen et al. investigation

740 (Chen et al., 2017), a novel 203-Ag-Ags $\mathrm{PO}_{4}$ composites formation via the Z-scheme

741 configuration and its use for visible-light-driven ethylene $\left(\mathrm{C}_{2} \mathrm{H}_{4}\right)$ photocatalytic

742 degradation was investigated. After comprehensively evaluating the photocatalytic

743 ethylene degradation performance by the corresponding composite photocatalysts, they

744 found that $\mathrm{In}_{2} \mathrm{O}_{3}-\mathrm{Ag}-\mathrm{Ag}_{3} \mathrm{PO}_{4}$ composite with 9:1 (90-IO-Ag-10-AP) mass ratio exhibited a

745 remarkable $\mathrm{C}_{2} \mathrm{H}_{4}$ photodegradation by decomposing almost 200 ppm $\mathrm{C}_{2} \mathrm{H}_{4}$ within $2 \mathrm{~h}$

746 under visible light irradiation (Fig. 8D). Additionally, only the production of $\mathrm{CO}_{2} \mathrm{was}$

747 detected during the photocatalytic oxidation of $\mathrm{C}_{2} \mathrm{H}_{4}$. The pseudo-first-order reaction

748 kinetics with the highest value of the rate constant $\left(52.93 \times 10^{-3} \mathrm{~h}^{-}\right)$provided the best fitting

749 for the whole photocatalytic oxidation reactions (Fig. 8E), and it was found to be higher

750 than the $\ln _{2} \mathrm{O}_{3}$ and $\mathrm{Ag}_{3} \mathrm{PO}_{4}$ with an average fold value of 24.4-fold and 41.1-fold,

751 respectively.

752 Furthermore, it was observed that during visible light irradiation, the degradation

753 proficiency of the catalyst changed after 3 reaction cycles. The schematic diagram of

754 charge carrier separation proposed for the photoexcited $\ln _{2} \mathrm{O}_{3}-\mathrm{Ag}-\mathrm{Ag}_{3} \mathrm{PO}_{4}$ composite

755 photocatalyst is represented in Fig. 8F. Moreover, it was observed that the photo-excited

756 electrons on the $\mathrm{CB}$ bottom of $\mathrm{Ag}_{3} \mathrm{PO}_{4}$ move to the $\mathrm{Ag}$ nanoparticles and then recombined

757 with the holes which transferred from the VB edge of $\ln 2 \mathrm{O}_{3}$ under visible light irradiation 
758 leading to the efficient separation of photo-generated charge carriers, which in turn slow 759 down the $\mathrm{Ag}_{3} \mathrm{PO}_{4}$ photo-corrosion. Simultaneously, the efficient reduction of adsorbed $\mathrm{O}_{2}$

760

761

762

763

764

765

766

767

over the $\ln _{2} \mathrm{O}_{3}$ surface resulted in reactive superoxide radical anions $\cdot \mathrm{O}_{2}{ }^{-}$due to photoexcited electrons over the $\mathrm{CB}$ bottom of $\ln _{2} \mathrm{O}_{3}$. Furthermore, the efficient oxidation of adsorbed water molecules or surface hydroxyl groups over $\mathrm{Ag}_{3} \mathrm{PO}_{4}$ resulted in hydroxyl radicals $\cdot \mathrm{OH}$ generation due to the holes over the $\mathrm{VB}$ edge $\mathrm{Ag}_{3} \mathrm{PO}_{4}$. Thus, the photoinduced strong $\bullet \mathrm{OH}$ and $\mathrm{O}_{2}{ }^{-}$radicals efficiently degraded the ethylene into $\mathrm{CO}_{2}$ and $\mathrm{H}_{2} \mathrm{O}$. Thus, this work gives a solid conclusion towards $\mathrm{Ag}_{3} \mathrm{PO}_{4}$ photo stabilization and $\mathrm{C}_{2} \mathrm{H}_{4}$ photocatalytic degradation by proving the formation of a Z-scheme composite as a promising pathway in the photocatalytic degradation field.

\subsection{Coupling $\mathrm{Ag}_{3} \mathrm{PO}_{4}$ with $\mathrm{Sr}_{2} \mathrm{Nb}_{2} \mathrm{O}_{7}$}

The $\mathrm{Sr}_{2} \mathrm{NB}_{2} \mathrm{O}_{7}$ is viewed as the most promising visible-light-driven photocatalyst, even among many-layered perovskite materials. Moreover, besides hydrogen reduction potential, it has a lower bandgap (3.9 eV) (Adhikari et al., 2018; Guo et al., 2014; Nisar et al., 2012). In connection with that, Guo et al. (Guo et al., 2014) reported different temperature based $(873 \mathrm{~K}, 923 \mathrm{~K}, 973 \mathrm{~K}, 1023 \mathrm{~K}, 1073 \mathrm{~K}$, and $1173 \mathrm{~K})$, novel $\mathrm{Ag}_{3} \mathrm{PO}_{4} /$ nitridized $\mathrm{Sr}_{2} \mathrm{Nb}_{2} \mathrm{O}_{7}$ (nitrided under $\mathrm{NH}_{3}$ flow $\left(500 \mathrm{~mL} \mathrm{~min}^{-1}\right)$ ) preparation throughout $3 \mathrm{~h}$ intending to adjust the band structures for efficient isopropyl alcohol (the initial concentration of IPA was about 1250-1500 ppm) degradation under visible light irradiation. Furthermore, the electronic structure calculations showed that the top of the valance band of $\mathrm{Sr}_{2} \mathrm{Nb}_{2} \mathrm{O}_{7}$ might be significantly increased after nitrogen doping (Fig. 9A). Therefore, it was concluded that the $\mathrm{Ag}_{3} \mathrm{PO}_{4} /$ nitridized $\mathrm{Sr}_{2} \mathrm{Nb}_{2} \mathrm{O}_{7}$ photocatalysts electronic structure might be altered by controlling nitrogen dose in nitridized $\mathrm{Sr}_{2} \mathrm{Nb}_{2} \mathrm{O}_{7}$. The report 
781 showed that all the composite photocatalysts displaying superior photoactivity than the 782 pristine materials. In particular, a remarkable photoactivity was observed using $783 \mathrm{Ag}_{3} \mathrm{PO}_{4} / \mathrm{SNON}-1023$ photocatalyst which achieved a maximum $\mathrm{CO}_{2}$ and acetone 784 evolution rates $10.32 \mathrm{ppm} \mathrm{h}^{-1}$ and $173.3 \mathrm{ppm} \mathrm{h}^{-1}$, respectively (Fig. 9B) and (Fig. 785 9C).These evolution rate are comparatively higher than other composite photocatalysts. 786 Moreover, it was found that by increasing the nitridation temperature $<1023 \mathrm{~K}$, increasing 787 evolution rate of acetone (Fig. 9B) and $\mathrm{CO}_{2}$ was observed (Fig. 9C). However, after 788 nitridation temperature $>1023 \mathrm{~K}$, increasing temperature resulted in the reduction of 789 acetone and $\mathrm{CO}_{2}$ evolution rates more significantly. This is due to generated holes 790 oxidation potential. Although the separation of electron-hole pairs increased due to the 791 prepared composite band structure characteristics the produced holes oxidation ability 792 was lower after transferring, as a result of the valence band position of the nitridized $793 \mathrm{Sr}_{2} \mathrm{Nb}_{2} \mathrm{O}_{7}$ (Fig. 9D). The optimal band gap of the nitridized $\mathrm{Sr}_{2} \mathrm{Nb}_{2} \mathrm{O}_{7}$ is almost $2.15 \mathrm{eV}$, 794 while that of $C B$ and VB potentials are $(-0.27 \mathrm{eV}$ and $+1.88 \mathrm{eV})$, respectively. According 795 to these findings, it was concluded that $\mathrm{Ag}_{3} \mathrm{PO}_{4}$ valance and conduction bands relative 796 potential as well as nitridized $\mathrm{Sr}_{2} \mathrm{Nb}_{2} \mathrm{O}_{7}$ have an important effects on photoactivity. 

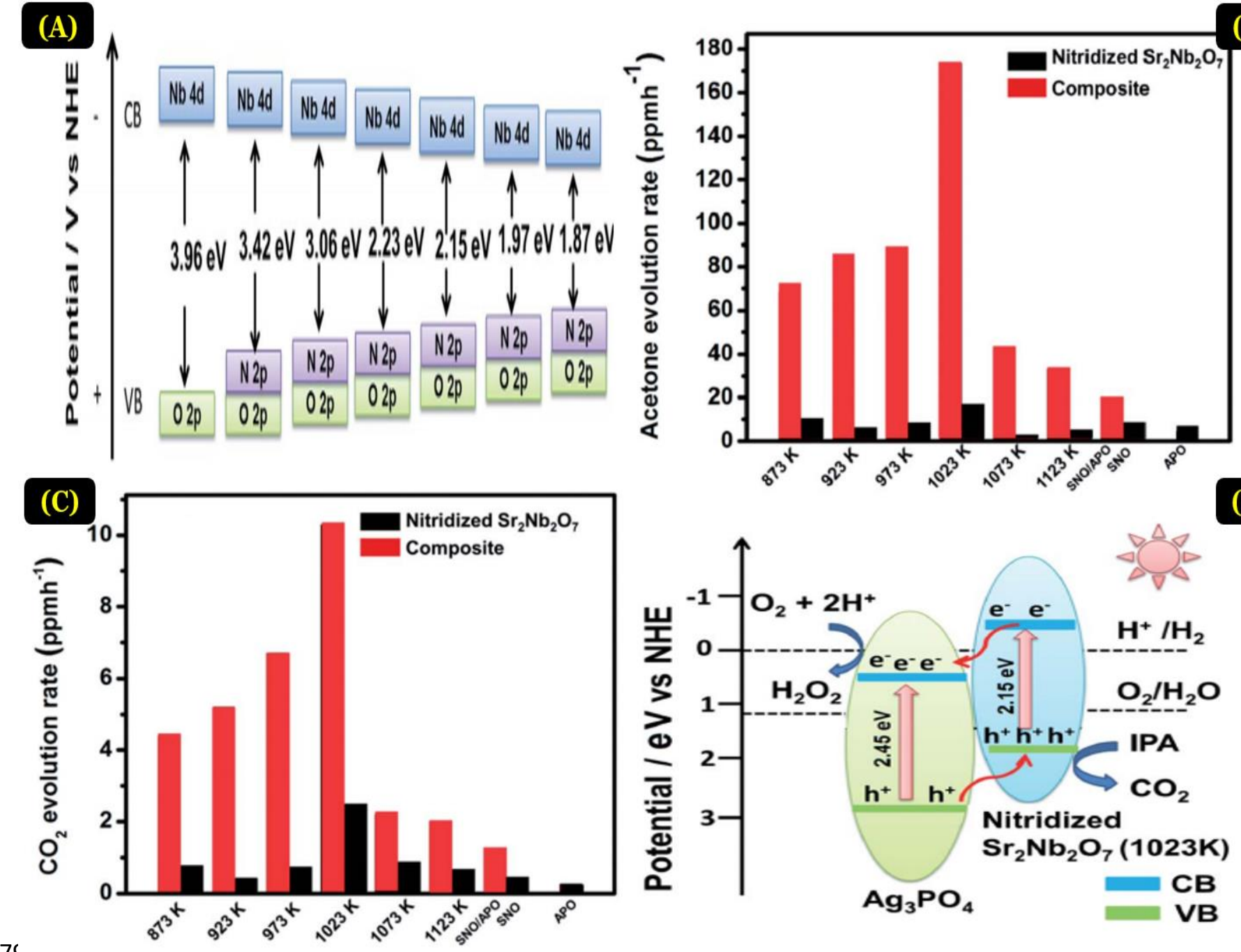

(D)

Fig. 9. (A) The schematic band structures of nitridized $\mathrm{Sr}_{2} \mathrm{Nb}_{2} \mathrm{O}_{7}$ (N: $0-6.18$ wt\%); (B) The 799 acetone evolution rates of the as-prepared composite photocatalysts; (C) The $\mathrm{CO}_{2}$ evolution rates 800 of the as-prepared composite photocatalysts; (D) The schematic band structure of the $801 \mathrm{Ag}_{3} \mathrm{PO}_{4} / \mathrm{SNON}-1023$ composite photocatalyst. Adapted with permission from ref. (Guo et al., 802 2014) Copyright 2014 Royal Society of Chemistry).

803

804

\subsection{Coupling $\mathrm{Ag}_{3} \mathrm{PO}_{4}$ with $\mathrm{Caln}_{2} \mathrm{~S}_{4}$}

805 The Caln $2 S_{4}$ belongs to the $A_{2} X_{4}$ semiconductor family. They possess suitable band 806 edge positions (Li et al., 2017), high chemical stability (Liu et al., 2019), and narrow 807 bandgaps (Wan et al., 2018), which make them more effective in the photocatalysis field 
808 due to their multiple potential applications (Ding et al., 2014; Jo and Natarajan, 2015; Li 809 et al., 2017; Liu et al., 2019).

810 The basis for enhancing $\mathrm{Ag}_{3} \mathrm{PO}_{4}$ photocatalysis by $\mathrm{Caln}{ }_{2} \mathrm{~S}_{4}$ is well summarized by 811 Shipeng et al. (Wan et al., 2018). The authors prepared Z-scheme Caln $\mathrm{S}_{4} / \mathrm{Ag}_{3} \mathrm{PO}_{4}$ 812 nanocomposite (called CIS/APO) via wet impregnation method, through $\mathrm{Caln}_{2} \mathrm{~S}_{4}$ 813 concentration changing from 0 to $15 \mathrm{wt} \%$. The photodegradation oxidation of nitric oxide 814 (NO) ( 400 ppm) using a $300 \mathrm{~W}$ Xe-lamp as a solar light production source using the as815 synthesized Caln $2 \mathrm{~S}_{4} / \mathrm{Ag}_{3} \mathrm{PO}_{4}$ composites photocatalytic behavior was also assessed. The 816 optimum NO photocatalytic oxidation using Caln ${ }_{2} \mathrm{~S}_{4} / \mathrm{Ag}_{3} \mathrm{PO}_{4}$ was achieved when Caln $\mathrm{S}_{4}$

817 content was kept constant up to (10 wt\%) (Fig. 10A). Moreover, it was observed that 818 10\%-CIS/APO nanocomposite exhibited 2-fold and 3.5-fold higher solar light-driven 819 photocatalytic oxidation (86.61\%) of nitric oxide after 80 min than the pristine $\mathrm{Ag}_{3} \mathrm{PO}_{4}$ and $820 \mathrm{Caln}_{2} \mathrm{~S}_{4}$, respectively (Fig. 10A). The $\mathrm{Caln}_{2} \mathrm{~S}_{4} / \mathrm{Ag}_{3} \mathrm{PO}_{4}$ nanocomposite photocatalyst also 821 exhibits high photostability up to four photocatalytic oxidation of NO cycles (Fig. 10B).

822 Such kind of visible-light-driven superior photocatalytic behavior is strictly associated with 823 the separated charge carriers extended lifetime, improved light-harvesting, and 824 photogenerated $\mathrm{e}^{-}, \mathrm{h}^{+}$pairs easy transportation at the heterojunction interfaces produced 825 from lattice match and energy level between $\mathrm{Caln}_{2} \mathrm{~S}_{4}$ and $\mathrm{Ag}_{3} \mathrm{PO}_{4}$ (Fig. 10C). 826 Furthermore, the results demonstrate that the coupling of $\mathrm{Caln}_{2} \mathrm{~S}_{4}$ and $\mathrm{Ag}_{3} \mathrm{PO}_{4}$ does not 827 follow the conventional $\mathrm{Caln}_{2} \mathrm{~S}_{4} / \mathrm{Ag}_{3} \mathrm{PO}_{4}$ heterojunction (type II) because of the more 828 positive potential of $\mathrm{Ag}_{3} \mathrm{PO}_{4} \mathrm{CB}(+0.45 \mathrm{eV})$ (Krungchanuchat et al., 2017) than the 829 produced $\cdot \mathrm{O}_{2}{ }^{-}$and $\cdot \mathrm{OH}$ formation $\left(\mathrm{O}_{2} / \cdot \mathrm{O}_{2}{ }^{-}=-0.33 \mathrm{eV} ; \mathrm{H}_{2} \mathrm{O}_{2} / \cdot \mathrm{OH}=+0.06 \mathrm{eV}\right)$ redox 830 potential (Krungchanuchat et al., 2017), as well as the more negative potential of Caln ${ }_{2} S_{4}$ 
831 VB $(+0.82 \mathrm{eV})$ (Wan et al., 2018) than the potential required for the oxidation of $\mathrm{H}_{2} \mathrm{O}_{2}$ to $832 \cdot \mathrm{O}_{2}^{-}(+1.00 \mathrm{eV})($ Krungchanuchat et al., 2017).In contrast, provided that the coupling of $833 \mathrm{Caln}_{2} \mathrm{~S}_{4}$ and $\mathrm{Ag}_{3} \mathrm{PO}_{4}$ could follow the Z-scheme mechanism, under visible light 834 illumination, the photogenerated electrons over the $\mathrm{Ag}_{3} \mathrm{PO}_{4}$ conduction band move 835 towards the Caln $\mathrm{S}_{4}$ valence band and recombine with holes of Caln $\mathrm{S}_{4}$ valence Band 836 (VB). As the highly negative CB potential of $\mathrm{Caln}_{2} \mathrm{~S}_{4}(-1.03 \mathrm{eV})$ could easily reduce $\left(\mathrm{O}_{2}\right.$ 837 and $\left.\mathrm{H}_{2} \mathrm{O}_{2}\right)$ into $\left(\cdot \mathrm{O}_{2}{ }^{-}\right.$and $\left.\bullet \mathrm{OH}\right)$, respectively. Similarly, the highly positive VB potential of $838 \mathrm{Ag}_{3} \mathrm{PO}_{4}(+2.90 \mathrm{eV})$ facilitates oxidizing $\mathrm{H}_{2} \mathrm{O}_{2}$ to $\cdot \mathrm{O}_{2}$. Thus, the existence of many active 839 free radicals $\left(\cdot \mathrm{O}_{2}{ }^{-}, \cdot \mathrm{OH}\right)$ resulted in the production of a strong oxidation ability of $840 \mathrm{Caln}_{2} \mathrm{~S}_{4} / \mathrm{Ag}_{3} \mathrm{PO}_{4}$ nanocomposite photocatalysts for efficient oxidation of $\mathrm{NO}$ than the 841 pristine Caln $2 \mathrm{~S}_{4}$ or $\mathrm{Ag}_{3} \mathrm{PO}_{4}$ photocatalyst. 
(A)
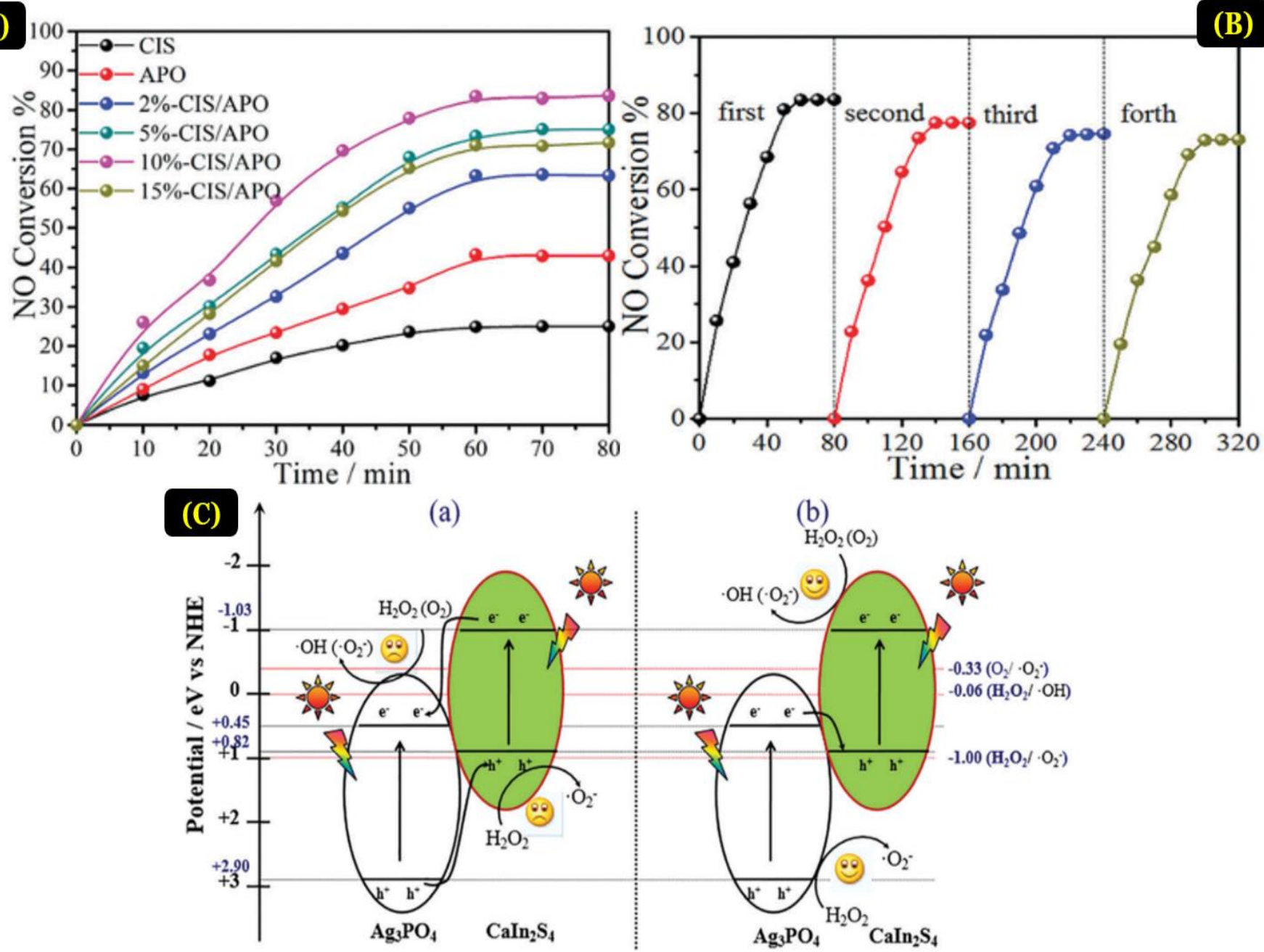

84

843

844

845

846

847

848

849

850

851

852

\section{Conclusions and Future Directions}

Silver phosphate is believed to be the most effective photocatalysts recorded to date since its first application in photocatalysis in 2009. Also, it is considered to be the most efficient visible-light-driven photocatalysts exhibiting remarkable photocatalytic properties 
853 than commonly employed oxidative photocatalysts such as $\mathrm{TiO}_{2}, \mathrm{ZnO}, \mathrm{BiVO}_{4}$, and $\mathrm{WO}_{3}$.

854 The only drawback for $\mathrm{Ag}_{3} \mathrm{PO}_{4}$ use as a photocatalyst is its photo-corrosion, limiting its 855 reusability potential in photocatalytic reactions. Consequently, many research efforts 856 have been devoted to improving $\mathrm{Ag}_{3} \mathrm{PO}_{4}$ stability and its photocatalytic performance in 857 environmental photo remediation studies. This review reveals that the construction of a 858 Z-scheme semiconductor by integrating $\mathrm{Ag}_{3} \mathrm{PO}_{4}$ with other photocatalyst or conventional 859 type-II heterojunctions photocatalyst could effectively enhance its stability and 860 photocatalytic activity towards gaseous pollutants elimination. The enhanced 861 photocatalytic oxidation of gaseous contaminants is closely associated with narrow 862 bandgap energy, improved absorption light range, reduce electron-hole pair 863 recombination, faster charge transfer, and negligible photo-corrosion.

864 Thus, this review's main purpose is to compile the current research progress on the 865 current strategies for enhancing $\mathrm{Ag}_{3} \mathrm{PO}_{4}$-based composite photocatalytic activities 866 towards gaseous pollutants elimination. Moreover, the mechanism responsible for the 867 enhanced photocatalytic performance of the $\mathrm{Ag}_{3} \mathrm{PO}_{4}$-based composite system has been 868 discussed in detail, which will provide guidelines for future research. Although 869 considerable advances in this area have already been made over the past few years, 870 most studies in this field are still at the initial stage. Thus, future work should focus on the 871 following aspects:

872 (i) Thoughtful research efforts are urgently required in the future ahead for $\mathrm{Ag}_{3} \mathrm{PO}_{4}$-based composite photocatalysts appliance to treat other volatile 874 organic compounds separately and mixed. Therefore, their application must 
be extended towards the degradation of other harmful gases, such as acetaldehyde, trichloroethylene...etc.

(ii) Another major objective has been proposed as a future direction to develop and improve the green and straightforward synthesis of $\mathrm{Ag}_{3} \mathrm{PO}_{4}$-based photocatalysts. For that aim, systematic studies are urgently needed to introduce sustainable production pathways to provide a selection based material fabrication with the desired morphology, crystal phase, surface structure, as these characteristics strongly influence its photocatalytic activity.

(iii) It has been reported that constructing core@shell structure photocatalysts could effectively improve the photostability of the $\mathrm{Ag}_{3} \mathrm{PO}_{4}$-based composite semiconductor. It is also a prerequisite to understanding better the relationship between semiconductor photocatalyst structural properties and its photocatalytic performance during experimentation when computational methods are integrated.

(iv) In a broad spectrum, it is highly required to have a better understanding to promote and evaluate the mechanism of the $\mathrm{Ag}_{3} \mathrm{PO}_{4}$-based composite system using different novel characterization and computational techniques, such as density functional theory (DFT), which have a significant value in order to provide valuable insight towards the deep understanding of the material structural characteristics, i.e., surfaces, interfaces, nanostructures and activity at the atomic and molecular level.

(v) Bare $\mathrm{Ag}_{3} \mathrm{PO}_{4}$ showed a low surface area, which inhibits the kinetics and the photocatalytic degradation rate. Therefore, it is recommended to combine bare 
$\mathrm{Ag}_{3} \mathrm{PO}_{4}$ with adsorbing/porous surface materials such as activated carbon, graphene, lignocellulosic biomass, or clays for enhanced surface area and photoactivity.

(vi) A wide range of systematic studies regarding gaseous phase pollutant remediation has been critically reviewed and elucidated in this review. Moreover, it is well understood that previously reported studies mainly focus on the performance of materials under laboratory-based controlled conditions. Although considerable performance is achieved, there are still some limitations when scaling up the system operating in real conditions.

Therefore, in conclusion, we believe that if these issues and challenges are adequately addressed, then in years to come, the use of $\mathrm{Ag}_{3} \mathrm{PO}_{4}$ based $\mathrm{Z}$ scheme or conventional type-II heterojunctions photocatalyst for gaseous phase contaminants photocatalytic oxidation would be tremendous and commercially feasible.

\section{Acknowledgments}

This work was supported by the Ibn Zohr University and LME laboratory (Morocco). 
Aarab, N., Hsini, A., Essekri, A., Laabd, M., Lakhmiri, R., Albourine, A., 2020a. Removal of an emerging pharmaceutical pollutant (metronidazole) using PPY-PANi copolymer: Kinetics, equilibrium and DFT identification of adsorption mechanism. Groundw. Sustain. Dev. 11, 100416. https://doi.org/10.1016/j.gsd.2020.100416

Aarab, N., Hsini, A., Laabd, M., Essekri, A., Laktif, T., Haki, M.A., Lakhmiri, R., Albourine, A., 2020b. Theoretical study of the adsorption of sodium salicylate and metronidazole on the PANi. Mater. Today Proc. 22, 100-103. https://doi.org/10.1016/j.matpr.2019.08.103

Abdellaoui, Y., Abou Oualid, H., Hsini, A., El Ibrahimi, B., Laabd, M., El Ouardi, M., GiácomanVallejos, G., Gamero-Melo, P., 2021. Synthesis of zirconium-modified Merlinoite from fly ash for enhanced removal of phosphate in aqueous medium: Experimental studies supported by Monte Carlo/SA simulations. Chem. Eng. J. 404, 126600. https://doi.org/10.1016/j.cej.2020.126600

Adhikari, S.P., Hood, Z.D., Chen, V.W., More, K.L., Senevirathne, K., Lachgar, A., 2018. Visiblelight-active $\mathrm{g}-\mathrm{C}_{3} \mathrm{~N}_{4} / \mathrm{N}$-doped $\mathrm{Sr}_{2} \mathrm{Nb}_{2} \mathrm{O}_{7}$ heterojunctions as photocatalysts for the hydrogen evolution reaction. Sustain. Energy Fuels 2, 2507-2515. https://doi.org/10.1039/c8se00319j

Aghighi, A., Haghighat, F., 2015. Using physical-chemical properties of reactants to estimate the performance of photocatalytic oxidation air cleaners. Build. Environ. 85, 114-122. https://doi.org/10.1016/j.buildenv.2014.11.020

Ahsaine, H.A., Slassi, A., Naciri, Y., Chennah, A., Jaramillo-Páez, C., Anfar, Z., Zbair, M., Benlhachemi, A., Navío, J.A., 2018. Photo/Electrocatalytic Properties of Nanocrystalline ZnO and La-Doped ZnO: Combined DFT Fundamental Semiconducting Properties and $\begin{array}{llllll}\text { Experimental Study. } \quad \text { ChemistrySelect } & 3, & 7778 \quad & \text { - } & 7791 .\end{array}$ https://doi.org/10.1002/slct.201801729

Ajmal, Z., Muhmood, A., Dong, R., Wu, S., 2020a. Probing the efficiency of magnetically modified biomass-derived biochar for effective phosphate removal. J. Environ. Manage. 253, 109730. https://doi.org/10.1016/j.jenvman.2019.109730

Ajmal, Z., Muhmood, A., Usman, M., Kizito, S., Lu, J., Dong, R., Wu, S., 2018. Phosphate removal from aqueous solution using iron oxides: Adsorption, desorption and regeneration characteristics. J. Colloid Interface Sci. 528, 145-155. https://doi.org/10.1016/j.jcis.2018.05.084

Ajmal, Z., Usman, M., Anastopoulos, I., Qadeer, A., Zhu, R., Wakeel, A., Dong, R., 2020b. Use of nano-/micro-magnetite for abatement of cadmium and lead contamination. J. Environ. Manage. 264, 110477. https://doi.org/10.1016/j.jenvman.2020.110477

Amaterz, Elhassan, Tara, A., Bouddouch, A., Taoufyq, A., Bakiz, B., Benlhachemi, A., Jbara, O., 2020. Photo-electrochemical degradation of wastewaters containing organics catalysed by phosphate-based materials: a review. Rev. Environ. Sci. Biotechnol. 9. https://doi.org/10.1007/s11157-020-09547-9

Amaterz, E., Tara, A., Bouddouch, A., Taoufyq, A., Bakiz, B., Lazar, F., Gilliot, M., Benlhachemi, A., Bazzi, L., Jbara, O., 2020. Hierarchical flower-like $\mathrm{SrHPO}_{4}$ electrodes for the photoelectrochemical degradation of Rhodamine B. J. Appl. Electrochem. https://doi.org/10.1007/s10800-020-01416-1 
Amonette, J.E., Matyáš, J., 2017. Functionalized silica aerogels for gas-phase purification, sensing, and catalysis: A review. Microporous Mesoporous Mater. 250, 100-119. https://doi.org/10.1016/j.micromeso.2017.04.055

Aramendía, M.A., Colmenares, J.C., Marinas, A., Marinas, J.M., Moreno, J.M., Navío, J.A., Urbano, F.J., 2007. Effect of the redox treatment of $\mathrm{Pt} / \mathrm{TiO}_{2}$ system on its photocatalytic behaviour in the gas phase selective photooxidation of propan-2-ol. Catal. Today 128, 235244. https://doi.org/10.1016/j.cattod.2007.07.009

Araña, J., Alonso, A.P., Rodríguez, J.M.D., Colón, G., Navío, J.A., Peña, J.P., 2009. FTIR study of photocatalytic degradation of 2-propanol in gas phase with different $\mathrm{TiO}_{2}$ catalysts. Appl. Catal. B Environ. 89, 204-213. https://doi.org/10.1016/j.apcatb.2008.11.027

Araña, J., Doña-Rodríguez, J.M., González-Díaz, O., Tello Rendón, E., Herrera Melián, J.A., Colón, G., Navío, J.A., Pérez Peña, J., 2004. Gas-phase ethanol photocatalytic degradation study with $\mathrm{TiO}_{2}$ doped with $\mathrm{Fe}, \mathrm{Pd}$ and $\mathrm{Cu}$. J. Mol. Catal. A Chem. 215, 153-160. https://doi.org/10.1016/j.molcata.2004.01.020

Ardizzone, S., Bianchi, C.L., Cappelletti, G., Gialanella, S., Pirola, C., Ragaini, V., 2007. Tailored anatase/brookite nanocrystalline $\mathrm{TiO}_{2}$. the optimal particle features for liquidand gas-phase photocatalytic reactions. J. Phys. Chem. C 111, 13222-13231. https://doi.org/10.1021/jp0741096

Ardizzone, S., Bianchi, C.L., Cappelletti, G., Naldoni, A., Pirola, C., 2008. Photocatalytic degradation of toluene in the gas phase: Relationship between surface species and catalyst features. Environ. Sci. Technol. 42, 6671-6676. https://doi.org/10.1021/es8009327

Azzouz, A., Kailasa, S.K., Lee, S.S., J. Rascón, A., Ballesteros, E., Zhang, M., Kim, K.H., 2018. Review of nanomaterials as sorbents in solid-phase extraction for environmental samples. TrAC - Trends Anal. Chem. 108, 347-369. https://doi.org/10.1016/j.trac.2018.08.009

Ba Mohammed, B., Hsini, A., Abdellaoui, Y., Abou Oualid, H., Laabd, M., El Ouardi, M., Ait Addi, A., Yamni, K., Tijani, N., 2020. Fe-ZSM-5 zeolite for efficient removal of basic Fuchsin dye from aqueous solutions: Synthesis, characterization and adsorption process optimization using BBD-RSM modeling. J. Environ. Chem. Eng. 8, 104419. https://doi.org/10.1016/j.jece.2020.104419

Ballari, M.M., Hunger, M., Hüsken, G., Brouwers, H.J.H., 2010. NOx photocatalytic degradation employing concrete pavement containing titanium dioxide. Appl. Catal. B Environ. 95, 245254. https://doi.org/10.1016/j.apcatb.2010.01.002

Banerjee, S., Dionysiou, D.D., Pillai, S.C., 2015. Self-cleaning applications of $\mathrm{TiO}_{2}$ by photoinduced hydrophilicity and photocatalysis. Appl. Catal. B Environ. 176-177, 396-428. https://doi.org/10.1016/j.apcatb.2015.03.058

Barea, E., Montoro, C., Navarro, J.A.R., 2014. Toxic gas removal-metal-organic frameworks for the capture and degradation of toxic gases and vapours. Chem. Soc. Rev. 43, 5419-5430. https://doi.org/10.1039/c3cs60475f

Barebita, H., Naciri, Y., Ferraa, S., Nimour, A., Guedira, T., 2020. Investigation of structural and photocatalytic behavior of $\mathrm{Bi}_{13} \mathrm{~B}_{1-2 x} \mathrm{~V}_{x} \mathrm{P}_{x} \mathrm{O}_{20.95+2 x}(0 \leq x \leq 0.5)$. Solid State Sci. 108, 106389. https://doi.org/10.1016/j.solidstatesciences.2020.106389

Belaissaoui, B., Le Moullec, Y., Favre, E., 2016. Energy efficiency of a hybrid membrane/condensation process for VOC (Volatile Organic Compounds) recovery from air: 

A generic approach. Energy 95, 291-302. https://doi.org/10.1016/j.energy.2015.12.006

Benafqir, M., Hsini, A., Laabd, M., Laktif, T., Ait Addi, A., Albourine, A., El Alem, N., 2019. Application of Density Functional Theory computation (DFT) and Process Capability Study for performance evaluation of Orthophosphate removal process using Polyaniline@Hematite-titaniferous sand composite (PANI@HTS) as a substrate. Sep. Purif. Technol. 236, 116286. https://doi.org/10.1016/j.seppur.2019.116286

Bianchi, C.L., Cerrato, G., Morandi, S., Di Michele, A., Djellabi, R., Capucci, V., 2020. Sustainable photocatalytic porcelain grés slabs active under LED light for indoor depollution and bacteria reduction, Handbook of Smart Photocatalytic Materials. INC. https://doi.org/10.1016/b978-012-819049-4.00008-8

Bianchi, C.L., Gatto, S., Pirola, C., Naldoni, A., Di Michele, A., Cerrato, G., Crocellà, V., Capucci, V., 2014. Photocatalytic degradation of acetone, acetaldehyde and toluene in gas-phase: Comparison between nano and micro-sized $\mathrm{TiO}_{2}$. Appl. Catal. B Environ. 146, 123-130. https://doi.org/10.1016/j.apcatb.2013.02.047

Bianchi, C.L., Pirola, C., Stucchi, M., Sacchi, B., Cerrato, G., Morandi, S., Di Michele, A., Carletti, A., Capucci, V., 2016. A New Frontier of Photocatalysis Employing Micro-Sized $\mathrm{TiO}_{2}$ : Air/Water Pollution Abatement and Self-Cleaning/ Antibacterial Applications. Semicond. Photocatal. - Mater. Mech. Appl. https://doi.org/10.5772/62892

Bickley, R.I., Munuera, G., Stone, F.S., 1973. Photoadsorption and photocatalysis at rutile surfaces. II. Photocatalytic oxidation of isopropanol. J. Catal. 31, 398-407. https://doi.org/10.1016/0021-9517(73)90311-4

Bierman, M.J., Lau, Y.K.A., Kvit, A. V., Schmitt, A.L., Jin, S., 2008. Dislocation-driven nanowire growth and Eshelby twist. Science (80-. ). 320, 1060-1063. https://doi.org/10.1126/science.1157131

Bouziani, A., Park, J., Ozturk, A., 2020. Synthesis of $\alpha-\mathrm{Fe}_{2} \mathrm{O}_{3} / \mathrm{TiO}_{2}$ heterogeneous composites by the sol-gel process and their photocatalytic activity. J. Photochem. Photobiol. A Chem. 400, 112718. https://doi.org/10.1016/j.jphotochem.2020.112718

Boyjoo, Y., Sun, H., Liu, J., Pareek, V.K., Wang, S., 2017. A review on photocatalysis for air treatment: From catalyst development to reactor design. Chem. Eng. J. 310, 537-559. https://doi.org/10.1016/j.cej.2016.06.090

Cai, T., Zeng, W., Liu, Y., Wang, L., Dong, W., Chen, H., Xia, X., 2020. A promising inorganicorganic Z-scheme photocatalyst $\mathrm{Ag}_{3} \mathrm{PO}_{4} / \mathrm{PDI}$ supermolecule with enhanced photoactivity and photostability for environmental remediation. Appl. Catal. B Environ. 263, 118327. https://doi.org/10.1016/j.apcatb.2019.118327

Cappelletti, G., Ardizzone, S., Bianchi, C.L., Gialanella, S., Naldoni, A., Pirola, C., Ragaini, V., 2009. Photodegradation of pollutants in air: Enhanced properties of nano- $\mathrm{TiO}_{2}$ prepared by ultrasound. Nanoscale Res. Lett. 4, 97-105. https://doi.org/10.1007/s11671-008-9208-3

Chai, Y., Ding, J., Wang, L., Liu, Q., Ren, J., Dai, W.L., 2015. Enormous enhancement in photocatalytic performance of $\mathrm{Ag}_{3} \mathrm{PO}_{4} / \mathrm{HAp}$ composite: A Z-scheme mechanism insight. Appl. Catal. B Environ. 179, 29-36. https://doi.org/10.1016/j.apcatb.2015.05.006

Che, H., Liu, C., Che, G., Liao, G., Dong, H., Li, Chunxue, Song, N., Li, Chunmei, 2020. Facile construction of porous intramolecular $\mathrm{g}-\mathrm{C}_{3} \mathrm{~N}_{4}$-based donor-acceptor conjugated copolymers as highly efficient photocatalysts for superior H2 evolution. Nano Energy 67, 104273. 
1059

1060

1061

1062

1063

1064

1065

1066

1067

1068

1069

1070

1071

1072

1073

1074

1075

1076

1077

1078

1079

1080

1081

1082

1083

1084

1085

1086

1087

1088

1089

https://doi.org/10.1016/j.nanoen.2019.104273

Chen, X., Huang, X., Yi, Z., 2014. Enhanced ethylene photodegradation performance of g- $\mathrm{C}_{3} \mathrm{~N}_{4}-$ $\mathrm{Ag}_{3} \mathrm{PO}_{4}$ composites with direct Z-scheme configuration. Chem. - A Eur. J. 20, 17590-17596. https://doi.org/10.1002/chem.201404284

Chen, X., Li, R., Pan, X., Huang, X., Yi, Z., 2017. Fabrication of $\ln _{2} \mathrm{O}_{3}-\mathrm{Ag}-\mathrm{Ag}_{3} \mathrm{PO}_{4}$ composites with Z-scheme configuration for photocatalytic ethylene degradation under visible light irradiation. Chem. Eng. J. 320, 644-652. https://doi.org/10.1016/j.cej.2017.03.072

Chen, Z., Bing, F., Liu, Q., Zhang, Z., Fang, X., 2015. Novel Z-scheme visible-light-driven $\mathrm{Ag}_{3} \mathrm{PO}_{4} / \mathrm{Ag} / \mathrm{SiC}$ photocatalysts with enhanced photocatalytic activity. J. Mater. Chem. A 3, 4652-4658. https://doi.org/10.1039/c4ta06530a

Chen, Z., Wang, W., Zhang, Z., Fang, X., 2013. High-Efficiency Visible-Light-Driven $\mathrm{Ag}_{3} \mathrm{PO}_{4} / \mathrm{Agl}$ Photocatalysts: Z - Scheme Photocatalytic Mechanism for Their Enhanced Photocatalytic Activity. J. Phys. Chem. CC 117, 19346-19352. https://doi.org/https://doi.org/10.1021/jp406508y

Chenchana, A., Nemamcha, A., Moumeni, H., Doña Rodríguez, J.M., Araña, J., Navío, J.A., González Díaz, O., Pulido Melián, E., 2019. Photodegradation of 2,4-dichlorophenoxyacetic acid over $\mathrm{TiO}_{2}(\mathrm{~B}) /$ anatase nanobelts and Au-TiO 2 (B)/anatase nanobelts. Appl. Surf. Sci. 467-468, 1076-1087. https://doi.org/10.1016/j.apsusc.2018.10.175

da Costa Filho, B.M., Araujo, A.L.P., Padrão, S.P., Boaventura, R.A.R., Dias, M.M., Lopes, J.C.B., Vilar, V.J.P., 2019a. Effect of catalyst coated surface, illumination mechanism and light source in heterogeneous $\mathrm{TiO}_{2}$ photocatalysis using a mili-photoreactor for $\mathrm{n}$-decane oxidation at gas phase. Chem. Eng. J. 366, 560-568. https://doi.org/10.1016/j.cej.2019.02.122

da Costa Filho, B.M., Araujo, A.L.P., Silva, G. V., Boaventura, R.A.R., Dias, M.M., Lopes, J.C.B., Vilar, V.J.P., 2017. Intensification of heterogeneous $\mathrm{TiO}_{2}$ photocatalysis using an innovative micro-meso-structured-photoreactor for n-decane oxidation at gas phase. Chem. Eng. J. 310, 331-341. https://doi.org/10.1016/j.cej.2016.09.080

da Costa Filho, B.M., Silva, G. V., Boaventura, R.A.R., Dias, M.M., Lopes, J.C.B., Vilar, V.J.P., 2019b. Ozonation and ozone-enhanced photocatalysis for VOC removal from air streams: Process optimization, synergy and mechanism assessment. Sci. Total Environ. 687, 13571368. https://doi.org/10.1016/j.scitotenv.2019.05.365

da Costa Filho, B.M., Vilar, V.J.P., 2019. Strategies for the intensification of photocatalytic oxidation processes towards air streams decontamination: A review. Chem. Eng. J. 123531. https://doi.org/10.1016/j.cej.2019.123531

Deng, X., Chen, Y., Wen, J., Xu, Y., Zhu, J., Bian, Z., 2020. Polyaniline- $\mathrm{TiO}_{2} \mathrm{Composite}$ photocatalysts for light-driven hexavalent chromium ions reduction. Sci. Bull. 65, 105-112. https://doi.org/10.1016/j.scib.2019.10.020

Ding, J., Hong, B., Luo, Z., Sun, S., Bao, J., Gao, C., 2014. Mesoporous monoclinic Caln2S4 with surface nanostructure: An efficient photocatalyst for hydrogen production under visible light. J. Phys. Chem. C 118, 27690-27697. https://doi.org/10.1021/jp508497a

Djeghri, N., Formenti, M., Juillet, F., Teichner, S.J., 1974. Photointeraction on the Surface of Titanium Dioxide between Oxygen and Alkanes. Faraday Discuss. Chem. Soc. 58, 185-193. https://doi.org/https://doi.org/10.1039/DC9745800185 
1090

1091

1092

1093

1094

1095

1096

1097

1098

1099

1100

1101

1102

1103

1104

1105

1106

1107

1108

1109

1110

1111

1112

1113

1114

1115

1116

1117

1118

1119

1120

1121

1122

1123

1124

1125

1126

1127

1128

1129

1130

1131

1132

1133

Djellabi, R., Fouzi Ghorab, M., Smara, A., Bianchi, C.L., Cerrato, G., Zhao, X., Yang, B., 2020. Titania-Montmorillonite for the Photocatalytic Removal of Contaminants from Water: Adsorb \& Shuttle Process. Green Mater. Wastewater Treat. 291-319. https://doi.org/10.1007/9783-030-17724-9_13

Djellabi, R., Yang, B., Adeel Sharif, H.M., Zhang, J., Ali, J., Zhao, X., 2019a. Sustainable and easy recoverable magnetic TiO2-Lignocellulosic Biomass@ $\mathrm{Fe}_{3} \mathrm{O}_{4}$ for solar photocatalytic water remediation. J. Clean. Prod. 233, 841-847. https://doi.org/10.1016/j.jclepro.2019.06.125

Djellabi, R., Yang, B., Xiao, K., Gong, Y., Cao, D., Sharif, H.M.A., Zhao, X., Zhu, C., Zhang, J., 2019b. Unravelling the mechanistic role of Ti-O-C bonding bridge at titania/lignocellulosic biomass interface for $\mathrm{Cr}(\mathrm{VI})$ photoreduction under visible light. J. Colloid Interface Sci. 553, 409-417. https://doi.org/10.1016/j.jcis.2019.06.052

Dong, G., Zhang, Y., Pan, Q., Qiu, J., 2014. A fantastic graphitic carbon nitride $\left(\mathrm{g}-\mathrm{C}_{3} \mathrm{~N}_{4}\right)$ material: Electronic structure, photocatalytic and photoelectronic properties. J. Photochem. Photobiol. C Photochem. Rev. 20, 33-50. https://doi.org/10.1016/j.jphotochemrev.2014.04.002

Dong, P., Hou, G., Liu, C., Zhang, X., Tian, H., Xu, F., Xi, X., Shao, R., 2016. Origin of activity and stability enhancement for Ag3PO4 photocatalyst after calcination. Materials (Basel). 9, 1-17. https://doi.org/10.3390/ma9120968

Ehn, M., Thornton, J.A., Kleist, E., Sipilä, M., Junninen, H., Pullinen, I., Springer, M., Rubach, F., Tillmann, R., Lee, B., Lopez-Hilfiker, F., Andres, S., Acir, I.H., Rissanen, M., Jokinen, T., Schobesberger, S., Kangasluoma, J., Kontkanen, J., Nieminen, T., Kurtén, T., Nielsen, L.B., Jørgensen, S., Kjaergaard, H.G., Canagaratna, M., Maso, M.D., Berndt, T., Petäjä, T., Wahner, A., Kerminen, V.M., Kulmala, M., Worsnop, D.R., Wildt, J., Mentel, T.F., 2014. A large source of low-volatility secondary organic aerosol. Nature 506, 476-479. https://doi.org/10.1038/nature13032

Erdogan, N., Bouziani, A., Park, J., Micusik, M., Kim, S.Y., Majkova, E., Omastova, M., Ozturk, A., 2019. Synthesis and enhanced photocatalytic activity of nitrogen-doped triphasic $\mathrm{TiO}_{2}$ nanoparticles. J. Photochem. Photobiol. A Chem. 377, 92-100. https://doi.org/10.1016/j.jphotochem.2019.03.047

Essekri, A., Hsini, A., Naciri, Y., Laabd, M., Ajmal, Z., El Ouardi, M., Ait Addi, A., Albourine, A., 2020. Novel citric acid-functionalized brown algae with a high removal efficiency of crystal violet dye from colored wastewaters: insights into equilibrium, adsorption mechanism, and reusability. Int. J. $\quad$ Phytoremediation $\quad 0,1-11$. https://doi.org/10.1080/15226514.2020.1813686

Farhanian, D., Haghighat, F., Lee, C.S., Lakdawala, N., 2013. Impact of design parameters on the performance of ultraviolet photocatalytic oxidation air cleaner. Build. Environ. 66, 148157. https://doi.org/10.1016/j.buildenv.2013.04.010

Fino, D., Bensaid, S., Piumetti, M., Russo, N., 2016. A review on the catalytic combustion of soot in Diesel particulate filters for automotive applications: From powder catalysts to structured reactors. Appl. Catal. A Gen. 509, 75-96. https://doi.org/10.1016/j.apcata.2015.10.016

Fiorenza, R., Di Mauro, A., Cantarella, M., laria, C., Scalisi, E.M., Brundo, M.V., Gulino, A., Spitaleri, L., Nicotra, G., Dattilo, S., Carroccio, S.C., Privitera, V., Impellizzeri, G., 2020. Preferential removal of pesticides from water by molecular imprinting on $\mathrm{TiO} 2$ photocatalysts. Chem. Eng. J. 379, 122309. https://doi.org/10.1016/j.cej.2019.122309 
Ganesh, V.A., Raut, H.K., Nair, A.S., Ramakrishna, S., 2011. A review on self-cleaning coatings. J. Mater. Chem. 21, 16304-16322. https://doi.org/10.1039/c1jm12523k

Ge, M., Zhu, N., Zhao, Y., Li, J., Liu, L., 2012. Sunlight-assisted degradation of dye pollutants in $\mathrm{Ag}$ 3PO 4 suspension. Ind. Eng. Chem. Res. 51, 5167-5173. https://doi.org/10.1021/ie202864n

Guo, J., Ouyang, S., Li, P., Zhang, Y., Kako, T., Ye, J., 2013. A new heterojunction $\mathrm{Ag}_{3} \mathrm{PO}_{4} / \mathrm{Cr}$ $\mathrm{SrTiO}_{3}$ photocatalyst towards efficient elimination of gaseous organic pollutants under visible light irradiation. Appl. Catal. B Environ. 134-135, 286-292. https://doi.org/10.1016/j.apcatb.2012.12.038

Guo, J., Zhou, H., Ouyang, S., Kako, T., Ye, J., 2014. An $\mathrm{Ag}_{3} \mathrm{PO}_{4} /$ nitridized $\mathrm{Sr}_{2} \mathrm{Nb}_{2} \mathrm{O}_{7}$ composite photocatalyst with adjustable band structures for efficient elimination of gaseous organic pollutants under visible light irradiation. Nanoscale 6, 7303-7311. https://doi.org/10.1039/c4nr00537f

Guo, T., Bai, Z., Wu, C., Zhu, T., 2008. Influence of relative humidity on the photocatalytic oxidation (PCO) of toluene by $\mathrm{TiO}_{2}$ loaded on activated carbon fibers: PCO rate and intermediates accumulation. Appl. Catal. B Environ. 79, 171-178. https://doi.org/10.1016/j.apcatb.2007.09.033

He, F., Wang, Z., Li, Y., Peng, S., Liu, B., 2020. The nonmetal modulation of composition and morphology of $\mathrm{g}-\mathrm{C}_{3} \mathrm{~N}_{4}$-based photocatalysts. Appl. Catal. B Environ. 118828. https://doi.org/10.1016/j.apcatb.2020.118828

He, R., Xu, D., Cheng, B., Yu, J., Ho, W., 2018. Review on nanoscale Bi-based photocatalysts. Nanoscale Horizons 3, 464-504. https://doi.org/10.1039/c8nh00062j

Hsini, A., Essekri, A., Aarab, N., Laabd, M., Addi, A.A., Lakhmiri, R., Albourine, A., 2020a. Elaboration of novel polyaniline@Almond shell biocomposite for effective removal of hexavalent chromium ions and Orange $\mathrm{G}$ dye from aqueous solutions. Environ. Sci. Pollut. Res. 1-14. https://doi.org/10.1007/s11356-020-08039-1

Hsini, A., Naciri, Y., Benafqir, M., Ajmal, Z., Aarab, N., Laabd, M., Navío, J.A., Puga, F., Boukherroub, R., Bakiz, B., Albourine, A., 2020b. Facile synthesis and characterization of a novel 1,2,4,5-benzene tetracarboxylic acid doped polyaniline@zinc phosphate nanocomposite for highly efficient removal of hazardous hexavalent chromium ions from water. J. Colloid Interface Sci. https://doi.org/10.1016/j.jcis.2020.10.036

Hsini, A., Naciri, Y., Laabd, M., El Ouardi, M., Ajmal, Z., Lakhmiri, R., Boukherroub, R., Albourine, A., 2020c. Synthesis and characterization of arginine-doped polyaniline/walnut shell hybrid composite with superior clean-up ability for chromium (VI) from aqueous media: Equilibrium, reusability and process optimization. J. Mol. Liq. 316, 113832. https://doi.org/10.1016/j.molliq.2020.113832

Huang, D., Chen, S., Zeng, G., Gong, X., Zhou, C., Cheng, M., Xue, W., Yan, X., Li, J., 2019. Artificial Z-scheme photocatalytic system: What have been done and where to go? Coord. Chem. Rev. 385, 44-80. https://doi.org/10.1016/j.ccr.2018.12.013

Hyuntae Cho, 2017. An Air Quality and Event Detection System with Life Logging for Monitoring Household Environments. Smart Sensors loT Front. 251-270. https://doi.org/10.1007/9783-319-55345-0_10

Jafarikojour, M., Sohrabi, M., Royaee, S.J., Hassanvand, A., 2015. Evaluation and Optimization 
of a Novel Immobilized Photoreactor for the Degradation of Gaseous Toluene. Clean - Soil, Air, Water 43, 662-670. https://doi.org/10.1002/clen.201300985

Ji, W., Rui, Z., Ji, H., 2019. Z-scheme $\mathrm{Ag}_{3} \mathrm{PO}_{4} / \mathrm{Ag} / \mathrm{SrTiO}_{3}$ Heterojunction for Visible-Light Induced Photothermal Synergistic VOCs Degradation with Enhanced Performance. Ind. Eng. Chem. Res. 58, 13950-13959. https://doi.org/10.1021/acs.iecr.9b02176

Jia, Y., Ma, Y., Zhu, L., Dong, J., Lin, Y., 2019. Efficient visible-light-responsive photocatalyst: Hybrid $\mathrm{TiO}_{2}-\mathrm{Ag}_{3} \mathrm{PO}_{4}$ nanorods. Chem. Phys. 521, 1-4. https://doi.org/10.1016/j.chemphys.2019.01.015

Jo, W.-K., Natarajan, T.S., 2015. Facile Synthesis of Novel Redox-mediator-free Direct Z-scheme Caln2S4 Marigold Flower- like $/ \mathrm{TiO}_{2}$ Photocatalysts with Superior Photocatalytic Efficiency. ACS Appl. Mater. Interfaces 7, 17138-17154. https://doi.org/https://doi.org/10.1021/acsami.5b03935

Jo, W.K., Kim, J.T., 2009. Application of visible-light photocatalysis with nitrogen-doped or unmodified titanium dioxide for control of indoor-level volatile organic compounds. J. Hazard. Mater. 164, 360-366. https://doi.org/10.1016/j.jhazmat.2008.08.033

Jo, W.K., Yang, C.H., 2009. Granular-activated carbon adsorption followed by annular-type photocatalytic system for control of indoor aromatic compounds. Sep. Purif. Technol. 66, 438-442. https://doi.org/10.1016/j.seppur.2009.02.014

Kahk, J.M., Sheridan, D.L., Kehoe, A.B., Scanlon, D.O., Morgan, B.J., Watson, G.W., Payne, D.J., 2014. The electronic structure of silver orthophosphate: Experiment and theory. J. Mater. Chem. A 2, 6092-6099. https://doi.org/10.1039/c3ta14191h

Kamal, M.S., Razzak, S.A., Hossain, M.M., 2016. Catalytic oxidation of volatile organic compounds (VOCs) - A review. Atmos. Environ. 140, 117-134. https://doi.org/10.1016/j.atmosenv.2016.05.031

Karafas, E.S., Romanias, M.N., Stefanopoulos, V., Binas, V., Zachopoulos, A., Kiriakidis, G., Papagiannakopoulos, P., 2019. Effect of metal doped and co-doped $\mathrm{TiO}_{2}$ photocatalysts oriented to degrade indoor/outdoor pollutants for air quality improvement. A kinetic and product study using acetaldehyde as probe molecule. J. Photochem. Photobiol. A Chem. 371, 255-263. https://doi.org/10.1016/j.jphotochem.2018.11.023

Kato, S., Hirano, Y., Iwata, M., Sano, T., Takeuchi, K., Matsuzawa, S., 2005. Photocatalytic degradation of gaseous sulfur compounds by silver-deposited titanium dioxide. Appl. Catal. B Environ. 57, 109-115. https://doi.org/10.1016/j.apcatb.2004.10.015

Kong, J., Rui, Z., Ji, H., 2016. Enhanced Photocatalytic Mineralization of Gaseous Toluene over $\mathrm{SrTiO}_{3}$ by Surface Hydroxylation. Ind. Eng. Chem. Res. 55, 11923-11930. https://doi.org/10.1021/acs.iecr.6b03270

Krishnamurthy, A., Adebayo, B., Gelles, T., Rownaghi, A., Rezaei, F., 2019. Abatement of gaseous volatile organic compounds: A process perspective. Catal. Today 0-1. https://doi.org/10.1016/j.cattod.2019.05.069

Krungchanuchat, S., Ekthammathat, N., Phuruangrat, A., Thongtem, S., Thongtem, T., 2017. High UV-visible photocatalytic activity of $\mathrm{Ag}_{3} \mathrm{PO}_{4}$ dodecahedral particles synthesized by a simple hydrothermal method. Mater. Lett. 201, 58-61. https://doi.org/10.1016/j.matlet.2017.04.131 
Lam, S.M., Sin, J.C., Abdullah, A.Z., Mohamed, A.R., 2012. Degradation of wastewaters containing organic dyes photocatalysed by zinc oxide: A review. Desalin. Water Treat. 41, 131-169. https://doi.org/10.1080/19443994.2012.664698

Li, G., Wang, Y., Mao, L., 2014. Recent progress in highly efficient Ag-based visible-light photocatalysts. RSC Adv. 4, 53649-53661. https://doi.org/10.1039/c4ra08044k

Li, J., Fang, W., Yu, C., Zhou, W., Zhu, L., Xie, Y., 2015. Ag-based semiconductor photocatalysts in environmental purification. Appl. Surf. Sci. 358, 46-56. https://doi.org/10.1016/j.apsusc.2015.07.139

Li, J., Meng, S., Wang, T., Xu, Q., Shao, L., Jiang, D., Chen, M., 2017. Novel Au/Caln2S4 nanocomposites with plasmon-enhanced photocatalytic performance under visible light irradiation. Appl. Surf. Sci. 396, 430-437. https://doi.org/10.1016/j.apsusc.2016.10.172

Li, X., Zhang, L., Yang, Z., Wang, P., Yan, Y., Ran, J., 2020. Adsorption materials for volatile organic compounds (VOCs) and the key factors for VOCs adsorption process: A review. Sep. Purif. Technol. 235, 116213. https://doi.org/10.1016/j.seppur.2019.116213

Li, X., Zhang, Z., Yao, C., Lu, X., Zhao, X., Ni, C., 2016. Attapulgite-CeO $2 / \mathrm{MoS}_{2}$ ternary nanocomposite for photocatalytic oxidative desulfurization. Appl. Surf. Sci. 364, 589-596. https://doi.org/10.1016/j.apsusc.2015.12.196

Liang, S., Zhang, D., Pu, X., Yao, X., Han, R., Yin, J., Ren, X., 2019. A novel $\mathrm{Ag}_{2} \mathrm{O} / \mathrm{g}-\mathrm{C}_{3} \mathrm{~N}_{4}$ p-n heterojunction photocatalysts with enhanced visible and near-infrared light activity. Sep. Purif. Technol. 210, 786-797. https://doi.org/10.1016/j.seppur.2018.09.008

Liao, L., Heylen, S., Sree, S.P., Vallaey, B., Keulemans, M., Lenaerts, S., Roeffaers, M.B.J., Martens, J.A., 2017. Photocatalysis assisted simultaneous carbon oxidation and NOx $\begin{array}{lllll}\text { reduction. Appl. } & \text { Catal. } & \text { B } & \text { Environ. } & \text { 381-387. }\end{array}$ https://doi.org/10.1016/j.apcatb.2016.09.042

Likodimos, V., 2018. Photonic crystal-assisted visible light activated $\mathrm{TiO}_{2}$ photocatalysis. Appl. Catal. B Environ. 230, 269-303. https://doi.org/10.1016/j.apcatb.2018.02.039

Liu, B., Liu, X., Li, L., Zhuge, Z., Li, Y., Li, C., Gong, Y., Niu, L., Xu, S., Sun, C.Q., 2019. Caln $2 S_{4}$ decorated $\mathrm{WS}_{2}$ hybrid for efficient $\mathrm{Cr}(\mathrm{VI})$ reduction. Appl. Surf. Sci. 484, 300-306. https://doi.org/10.1016/j.apsusc.2019.03.322

Liu, J.J., Fu, X.L., Chen, S.F., Zhu, Y.F., 2011. Electronic structure and optical properties of $\mathrm{Ag}_{3} \mathrm{PO}_{4}$ photocatalyst calculated by hybrid density functional method. Appl. Phys. Lett. 99, 2011-2014. https://doi.org/10.1063/1.3660319

Liu, W.T., Wu, B.H., Lai, Y.T., Tai, N.H., Perng, T.P., Chen, L.J., 2018. Enhancement of water splitting by controlling the amount of vacancies with varying vacuum level in the synthesis system of $\mathrm{SnO}_{2-x} / \mathrm{In}_{2} \mathrm{O}_{3-y}$ heterostructure as photocatalyst. Nano Energy 47, $18-25$. https://doi.org/10.1016/j.nanoen.2018.02.037

Liu, Y., Kong, J., Yuan, J., Zhao, W., Zhu, X., Sun, C., Xie, J., 2018. Enhanced photocatalytic activity over flower-like sphere $\mathrm{Ag} / \mathrm{Ag}_{2} \mathrm{CO}_{3} / \mathrm{BiVO}_{4}$ plasmonic heterojunction photocatalyst for tetracycline degradation. Chem. Eng. J. 331, 242-254. https://doi.org/10.1016/j.cej.2017.08.114

Lopes, F.V.S., Monteiro, R.A.R., Silva, A.M.T., Silva, G. V., Faria, J.L., Mendes, A.M., Vilar, V.J.P., Boaventura, R.A.R., 2012. Insights into $\mathrm{UV}-\mathrm{TiO}_{2}$ photocatalytic degradation of PCE 
for air decontamination systems. Chem. Eng. J. 204-205, 244-257. https://doi.org/10.1016/j.cej.2012.07.079

Low, J., Jiang, C., Cheng, B., Wageh, S., Al-Ghamdi, A.A., Yu, J., 2017. A Review of Direct ZScheme Photocatalysts. Small Methods 1, 1700080. https://doi.org/10.1002/smtd.201700080

Lu, B., Ma, N., Wang, Y., Qiu, Y., Hu, H., Zhao, J., Liang, D., Xu, S., Li, X., Zhu, Z., Cui, C., 2015. Visible-light-driven $\mathrm{TiO}_{2} / \mathrm{Ag}_{3} \mathrm{PO}_{4} / \mathrm{GO}$ heterostructure photocatalyst with dual-channel for photo-generated charges separation, Journal of Alloys and Compounds. https://doi.org/10.1016/j.jallcom.2015.01.008

Luengas, A., Barona, A., Hort, C., Gallastegui, G., Platel, V., Elias, A., 2015. A review of indoor air treatment technologies. Rev. Environ. Sci. Biotechnol. 14, 499-522. https://doi.org/10.1007/s11157-015-9363-9

Ma, X., Lu, B., Li, D., Shi, R., Pan, C., Zhu, Y., 2011. Origin of photocatalytic activation of silver orthophosphate from first-principles. J. Phys. Chem. C 115, 4680-4687. https://doi.org/10.1021/jp111167u

Malakar, S., Saha, P. Das, Baskaran, D., Rajamanickam, R., 2017. Comparative study of biofiltration process for treatment of VOCs emission from petroleum refinery wastewater-A review. Environ. Technol. Innov. 8, 441-461. https://doi.org/10.1016/j.eti.2017.09.007

Mamaghani, A.H., Haghighat, F., Lee, C.S., 2017. Photocatalytic oxidation technology for indoor environment air purification: The state-of-the-art. Appl. Catal. B Environ. 203, 247-269. https://doi.org/10.1016/j.apcatb.2016.10.037

Martín-Gómez, A.N., Navío, J.A., Jaramillo-Páez, C., Sánchez-Cid, P., Hidalgo, M.C., 2020. Hybrid $\mathrm{ZnO} / \mathrm{Ag}_{3} \mathrm{PO}_{4}$ photocatalysts, with low and high phosphate molar percentages. J. $\begin{array}{llll}\text { Photochem. } & \text { Photobiol. } & \text { 388, } & \end{array}$ https://doi.org/10.1016/j.jphotochem.2019.112196

Martin, D.J., Liu, G., Moniz, S.J.A., Bi, Y., Beale, A.M., Ye, J., Tang, J., 2015. Efficient visible driven photocatalyst, silver phosphate: performance, understanding and perspective. Chem. Soc. Rev. 44, 7808-7828. https://doi.org/10.1039/c5cs00380f

Masih, D., Ma, Y., Rohani, S., 2017. Graphitic $\mathrm{C}_{3} \mathrm{~N}_{4}$ based noble-metal-free photocatalyst systems: A review. Appl. Catal. B Environ. 206, 556-588. https://doi.org/10.1016/j.apcatb.2017.01.061

Mazierski, P., Mikolajczyk, A., Bajorowicz, B., Malankowska, A., Zaleska-Medynska, A., Nadolna, J., 2018. The role of lanthanides in $\mathrm{TiO}_{2}$-based photocatalysis: A review. Appl. Catal. B Environ. 233, 301-317. https://doi.org/10.1016/j.apcatb.2018.04.019

Monteiro, R.A.R., Miranda, S.M., Rodrigues-Silva, C., Faria, J.L., Silva, A.M.T., Boaventura, R.A.R., Vilar, V.J.P., 2015. Gas phase oxidation of n-decane and PCE by photocatalysis using an annular photoreactor packed with a monolithic catalytic bed coated with P25 and PC500. Appl. Catal. B Environ. 165, 306-315. https://doi.org/10.1016/j.apcatb.2014.10.026

Mu, J., Chen, B., Zhang, M., Guo, Z., Zhang, P., Zhang, Z., Sun, Y., Shao, C., Liu, Y., 2012. Enhancement of the visible-light photocatalytic activity of $\mathrm{In}_{2} \mathrm{O}_{3}-\mathrm{TiO}_{2}$ nanofiber heteroarchitectures. ACS Appl. Mater. Interfaces 4, 424-430. https://doi.org/10.1021/am201499r 
1303

1304

1305

1306

1307

1308

1309

1310

1311

1312

1313

1314

1315

1316

1317

1318

1319

1320

1321

1322

1323

1324

1325

1326

1327

1328

1329

1330

1331

1332

1333

1334

1335

1336

1337

1338

1339

1340

1341

1342

1343

1344

1345

Murcia, J.J., Hidalgo, M.C., Navío, J.A., Vaiano, V., Ciambelli, P., Sannino, D., 2012. Ethanol partial photoxidation on $\mathrm{Pt} / \mathrm{TiO}_{2}$ catalysts as green route for acetaldehyde synthesis. Catal. Today 196, 101-109. https://doi.org/10.1016/j.cattod.2012.02.033

Naciri, Y., Ait Ahsaine, H., Chennah, A., Amedlous, A., Taoufyq, A., Bakiz, B., Ezahri, M., Villain, S., Benlhachemi, A., 2018. Facile synthesis, characterization and photocatalytic performance of $\mathrm{Zn}_{3}\left(\mathrm{PO}_{4}\right)_{2}$ platelets toward photodegradation of Rhodamine $\mathrm{B}$ dye. J. Environ. Chem. Eng. 6, 1840-1847. https://doi.org/10.1016/j.jece.2018.02.009

Naciri, Y., Bouddouch, A., Bakiz, B., Taoufyq, A., Ezahri, M., Benlhachemi, A., 2019a. Photocatalytic degradation of sulfadiazine by $\mathrm{Zn}_{3}\left(\mathrm{PO}_{4}\right)_{2} / \mathrm{BiPO}_{4}$ composites upon UV light irradiation. Mater. Today Proc. 3, 8-11. https://doi.org/10.1016/j.matpr.2019.08.071

Naciri, Y., Chennah, A., Jaramillo-Páez, C., Navío, J.A., Bakiz, B., Taoufyq, A., Ezahri, M., Villain, S., Guinneton, F., Benlhachemi, A., 2019b. Preparation, characterization and photocatalytic degradation of Rhodamine $\mathrm{B}$ dye over a novel $\mathrm{Zn}_{3}\left(\mathrm{PO}_{4}\right)_{2} / \mathrm{BiPO}_{4}$ catalyst. J. Environ. Chem. Eng. 7, 103075. https://doi.org/10.1016/j.jece.2019.103075

Naciri, Y., Hsini, A., Ajmal, Z., Bouddouch, A., Bakiz, B., Navío, J.A., Albourine, A., Valmalette, J.C., Ezahri, M., Benlhachemi, A., 2020a. Influence of Sr-doping on structural, optical and photocatalytic properties of synthesized $\mathrm{Ca}_{3}\left(\mathrm{PO}_{4}\right)_{2}$. J. Colloid Interface Sci. 572, 269-280. https://doi.org/10.1016/j.jcis.2020.03.105

Naciri, Y., Hsini, A., Ajmal, Z., Navío, J.A., Bakiz, B., Albourine, A., Ezahri, M., Benlhachemi, A., $2020 \mathrm{~b}$. Recent progress on the enhancement of photocatalytic properties of $\mathrm{BiPO}_{4}$ using $\pi-$ conjugated materials. Adv. Colloid Interface Sci. 280, 102160. https://doi.org/10.1016/j.cis.2020.102160

Navakoteswara Rao, V., Lakshmana Reddy, N., Mamatha Kumari, M., Ravi, P., Sathish, M., Kuruvilla, K.M., Preethi, V., Reddy, K.R., Shetti, N.P., Aminabhavi, T.M., Shankar, M. V., 2019. Photocatalytic recovery of $\mathrm{H}_{2}$ from $\mathrm{H}_{2} \mathrm{~S}$ containing wastewater: Surface and interface control of photo-excitons in $\mathrm{Cu}_{2} \mathrm{~S} @ T i O_{2}$ core-shell nanostructures. Appl. Catal. B Environ. 254, 174-185. https://doi.org/10.1016/j.apcatb.2019.04.090

Ng, H.N., Calvo, C., Faggiani, R., 1978. A new investigation of the structure of silver orthophosphate. Acta Crystallogr. Sect. B Struct. Crystallogr. Cryst. Chem. 34, 898-899. https://doi.org/10.1107/s0567740878014570

Nie, L., Duan, B., Lu, A., Zhang, L., 2019. Pd/TiO 2 @ Carbon Microspheres Derived from Chitin for Highly Efficient Photocatalytic Degradation of Volatile Organic Compounds. ACS Sustain. Chem. Eng. 7, 1658-1666. https://doi.org/10.1021/acssuschemeng.8b05426

Nisar, J., Pathak, B., Ahuja, R., 2012. Screened hybrid density functional study on Sr $2 \mathrm{Nb} 2 \mathrm{O} 7$ for visible light photocatalysis. Appl. Phys. Lett. 100, 181903. https://doi.org/10.1063/1.4709486

Olmo, N.R.S., Saldiva, P.H. do N., Braga, A.L.F., Lin, C.A., Santos, U. de P., Pereirai, L.A.A., 2011. A review of low-level air pollution and adverse effects on human health: Implications for epidemiological studies and public policy. Clinics 66, 681-690. https://doi.org/10.1590/S1807-59322011000400025

Park, H., Park, Y., Kim, W., Choi, W., 2013. Surface modification of $\mathrm{TiO}_{2}$ photocatalyst for environmental applications. J. Photochem. Photobiol. C Photochem. Rev. 15, 1-20. https://doi.org/10.1016/j.jphotochemrev.2012.10.001 
1346

1347

1348

1349

1350

1351

1352

1353

1354

1355

1356

1357

1358

1359

1360

1361

1362

1363

1364

1365

1366

1367

1368

1369

1370

1371

1372

1373

1374

1375

1376

1377

1378

1379

1380

1381

1382

1383

1384

1385

1386

1387

1388

Passalía, C., Alfano, O.M., Brandi, R.J., 2017. Integral design methodology of photocatalytic reactors for air pollution remediation. Molecules 22, 1-17. https://doi.org/10.3390/molecules22060945

Patil, S.B., Basavarajappa, P.S., Ganganagappa, N., Jyothi, M.S., Raghu, A. V., Reddy, K.R., 2019. Recent advances in non-metals-doped $\mathrm{TiO}_{2}$ nanostructured photocatalysts for visiblelight driven hydrogen production, $\mathrm{CO} 2$ reduction and air purification. Int. J. Hydrogen Energy 44, 13022-13039. https://doi.org/10.1016/j.jhydene.2019.03.164

Pettit, T., Bettes, M., Chapman, A.R., Hoch, L.M., James, N.D., Irga, P.J., Torpy, F.R., 2019. The botanical biofiltration of VOCs with active airflow: is removal efficiency related to chemical properties? Atmos. Environ. 214. https://doi.org/10.1016/j.atmosenv.2019.116839

Pettit, T., Irga, P.J., Torpy, F.R., 2018. Towards practical indoor air phytoremediation: A review. Chemosphere 208, 960-974. https://doi.org/10.1016/j.chemosphere.2018.06.048

Photoadsorption, I., 1973. Photoadsorption and photocatalysis at rutile surfaces: I. Photoadsorption of oxygen. J. Catal. 31, 389-397. https://doi.org/s://doi.org/10.1016/00219517(73)90310-2

Pichat, P., 2019. A brief survey of the practicality of using photocatalysis to purify the ambient air (indoors or outdoors) or air effluents. Appl. Catal. B Environ. 245, 770-776. https://doi.org/10.1016/j.apcatb.2018.12.027

Pirhashemi, M., Habibi-Yangjeh, A., Rahim Pouran, S., 2018. Review on the criteria anticipated for the fabrication of highly efficient $\mathrm{ZnO}$-based visible-light-driven photocatalysts. J. Ind. Eng. Chem. 62, 1-25. https://doi.org/10.1016/j.jiec.2018.01.012

Puga, F., Navío, J.A., Jaramillo-Páez, C., Sánchez-Cid, P., Hidalgo, M.C., 2020. Microwaveassisted sol-gel synthesis of $\mathrm{TiO}_{2}$ in the presence of halogenhydric acids. Characterization and photocatalytic activity. J. Photochem. Photobiol. A Chem. 394, 112457. https://doi.org/10.1016/j.jphotochem.2020.112457

Qadeer, A., Liu, S., Liu, M., Liu, X., Ajmal, Z., Huang, Y., Jing, Y., Khalil, S.K., Zhao, D., Weining, D., Wei, X.Y., Liu, Y., 2019. Historically linked residues profile of OCPs and PCBs in surface sediments of typical urban river networks, Shanghai: Ecotoxicological state and sources. J. Clean. Prod. 231, 1070-1078. https://doi.org/10.1016/j.jclepro.2019.05.203

Qadeer, A., Saqib, Z.A., Ajmal, Z., Xing, C., Khan Khalil, S., Usman, M., Huang, Y., Bashir, S., Ahmad, Z., Ahmed, S., Thebo, K.H., Liu, M., 2020. Concentrations, pollution indices and health risk assessment of heavy metals in road dust from two urbanized cities of Pakistan: Comparing two sampling methods for heavy metals concentration. Sustain. Cities Soc. 53, 101959. https://doi.org/10.1016/j.scs.2019.101959

Qiu, W., Dou, K., Zhou, Y., Huang, H., Chen, Y., Lu, H., 2018. Hierarchical pore structure of activated carbon fabricated by $\mathrm{CO}_{2}$ /microwave for volatile organic compounds adsorption. Chinese J. Chem. Eng. 26, 81-88. https://doi.org/10.1016/j.cjche.2017.04.006

Rao, X., Dou, H., Long, D., Zhang, Y., 2020. Ag $\mathrm{PO}_{4} / \mathrm{g}-\mathrm{C}_{3} \mathrm{~N}_{4}$ nanocomposites for photocatalytic degradating gas phase formaldehyde at continuous flow under $420 \mathrm{~nm}$ LED irradiation. Chemosphere 244, 125462. https://doi.org/10.1016/j.chemosphere.2019.125462

Rawal, S.B., Sung, S. Do, Lee, W.I., 2012. Novel $\mathrm{Ag}_{3} \mathrm{PO}_{4} / \mathrm{TiO}_{2}$ composites for efficient decomposition of gaseous 2-propanol under visible-light irradiation. Catal. Commun. 17, 131-135. https://doi.org/10.1016/j.catcom.2011.10.034 
Reyna-Cavazos, K.A., la Cruz, A.M. de, Longoria Rodríguez, F.E., López-Cuellar, E., 2020. Synthesis of bismuth oxyiodide (BiOl) by means of microwaves in glycerol with high photocatalytic activity for the elimination of NOx and SO2. Res. Chem. Intermed. 46, 923941. https://doi.org/10.1007/s11164-019-03998-8

Rodriguez Castillo, A.S., Biard, P.F., Guihéneuf, S., Paquin, L., Amrane, A., Couvert, A., 2019. Assessment of VOC absorption in hydrophobic ionic liquids: Measurement of partition and diffusion coefficients and simulation of a packed column. Chem. Eng. J. 360, 1416-1426. https://doi.org/10.1016/j.cej.2018.10.146

S. Ferraa, Naciri, Y., Hsini, A., Barebita, H., Bouziani, A., A.Albourine, A.Nimour, Guedira, T., 2020. Evolution of the physicochemical and photocatalytic properties of $\mathrm{BaO}$ embedded in bismuth phosphovanadates glasses. Chem. Phys. Lett. 138173.

Saadetnejad, D., Yıldırım, R., 2018. Photocatalytic hydrogen production by water splitting over $\mathrm{Au} / \mathrm{Al}-\mathrm{SrTiO}_{3}$. Int. J. Hydrogen Energy 43, 1116-1122. https://doi.org/10.1016/j.jhydene.2017.10.154

Sansotera, M., Geran Malek Kheyli, S., Baggioli, A., Bianchi, C.L., Pedeferri, M.P., Diamanti, M.V., Navarrini, W., 2019. Absorption and photocatalytic degradation of VOCs by perfluorinated ionomeric coating with $\mathrm{TiO}_{2}$ nanopowders for air purification. Chem. Eng. J. 361, 885-896. https://doi.org/10.1016/j.cej.2018.12.136

Schneider, J., Matsuoka, M., Takeuchi, M., Zhang, J., Horiuchi, Y., Anpo, M., Bahnemann, D.W., 2014. Understanding $\mathrm{TiO}_{2}$ photocatalysis: Mechanisms and materials. Chem. Rev. 114, 9919-9986. https://doi.org/10.1021/cr5001892

Shaim, A., Amaterz, E., Naciri, Y., Taoufyq, A., Bakiz, B., Ezahri, M., Benlhachemi, A., Ouammou, A., Chahine, A., 2019. Synthesis, characterization and photocatalytic activity of titanophosphate glasses. Mediterr. J. Chem. 8, 66-73. https://doi.org/10.13171/mjc8119032221as

Shammay, A., Sivret, E.C., Le-Minh, N., Lebrero Fernandez, R., Evanson, I., Stuetz, R.M., 2016. Review of odour abatement in sewer networks. J. Environ. Chem. Eng. 4, 3866-3881. https://doi.org/10.1016/j.jece.2016.08.016

Shayegan, Z., Haghighat, F., Lee, C.S., 2020. Carbon-doped $\mathrm{TiO}_{2}$ film to enhance visible and UV light photocatalytic degradation of indoor environment volatile organic compounds. J. Environ. Chem. Eng. 8, 104162. https://doi.org/10.1016/j.jece.2020.104162

Shayegan, Z., Lee, C.S., Haghighat, F., 2018. $\mathrm{TiO}_{2}$ photocatalyst for removal of volatile organic compounds in gas phase - A review. Chem. Eng. J. 334, 2408-2439. https://doi.org/10.1016/j.cej.2017.09.153

Shen, Y., Zhu, Z., Wang, X., khan, A., Gong, J., Zhang, Y., 2018. Synthesis of Z-scheme g$\mathrm{C}_{3} \mathrm{~N}_{4} / \mathrm{Ag} / \mathrm{Ag}_{3} \mathrm{PO}_{4}$ composite for enhanced photocatalytic degradation of phenol and selective oxidation of gaseous isopropanol. Mater. Res. Bull. 107, 407-415. https://doi.org/10.1016/j.materresbull.2018.08.017

Sleiman, M., Conchon, P., Ferronato, C., Chovelon, J.M., 2009. Photocatalytic oxidation of toluene at indoor air levels (ppbv): Towards a better assessment of conversion, reaction intermediates and mineralization. Appl. Catal. B Environ. 86, 159-165. https://doi.org/10.1016/j.apcatb.2008.08.003

Sui, H., An, P., Li, X., Cong, S., He, L., 2017. Removal and recovery of o-xylene by silica gel using 
vacuum swing adsorption. Chem. Eng. J. 316, 232-242. https://doi.org/10.1016/j.cej.2017.01.061

Suresh, S., Bandosz, T.J., 2018. Removal of formaldehyde on carbon -based materials: A review of the recent approaches and findings. Carbon N. Y. 137, 207-221. https://doi.org/10.1016/j.carbon.2018.05.023

Swetha, G., Gopi, T., Chandra Shekar, S., Ramakrishna, C., Saini, B., Rao, P.V.L., 2017. Combination of adsorption followed by ozone oxidation with pressure swing adsorption technology for the removal of VOCs from contaminated air streams. Chem. Eng. Res. Des. 117, 725-732. https://doi.org/10.1016/j.cherd.2016.11.036

Tang, M., Ao, Y., Wang, C., Wang, P., 2020. Facile synthesis of dual Z-scheme g$\mathrm{C}_{3} \mathrm{~N}_{4} / \mathrm{Ag}_{3} \mathrm{PO}_{4} / \mathrm{Agl}$ composite photocatalysts with enhanced performance for the degradation of a typical neonicotinoid pesticide. Appl. Catal. B Environ. 268, 118395. https://doi.org/10.1016/j.apcatb.2019.118395

Taranto, J., Frochot, D., Pichat, P., 2009. Photocatalytic air purification: Comparative efficacy and pressure drop of a $\mathrm{TiO}_{2}$-coated thin mesh and a honeycomb monolith at high air velocities using a $0.4 \mathrm{~m} 3$ close-loop reactor. Sep. Purif. Technol. 67, 187-193. https://doi.org/10.1016/j.seppur.2009.03.017

Thevenet, F., Sivachandiran, L., Guaitella, O., Barakat, C., Rousseau, A., 2014. Plasma-catalyst coupling for volatile organic compound removal and indoor air treatment: A review. J. Phys. D. Appl. Phys. 47. https://doi.org/10.1088/0022-3727/47/22/224011

Tian, N., Zhang, Y., Li, X., Xiao, K., Du, X., Dong, F., Waterhouse, G.I.N., Zhang, T., Huang, H., 2017. Precursor-reforming protocol to $3 \mathrm{D}$ mesoporous $\mathrm{g}-\mathrm{C}_{3} \mathrm{~N}_{4}$ established by ultrathin selfdoped nanosheets for superior hydrogen evolution. Nano Energy 38, 72-81. https://doi.org/10.1016/j.nanoen.2017.05.038

Wan, S., Ou, M., Zhong, Q., Zhang, S., 2018. Z-scheme Caln $\mathrm{S}_{4} / \mathrm{Ag}_{3} \mathrm{PO}_{4}$ nanocomposite with superior photocatalytic NO removal performance: Fabrication, characterization and mechanistic study. New J. Chem. 42, 318-326. https://doi.org/10.1039/c7nj03588h

Wang, K., Liu, C., Du, P., Zheng, J., Gong, X., 2015. Bulk heterojunction perovskite hybrid solar cells with large fill factor. Energy Environ. Sci. 8, 1245-1255. https://doi.org/10.1039/c5ee00222b

Wang, X., Yu, J., Fu, C., Li, T., Yu, H., 2019. Self-templated formation of $\mathrm{AgCl} / \mathrm{TiO}_{2}$ hollow octahedra for improved visible-light photocatalytic activity. Appl. Surf. Sci. 494, 740-748. https://doi.org/10.1016/j.apsusc.2019.07.221

Wen, X.J., Shen, C.H., Fei, Z.H., Fang, D., Liu, Z.T., Dai, J.T., Niu, C.G., 2020. Recent developments on $\mathrm{Agl}$ based heterojunction photocatalytic systems in photocatalytic application. Chem. Eng. J. 383, 123083. https://doi.org/10.1016/j.cej.2019.123083

Wood, P.M., 1988. The potential diagram for oxygen at pH 7. Biochem. J. 253, 287-289. https://doi.org/10.1042/bj2530287

Xian, S., Yu, Y., Xiao, J., Zhang, Z., Xia, Q., Wang, H., Li, Z., 2015. Competitive adsorption of water vapor with VOCs dichloroethane, ethyl acetate and benzene on MIL-101(Cr) in humid atmosphere. RSC Adv. 5, 1827-1834. https://doi.org/10.1039/c4ra10463c

Xiao, G., Wang, X., Li, D., Fu, X., 2008. InVO4-sensitized $\mathrm{TiO}_{2}$ photocatalysts for efficient air 
purification with visible light. J. Photochem. Photobiol. A Chem. 193, 213-221. https://doi.org/10.1016/j.jphotochem.2007.06.027

Xie, J., Yang, Y., He, H., Cheng, D., Mao, M., Jiang, Q., Song, L., Xiong, J., 2015. Facile synthesis of hierarchical $\mathrm{Ag}_{3} \mathrm{PO}_{4} / \mathrm{TiO}_{2}$ nanofiber heterostructures with highly enhanced visible light photocatalytic properties. Appl. Surf. Sci. 355, 921-929. https://doi.org/10.1016/j.apsusc.2015.07.175

Xin, X., Li, S.H., Zhang, N., Tang, Z.R., Xu, Y.J., 2019. 3D graphene/AgBr/Ag cascade aerogel for efficient photocatalytic disinfection. Appl. Catal. B Environ. 245, 343-350. https://doi.org/10.1016/j.apcatb.2018.12.066

Xu, L., Huang, W.Q., Wang, L.L., Huang, G.F., Peng, P., 2014. Mechanism of superior visiblelight photocatalytic activity and stability of hybrid $\mathrm{Ag}_{3} \mathrm{PO}_{4} /$ graphene nanocomposite. J. Phys. Chem. C 118, 12972-12979. https://doi.org/10.1021/jp5034273

Xue, W., Huang, D., Wen, X., Chen, S., Cheng, M., Deng, R., Li, B., Yang, Y., Liu, X., 2020. Silver-based semiconductor Z-scheme photocatalytic systems for environmental pur ification. Jour nal Hazard. Mater ials 390, 122128. https://doi.org/10.1016/j.jhazmat.2020.122128

Yang, H., Tian, J., Bo, Y., Zhou, Y., Wang, X., Cui, H., 2017. Visible photocatalytic and photoelectrochemical activities of $\mathrm{TiO}_{2}$ nanobelts modified by $\ln 2 \mathrm{O} 3$ nanoparticles. J. Colloid Interface Sci. 487, 258-265. https://doi.org/10.1016/j.jcis.2016.10.051

Yang, S.B., Chun, H.H., Tayade, R.J., Jo, W.K., 2015. Iron-functionalized titanium dioxide on flexible glass fibers for photocatalysis of benzene, toluene, ethylbenzene, and o-xylene (BTEX) under visible- or ultraviolet-light irradiation. J. Air Waste Manag. Assoc. 65, 365373. https://doi.org/10.1080/10962247.2014.995838

Yi, Z., Ye, J., Kikugawa, N., Kako, T., Ouyang, S., Stuart-Williams, H., Yang, H., Cao, J., Luo, W., Li, Z., Liu, Y., Withers, R.L., 2010. An orthophosphate semiconductor with photooxidation properties under visible-light irradiation. Nat. Mater. 9, 559-564. https://doi.org/10.1038/nmat2780

Yue, X., Yi, S., Wang, R., Zhang, Z., Qiu, S., 2018. Well-controlled $\mathrm{SrTiO}_{3} @ \mathrm{Mo}_{2} \mathrm{C}$ core-shell nanofiber photocatalyst: Boosted photo-generated charge carriers transportation and enhanced catalytic performance for water reduction. Nano Energy 47, 463-473. https://doi.org/10.1016/j.nanoen.2018.03.014

Zazueta, A.L.L., Destaillats, H., Li Puma, G., 2013. Radiation field modeling and optimization of a compact and modular multi-plate photocatalytic reactor (MPPR) for air/water purification by Monte Carlo method. Chem. Eng. J. 217, 475-485. https://doi.org/10.1016/j.cej.2012.11.085

Zhang, J., Bang, J.H., Tang, C., Kamat, P. V., 2010. Tailored TiO2-SrTiO3 heterostructure nanotube arrays for improved photoelectrochemical performance. ACS Nano 4, 387-395. https://doi.org/10.1021/nn901087c

Zhang, N., Nguyen, A. V., Zhou, C., 2018. A review of the surface features and properties, surfactant adsorption and floatability of four key minerals of diasporic bauxite resources. Adv. Colloid Interface Sci. 254, 56-75. https://doi.org/10.1016/j.cis.2018.03.005

Zhang, X., Gao, B., Creamer, A.E., Cao, C., Li, Y., 2017. Adsorption of VOCs onto engineered carbon materials: A review. J. Hazard. Mater. 338, 102-123. 
Zhao, F.M., Pan, L., Wang, S., Deng, Q., Zou, J.J., Wang, L., Zhang, X., 2014. $\mathrm{Ag}_{3} \mathrm{PO}_{4} / \mathrm{TiO}_{2}$ composite for efficient photodegradation of organic pollutants under visible light. Appl. Surf. Sci. 317, 833-838. https://doi.org/10.1016/j.apsusc.2014.09.022

Zhao, J., Yang, X., 2003. Photocatalytic oxidation for indoor air purification: A literature review. Build. Environ. 38, 645-654. https://doi.org/10.1016/S0360-1323(02)00212-3

Zhao, Z., Fan, J., Liu, W., Xue, Y., Yin, S., 2017. In-situ hydrothermal synthesis of $\mathrm{Ag}_{3} \mathrm{PO}_{4} / \mathrm{g}-\mathrm{C}_{3} \mathrm{~N}_{4}$ composite and their photocatalytic decomposition of NOx. J. Alloys Compd. 695, 2812-2819. https://doi.org/10.1016/j.jallcom.2016.12.001

Zhong, L., Haghighat, F., Lee, C.S., 2013. Ultraviolet photocatalytic oxidation for indoor environment applications: Experimental validation of the model. Build. Environ. 62, 155-166. https://doi.org/10.1016/j.buildenv.2013.01.009

Zhou, H., Wen, Z., Liu, J., Ke, J., Duan, X., Wang, S., 2019. Z-scheme plasmonic Ag decorated $\mathrm{WO}_{3} / \mathrm{Bi}_{2} \mathrm{WO}_{6}$ hybrids for enhanced photocatalytic abatement of chlorinated-VOCs under solar light irradiation. Appl. Catal. B Environ. 242, 76-84. https://doi.org/10.1016/j.apcatb.2018.09.090

Zhou, P., Yu, J., Jaroniec, M., 2014. All-solid-state Z-scheme photocatalytic systems. Adv. Mater. 26, 4920-4935. https://doi.org/10.1002/adma.201400288

Zhu, L., Shen, D., Luo, K.H., 2020. A critical review on VOCs adsorption by different porous materials: Species, mechanisms and modification methods. J. Hazard. Mater. 389, 122102. https://doi.org/10.1016/j.jhazmat.2020.122102

Zouzelka, R., Rathousky, J., 2017. Photocatalytic abatement of NOx pollutants in the air using commercial functional coating with porous morphology. Appl. Catal. B Environ. 217, 466476. https://doi.org/10.1016/j.apcatb.2017.06.009 